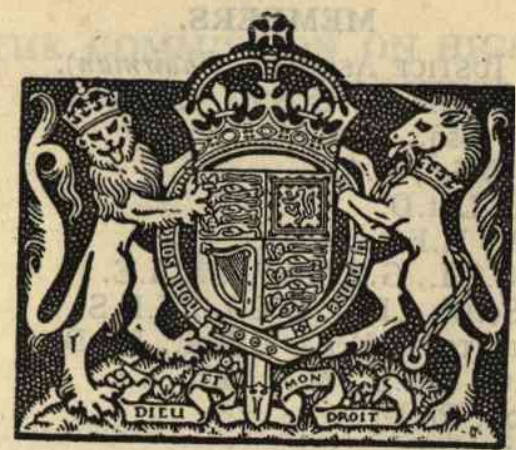

COLONIAL OFFICE

\title{
Report of the Commission
}

\section{on Higher Education in the Colonies}

Presented by the Secretary of State for the Colonies to Parliament by Command of His Majesty

Fune 1045

LONDON

HIS MAJESTY'S STATIONERY OFFICE PRICE $2 s$. Od. NET

Cmd. 6647 


\section{MEMBERS.}

The Honourable Mr. Justice Asquith (Chairman).

Sir Donald Cameron, G.C.M.G., K.B.E., LL.D.

A. M. Carr-Saunders, Esq., M.A.

H. J. Channon, Esq., D.Sc., B.A.

Sir Fred Clarke, M.A., Litt.D.

J. F. DufF, Esq., M.A., M.Ed., LL.D.

The Lord HaILEY, G.C.S.I., G.C.M.G., G.C.I.E.

Sir James C. IRVine, Sc.D., LL.D. D.C.L., F.R.S.

Sir Richard W. Livingstone, M.A., D.Litt., LL.D.

R. Marrs. Esq., C.M.G., C.I.E., M.A., LL.D.

Professor L. M. PENSON, Ph.D.

Miss Margery Perham, M.A.

R. E. Priestley, Esq., M.C., M.A., D.Sc.

Professor J. A. RYLE, M.A, M.D., F.R.C.P.

R. V. Southwell, Esq., M.A., LL.D., F.R.S., M.I.M.E.

J. A. VENN, Esq., Litt.D., F.S.A.

Professor A. V. Hill, O.B.E., M.A., Sc.D., F.R.S., was prevented by force of circumstances from continuing as a member of the Commission.

Mr. D. W. Malcolm was Secretary until May, 1944, when he was succeeded by Mr. S. Robinson.

\section{TABLE OF GONTENTS}

\section{PART I}

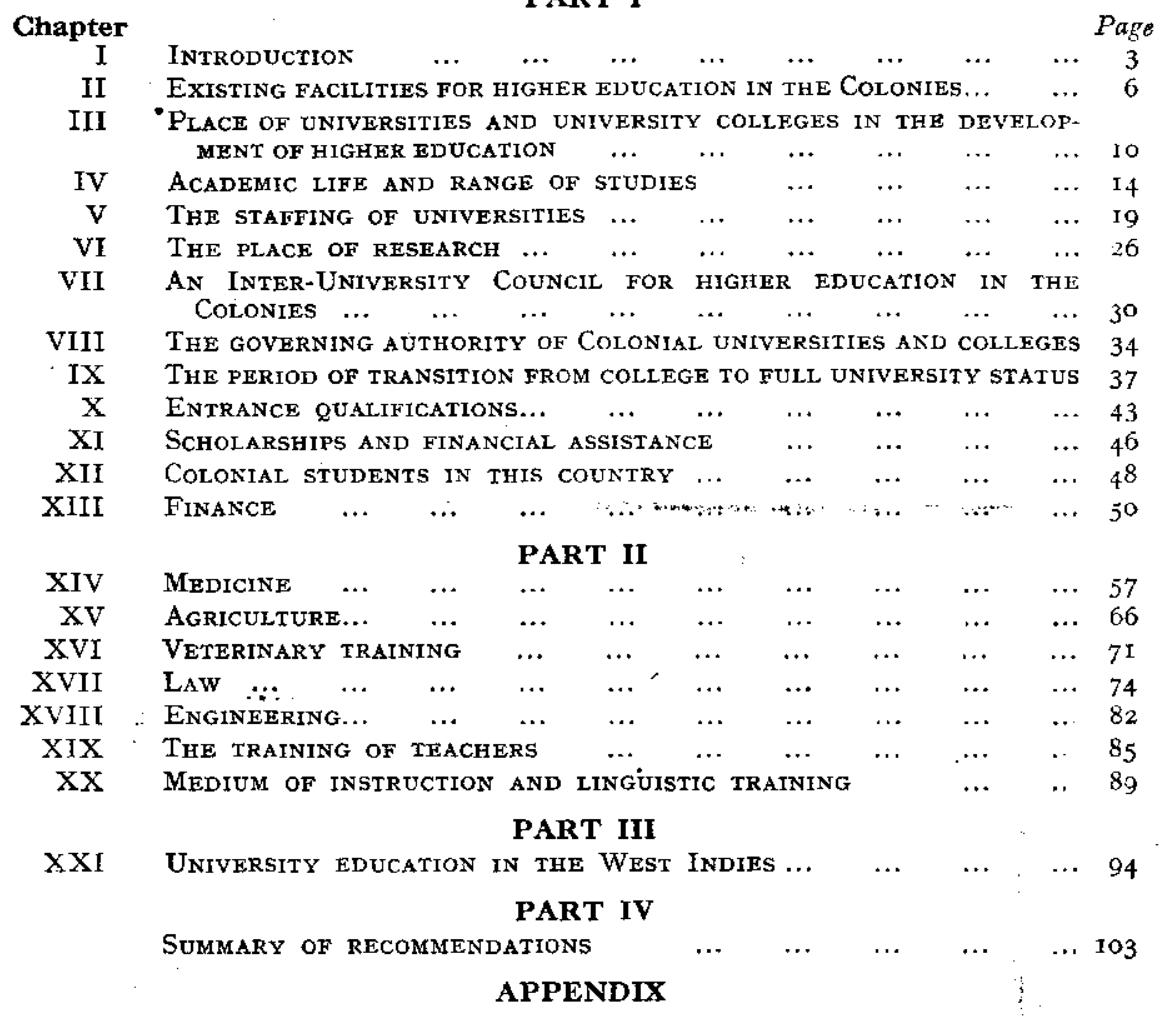

The estimated cost of this report (including the expenses of the Commission) is $f 895$ IIs. od., of which $f I 48$ IIs. od. represents the cost of printing and publication. 


\section{REPORT OF THE GOMMISSION ON HIGHER EDUCATION IN THE GOLONIES}

\section{PART I}

\section{CHAPTER I}

\section{Introduction}

We were appointed in August, I943, as a Commission to conduct an enquiry and make recommendations under the following terms of reference:-

" To consider the principles which should guide the promotion of higher education, learning and research and the development of universities in the Colonies; and to explore means whereby universities and other appropriate bodies in the United Kingdom may be able to co-operate with institutions of higher education in the Colonies in order to give effect to these principles."

In pursuance of this charge, the Commission has met 3 I times; its meetings occurring, as a rule, once or twice a fortnight and occupying in each case the best part of a day. It has taken oral evidence from $2 \mathrm{I}$ witnesses, and received and considered written memoranda of interest and value from a great variety of sources. We have also received the utmost assistance from the deliberations of the Advisory Committee on Education in the Colonies bearing on this subject. In this introductory chapter of our report our object is threefold:-

(i) To record the construction which we place on our terms of reference.

(ii) To indicate the method of approach which we have adopted to the problems which those terms of reference (as we read them) present.

(iii) To foreshadow the structure of this report.

\section{The terms of reference}

And first, therefore, as to our terms of reference and the interpretation which we place on them.

(a) By " higher education" we understand post-secondary education; the type of education which in the United Kingdom and elsewhere is provided by universities, university colleges and certain other institutions discharging similar functions, and which is the successor to that afforded by secondary schools.

(b) We read the term "Colonies" in a liberal sense. We think for many reasons that we should construe our charge too narrowly if we confined our outlook to what used to be called "Crown Colonies" in the strict acceptance of that term. We apprehend that in employing the term "Colonies" it was intended to include in our purview the higher educational needs of persons normally resident in

(I) the "Colonies", stricto sensu;

(2) British Protectorates and Protected States;

(3) the territories over which His Majesty exercises a Mandate;

(4) the High Commission Territories in South Africa, namely, Swazi-

land, Bechuanaland, and Basutoland.

And to those we would add

(5) the Anglo-Egyptian Sudan, which being subject to the "Condominium " falls within none of the above categories; the Government of which, through the Foreign Office, has invited us to extend our recommendations to it. 
Under this head we would add that among "Colonies" we have included Malaya and Hong Kong, making assumption that these important territories will be restored to the Crown in time for our recommendations to be of more than academic interest to them. Where, therefone, in this report, the terms "Colony" or "Colonial " are used, they should be construed in the comprehensive sense above indicated.

(c) Adopting this terminology, we have next to consider the meaning to

be attributed to the expression " higher education in the Colonies." We

do not consider that this expression was designed to limit our purview to higher education available, or to be made available, to Colonial subjects within the territorial ambit of the respective Colonies in question.

At present higher education, so far as Colonial subjects enjoy it, is provided in point of locality in the Colonies themselves; in the United Kingdom; and to some extent in the Dominions and in India. We conceive that we should in this connection construe " higher education in the Colonies" as comprising facilities for higher education available for Colonial subjects without any strict limitation as to locality: and we have framed our report on that assumption.

\section{The general method of approach to the problems posed in the terms of reference}

We have been invited primarily to deal with " principles".

(a) We take this invitation, on the one hand, as exhorting us to abstain from the (virtualiy impossible) task of enumerating, and dealing specifically and in detail with the particular and infinitely various needs in respect of higher education of individual Colonies. Such an enquiry, even if possible, would, we feel, be foreign to the intention with which our Commission was constituted. It would " exhaust Time, and trench upon Eternity".

(b) On the other hand, we think we should equally defeat that intention if we confined ourselves to a bare recital of generalities and ignored the special application which any general principles must bear to certain large areas, the problems of which are individual and peculiar. If we relegated ourselves to so jejune a task, our recomendations would be brief, perfunctory, and infructuous. In this matter, as in so many others, a balance must be struck between the universal and the particular.

(c) In the attempt to achieve such a balance, we have been afforded some guidance by the appointment, together with this Commission, of a linked Commission charged to investigate the general problem with special reference to the needs of higher education in West Africa. Our more general enquiry has indeed been co-ordinated with that more specific one in a practical way by the appointment of two of our members, Dr. H. J. Channon and Dr. J. F. Duff, as members also of the West Africa Commission. We feel that this liaison has been valuable not only intrinsically, but also as affording a pointer to the degree of particularity to which it was intended that we should push our own enquiries, and the point at which it was intended that they should stop.

Early in our own sessions we felt that the considerations which had prompted the decision to direct a special enquiry in respect of West Africa, applied with equal force to the West Indies, or to be more accurate, to the Caribbean area. If any general principles we could formulate called for a special application in the one area, then equally, in our view, they called for a special application in the other. We accordingly obtained sanction to send, to what we will call for short the "West Indies", the strongest delegation we could muster from among our own members_Sir James Irvine and Miss Perhamtogether with Dr. Priestley, the Vice-Chancellor of Birmingham University, 
whose accession to the Commission at this time was most opportune. Along with certain representatives of the West Indies, from whom they received invaluable assistance, our delegates have conducted this special investigation, parallel to that conducted in West Africa by the West Africa Commission. The fruits of this delegation's arduous labours have, we believe, more than justified the decision to take this course.

\section{The scope of specific proposals}

We may attcmpt then to crystallise our method of approach to our task in the following short propositions:-

(a) Our main objective was to formulate, as we were enjoined to do, principles applicable generally to the Colonies; not to elaborate in detail higher educational programmes for particular Colonies.

(b) But in respect of certain large areas of the Colonial Empire which presented individual and complex problems an attempt at some such elaboration appeared to us ineluctable.

\section{Dual character of our task}

We must make clear at this early stage of our report that the institutions of higher education in the Colonies fall into two clearly defined classes. On the one side are the Universities of Malta, Jerusalem, Ceylon and Hong Kong, the last temporarily under Japarese control. These institutions have, of course, the attributes of all universities, and are fully autonomous. The Universities of Malta, Jerusalem and Hong Kong are members of the Universities Bureau of the British Empire. The second category contains those institutions in the Colonies, which are below the status of universities, and for the most part even that of university colleges. In one region, construction from the foundation must be recommended. Clearly it is the second category which will need the fullest possible assistance and guidance from this country, though the University of Hong Kong may stand in need of special services during the phase of restoration after the defeat of Japan. 'It will therefore be understood that by far the greater part of our report will refer to the institutions below university status.

Nevertheless, we hope that some of the suggestions we put forward may be of interest even to the Colonial universities. This observation refers above all to the Inter-University Council which we propose in chapter VII, since this is not planned only as an agency through which help from home universities may be drawn by Colonial colleges, but also as a centre for academic contact and mutual service. Moreover we anticipate that the colleges will go forward rapidly and join the group of Colonial universities, and we hope that the close relationship established between them and the universities of this country during their minority will extend into their maturity even though it will change in character. In this connection we would add that we have not found it convenient to indicate the degree to which each section of our report is applicable to differing institutions, and we hope that its readers, and especially those in the Colonial universities, will study it with this governing direction in their minds.

This leads us to a further question affecting the scope of our recommendations. Our terms of reference make no mention of the Dominions or India: it would, however, show little appreciation of the political and geographical character of the Commonwealth and Empire if we were to make our recommendations without regard to the part which their universities can play in the developments envisaged in this report. It is not for us to prescribe in what measure or by what machinery this association may come into being. But here again we wish to emphasise at the ontset of our report, the earnest hope which has accompanied all our deliberations, that the universities of the 
Dominions and India will join with those in this country in entering into close and effective relationships with the institutions of higher education in the Colonies. We are aware that the Universities Bureau of the British Empire already offers facilities for co-operation in this sphere and we intend that our own proposals shall reinforce and extend those facilities.

There is another reason why we should emphasize our desire to see this relationship established. Political status is no more static than academic status and, as Colonial colleges will become universities, so may Colonies attain a greater measure of political autonomy. We hope by that time that as a result, at least in part, of our recommendations, such close and mutually beneficial relationships will have been promoted between institutions of higher education in Britain, the Dominions and the Colonies, that a change of political status will not loosen the ties of academic fraternity.

\section{The general structure of the report}

We have framed our report in four parts. The first deals with the general principles which should determine an adequate provision of higher education, and refers at the same time to some of the special problems to which the application of these principles must give-rise in the circumstances at present prevailing in the Colonies. We have thought it advisable to give as chapter II of Part I of our report a brief survey of the facilities for higher education now available to students in the Colonial Empire generally. A bare recital of the facts in regard to certain areas, and notably Africa and the West Indies, is sufficient to show the inadequacy in their case of the existing facilities for this purpose. In the succeeding chapters of Part I we present the case for the establishment of university colleges so constituted as to be capable of development, at as early a date as possible, into Colonial universities with a full degree giving status. We have in the course of making these recommendations paid special attention also to that part of our terms of reference which invites us to explore the means " whereby the universities and other appropriate bodies of the United Kingdom may be able to co-operate with institutions of higher education in the Colonies."

We proceed in Part II to deal with the special problems involved in the provision of professional and vocational courses in the universities and university colleges. The urgency of the need for professional men of all kinds in the Colonies, and the importance of the role which can be played by the universities in supplying them have seemed to us to justify a more detailed treatment of these aspects of university activity.

In Part III we give a summary of the report of our West Indies Committee and certain observations which have resulted from our consideration of it. We summarize in Part IV the principal recommendations of our own report.

In concluding this introduction to our report, we take the opportunity of acknowledging our obligation to the services rendered the Commission by Mr. Donald Malcolm, who acted as its Secretary from August, I943, to May, I 944 , and to Mr. S. Robinson who acted in that capacity up to the termination of its proceedings.

\section{CHAPTER II}

\section{EXISTING FACILITIES FOR HIGHER EDUCATION IN THE COLONIES}

There are at present in the Colonial Empire only four institutions of higher education which have the status of universities. We give here a short reference to their history, the number of students and the Faculties comprised. Some further particulars relating to finance will be found in chapter XIII. 


\section{The four existing Colonial Universities}

The Royal University of Malta is unique among these institutions in the length of its history. It was constituted in 1769 by the Grand Master of the Knights of St. John of Jerusalem in buildings which had formed the College of the Society of Jesus in Valetta, itself founded in I592. There are six Faculties-Theology, Law, Medicine and Surgery, Engineering and Architecture, Literature, and Science, in which degrees are taken, the medical degree being recognised by the General Medical Council. Courses are also provided for the diplomas of Notary Public, Legal Procurator, Pharmacist, Dental Surgeon and Midwife. The addition of Faculties of Economics and Education is under consideration, and we also understand that there is in contemplation a considerable programme of development which would embrace the institution of postgraduate courses in certain subjects. The number of regular students at the present time is 233 , of whom a small number are women.

The Hebrew University of Jerusalem, which took shape after the last war in the course of the development of the Jewish national movement, seeks to serve the country of Palestine as a whole, but aims also at providing a centre from which the Jewish contribution to world culture may radiate. The original design of the University was as a centre of research, since those responsible for its creation hesitated to found an institution of academic teaching which without adequate preparation might be inferior to that of a good European university. The opportunities afforded for research attracted a number of distinguished scholars from the continent of Europe and elsewhere. Of late years, however, the University has extended its activity to academic teaching. There are now Faculties of the Humanities and of Science, each providing a four years' course leading to the award of degrees. There is not at present a full Faculty of Medicine and a full Faculty with an undergraduate school forms the largest item in the plans for post-war development. There is a School of Agriculture attached to the University. A School of Engineering at Haifa, separately administered, serves the purpose of an Engineering Faculty and grants a diploma after a four years' course. Teachers are trained in a Department of Education. The students in recent years have numbered between 500 and 600 drawn from all the countries of Europe and from many in Asia and America. The University has been constituted without formal charter or instrument of the Legislature.

The University of Hong Kong was established in IgrI. The College of Medicine, which had been established at Hong Kong in 1887 , was then absorbed. One of the objects of the University is stated to be the maintenance of good understanding with China. The higher education of the inhabitants of the Colony itself might not alone have justified the establishment of a university, but efforts were made to maintain and develop it, in co-operation with the Universities of China, as a common focal point of British and Chinese cultures. Many of the students came from China and Malaya. The University comprised Faculties of Arts, Science, Engineering and Medicine. The Faculty of Arts included a Department of Education and a Department of Chinese Studies. The Faculty of Engineering offered a course in Civil Engineering and in Mechanical and Electrical Engineering. The Medical degree is recognised by the General Medical Council. During I939 there were 538 students on the roll of whom $x$ I 8 were women.

In Ceylon a Medical College was founded at Colombo in I870. It provided courses leading to a licence in Medicine and Surgery which was recognised by the General Medical Council as early as I888. Ceylon University College was founded in Ig2I and offered courses in English, Sinhalese, Tamil, Classics, Sanskrit, Pali, History, Economics, Philosophy, Geography, Mathematics, 
Physics, Chemistry, Botany and Zoology. The University of Ceylon, which was established in r942, incorporated these two Colleges. On the medical side it gives courses for the degrees of M.B. and B.S. and a Dental School has been set up. In 1944 there were $3^{13}$ medical and dental students of whom 26 were women. The University has also Faculties of Arts and Science and Oriental Studies. In I943 there were 646 students in these Faculties, 72 of them being women. In I 94387 degrees were conferred by the University, and there were 34 postgraduate students, including seven in the Faculty of Medicine. The funds of the University and its preceding institutions have been wholly provided by the Government of Ceylon. The students are drawn almost entirely from the island.

\section{Institutions not possessing university status}

Full university facilities are thus available in only a very small part of the Colonial Empire. The Colonies, with the Sudan, comprise in all a population of more than 66 million and an area of more than three million square miles. Of this population more than one-third is in West Africa and one-third is in East Africa. The area of East Africa, including the Sudan, is more than two million square miles; that of West Africa nearly half a million square miles. Some approach has however been made in these and other regions to the provision of education aiming at university standards and in more than one institution greater progress would have been made but for the circumstances of the war. We refer here to the more important of these institutions.

\section{(a) West Indies}

The Imperial College of Tropical Agriculture, Trinidad, occupies a special position, undertaking training and research in agricultural sciences for the Colonial Empire as a whole. There are courses for the associateship and for the diploma in Agriculture and also for the associateship and for the diploma in Sugar Technology, the diploma courses being designed primarily for students from the Caribbean area. The majority of students taking the course of the associateship of agriculture are scholars selected under the scheme of training for the Colonial Agricultural Service. The number of diploma students in 1945 is 35 . There are 26 other students.

Codrington' College, Barbados, was founded in I7IO, and has been affiliated with the University of Durham since 1875 . It is directed mainly to preparing students for service as ministers of religion. Students have taken the B.A. degree of Durham University, the honours degree in Classical and General Literature and the honours degree in Theology as well as the licence in Theology. The number of students in 1944 was I6.

\section{(b) West Africa}

Fourah Bay College in Sierra Leone, founded by the Church Missionary Society in 1827 to train ministers and lay-workers, is also affiliated with the University of Durham; its students have been prepared for the B.A. degree and the diplomas in Theology and in Education. In I944 the number of students was 16.

At Achimota in the Gold Coast is. the Prince of Wales' College. Its aim has been described as the production of the type of student who is western in his intellectual attitude towards life but who remains African in sympathy, and it seeks to preserve and develop what is deserving of respect in African life. The College provided at the outset a complete course of education from kindergarten to the post secondary stage, but the kindergarten and primary schools have recently been disbanded and as soon as opportunity offers it is proposed to separate the secondary and post secondary teaching. Students are accepted in the College for 
the courses leading to the following examinations of the University of London:-Intermediate Arts, Intermediate Science, Intermediate Engineering, B.Sc. (Engineering), Intermediate Science (Economics). A department for the training of primary teachers provides a four-years' course for students who have completed primary education. In I943 there were 98 post secondary students (including two women), some of whom came from Nigeria, Sierra Leone and the Gambia. The College is provided with ample buildings, well laid out on high ground.

The Higher College at Yaba in Nigeria, formally opened in I934, provides science courses for students seeking to become Assistant Agricultural, Forestry, Medical, Survey, and Veterinary officers. It makes provision for engincering students, and for secondary school teachers, the course in this latter case following the pattern in universities in this country. The engineering course lasts four years, with practical work in the vacations. The other courses are also approximately of the length of those given in the same subjects in this country, the professional part of the courses being given at the appropriate government department after training in fundamental science at the College. Diplomas are granted on successful completion of the full course. The number of students at the College is about roo. A few students come from the Gold Coast, Dahomey and Sierra Leone; there have been two women students.

\section{(c) East Africa and the Sudan.}

In East Africa the leading institution is Makerere College, which has developed from a trade school, and has since 1937 prepared itself to become a university through the stage of a university college. Whilst the building programme has not been carried through on account of the war, those buildings which are completed are on a scale commensurate with the final objective. The College provides courses for vocational training for teachers and for Medical, Agricultural and Veterinary Assistants; they are completed at schools affiliated to the College but not yet under its control. Diplomas are awarded in all the courses given. In I943 there were II4 students resident in the College and 24 in the associated departmental schools. They were drawn from Uganda, Tanganyika, Kenya and Zanzibar, and a small number also from Nyasaland, Northern Rhodesia and the Southern Sudan.

Gordon Memorial College, Khartoum, was founded in I899 on the initiative of Lord Kitchener of Khartoun. At first an institution of primary education and later of secondary school standard, it is now about to become the centre of activities hitherto carried on at certain vocational schools which have been financed and administered by the Sudan Government, namely the School of Arts, the School of Science, the School of Engineering, the Veterinary School, the School of Agriculture and the School of Administration and Police. These Schools granted their own diplomas. It is the intention that the College shall be raised to the status of a university college as soon as may be practicable. It is hoped that at a later date the Kitchener School of Medicine, which was founded in I924 and which also grants diplomas, will associate itself with Gordon College.

We should mention also the South African Native College at Fort Hare in the Union of South Africa, since it draws students from the High commission Territories and to a small extent from the Colonies further north. The students sit for examinations of the University of South Africa. In r943 the number of students following full-time courses was 220 . 


\section{(d) Malaya}

In Malaya there is King Edward VII Medical College, Singapore, founded in Igo4 to train local practitioners. The College held a high place among Medical Schools of the Far East; the six-years' course was similar to that given in this country and the diploma is recognised by the General Medical Council. Its Dental School conducted a five-years' course and awarded a diploma. There were annual postgraduate courses in malaria sponswred by the Health Organisation of the League of Nations.

Raffles College, Singapore, opened in I928, was founded to meet the urgent need for qualified teachers for secondary schools and to offer facilities for training in scientific subjects. There were courses of three years in Arts and in Science leading to diplomas. A limited number of students has taken the degree examinations of the University of London.

Arrangements for higher education in Malaya were examined in r939 by a Commission,* which recommended that the two colleges should be fused into a university college and that it should develop in time to a full university.

\section{(e) Pacific area}

In the Pacific area there are no comparable institutions of higher education, but it may be mentioned that the Central Medical School at Suva in Fiji provides instruction for native practitioners for Fiji and a number of islands in this region.

\section{CHAPTER III}

\section{PLACE OF UNIVERSITIES AND UNIVERSITY COLLEGES IN THE DEVELOPMENT OF HIGHER EDUCATION}

\section{The case for the establishment of universities in areas not now provided with them}

As we have indicated the four Colonial universities now in existence serve only a small proportion of those who live in the Colonies. Early in our deliberations we decided to urge the early creation of universities so situated that, as far as is compatible with geography, the remaining areas of the Colonial Empire shall be served by one of them. The time will come when the development of the numerous peoples of the Colonial Empire will be such as to require more universities; we can at this stage consider only the next few decades.

The main consideration in our minds in making this decision is that $H$ is Majesty's Government has entered upon a programme of social and economic development for the Colonies which is not merely the outcome of a desire to fulfil our moral obligations as trustees of the welfare of Colonial peoples, but is also designed to lead to the exercise of self government by them. In the stage preparatory to self government universities have an important part to play; indeed they may be said to be indispensable. To them we must look for the production of men and women with the standards of public service and capacity for leadership which self rule requires. It is the university which should offer the best means of counteracting the influence of racial differences and sectional rivalries which impede the formation of political institutions on a national basis. Moreover, universities serve the double purpose of refining and maintaining all that is best in local traditions and cultures and at the same time of providing a means whereby those 
brought up under the influence of these traditions and cultures may enter on a footing of equality into the world-wide community of intellect. In short, we look on the establishment of universities as an inescapable corollary of any policy which aims at the achievement of Colonial self-government. We believe that there can be no more welcome proof of the sincerity of this policy than the provision at an early date of facilities for university education in the Colonies themselves.

This programme of development. will require an increasing number of men with professional qualifications: doctors, agriculturists, veterinarians, engineers, surveyors, geologists, and persons qualified to contribute to the improvement of systems of law and land tenure or to assist in the framing and administration of regulations concerning the employment of labour. The need for professional men and specialists of these types, both to fill the superior appointments and to train the large body of assistants required in these services, is everywhere apparent, and development will be impeded until the deficiency is made good. Considerations of policy and finance alike make it essential that as large a proportion as possible shall be locally recruited and trained. The cost of training elsewhere would be prohibitive, and in the light of the conditions to which we shall refer more fully in chapter XII, it is undesirable that the training of the entire professional class should be conducted remote from local conditions and out of the range of local influences. The recognition of this urgent need is a second consideration, almost equal in weight to the first, which leads us to recommend the establishment of universities.

Since we recommend the institution of new universities largely in order to provide this much needed professional training and at the same time believe that those who pass through universities should be liberally educated, it is evident that in our view there is no fundamental antithesis between liberal and vocational education. We hold that this distinction can be transcended. It is true that this has not yet been fully achieved in our universities, but this only means that any new universities will find themselves, in company with those which exist, at grips with this problem. It is a difficulty which must be faced and not an objection to our proposal. There is an objection of another kind which may be raised; it is held in some quarters that the needs of vocational education are better met by specialised training institutions than by universities. It is urged that the former are advantageous because under Colonial conditions great distances and poor communications make centralised institutions inconvenient. The chief point made, however, relates to economy in finance and staff; the students for whom a specialised institution caters will be restricted to those who have definitely decided on a professional career; the authorities responsible for the institutions will be less ambitious in the matter of buildings and equipment, and they will be able in many cases to avail themselves of the services of departmental or technical officers as instructors.

\section{The relation of universities to professional education and to development of education at the secondary or primary stage}

Waiving the fact that the validity of some of these arguments may be questioned, we hold that such relevance as they possess is overridden by the importance, in the interests of higher education, of the provision of universities which shall be centres, as far as possible, of all professional education in the regions which they serve. A university is in a far better position than a specialised institution to provide the courses, whether in arts or science, which are the necessary preliminary to professional studies. Its academic standing enables it to enlist the services of a staff of superior qualifications, 
and the fact that it can offer to the student the prospect of a degree should make it possible to prescribe higher standards both of initial entry and of subsequent study. There is a further consideration which is of equal importance in our view. It is not enough that a professional man should attain competence in his own subject; association with the life of a university will give him a larger range of interest and enhance his value both in pursuit of his profession and as a member of socicty. Our aim should be to produce not only doctors, but educated doctors; not only agriculturists, but educated agriculturists; and to this end universities minister far more effectively than specialised institutions.

To the list of professions given above that of the teacher must be added and given a high place. Mention of this profession was postponed, not because education for it is not an appropriate task for universities, but because the training of teachers raises a question which demands special consideration. Our duty is to discuss the problems arising in the field of higher education, and it would be beyond our province to deal in detail with instruction at lower levels; but the situation in primary and secondary schools has a direct bearing on our problem. On the one hand the facilities for instruction at the secondary stage determine the number of students fitted for entry into institutions of a higher category; on the other, the efficiency of higher education must govern the scope of instruction and determine the supply of qualified teachers in secondary schools. The position in regard to instruction at the lower level has a further bearing, though of a somewhat different order, on the development of higher education. The inadequacy of facilities for popular instruction and the backwardness of large sections of the Colonial population have created in some quarters the feeling that at the present stage the education of the masses must have the primary claim to consideration. Institutions of higher education are relatively expensive; their immediate benefit is confined to small sections of the population; and it has been urged that we ought not to divert to them the resources which are urgently needed for extending facilities for primary and secondary instruction.

While admitting that the development of popular instruction is most urgent, we cannot agree with the inference that the development of university education should be postponed. On the contrary, we hold that the latter is all the more imperative on this account. For the situation does not present a simple issue between the claims of higher and lower education; progress at any level of education is dependent upon progress at other levels, and institutions of higher education are essential if we are to secure teachers in sufficient numbers and of a quality adequate to establish proper standards of teaching in secondary schools and if we are to be able efficiently to staff the departments of public instruction. Just as the efficiency of the secondary school depends largely on the university, so in turn that of the primary depends on the secondary school. Indeed, the lesson to be drawn from history is quite clear even if at first sight paradoxical; it is that where education as a whole is backward, effort is most rewarding when it is directed to the higher levels. It may be remembered that the development of universities in Europe preceded the systematic organisation of popular education.

\section{The establishment of university colleges as the first step in the development of universities}

In the opening paragraph of this chapter we urged the establishment of universities as soon as practicable. We regard as practicable, and indeed as urgent, the immediate setting up of university colleges. By a university college we mean an institution of higher education at a university level 
which is not empowered to grant degrees. We believe that there should be no undue delay in converting these colleges into universities. But here we desire to issue a warning; we hold strongly that no step could be taken which would more gravely prejudice the interests of these institutions than the premature grant of degree giving powers. An institution with the status of a university which does not command the respect of other universities brings no credit to the community which it serves. We cannot say how long the university college stage will last, because the length of this period depends upon much that cannot be foreseen. We shall recommend later the institution of an Inter-University Council, one duty of which will be to assist and watch the development of the colleges; this body will be in a position to advise when a university college can be raised to the status of a university. There will therefore be a period of unknown length during which the colleges will not grant degrees. We have given careful consideration to the problems which will arise during this phase and make recommendations to meet them in chapter IX.

\section{The appropriate areas to be served by universities}

We also recommend in the first paragraph of this chapter that the proposed universities should serve appropriate areas. Our own report contains specific recommendations for the West Indies, and we understand that the West Africa Commission will outline a scheme for West Africa. As regards Malaya, we desire to support the recommendation of the Commission of $1939^{*}$ for the establishment of a university at an early stage. Similarly we desire to support the like proposal which has been made to develop Makerere College in East Africa to full university status. We hope that every encouragement will be given to the scheme contemplated for the development of Gordon Memorial College, Khartoum. There remain other areas, such as Central Africa and the Pacific, in regard to which we are not in a position to make specific proposals at the present time; it is our expectation that the InterUniversity Council will be able to advise on their detailed problems.

There remain, however, certain general problems which arise when the area to be served by a university is under consideration. The area must be of sufficient extent; the test is neither size nor population, but capacity to supply an adequate flow of students able to profit from higher education. In the delimitation of the area difficulties and even conflict will inevitably arise; it may, for example, appear desirable, when the above-mentioned test is applied, that one university should serve two or more territories each of which on account of legitimate local patriotism or proper educational ambition would prefer to have its own university. These territories may not be satisfied unless each has its college now and presently its university; or each may be willing to see a university serving all the territories provided that the university is not located in one of the others. In either case there is a deadlock.

If a solution is sought by way of conceding colleges to areas which are too small as judged by our test, the colleges will be financially wasteful and educationally of less benefit than larger institutions; moreover, the date when they can hope to qualify for the status of a university will be postponed long after that when a college serving the whole area could hope for promotion. Federation may be proposed as a way of escape from the latter difficulty. It is hardly necessary to say that we do not favour federation in principle; where it prevails it is due to the nature of historical development or to special local conditions rather than to a specific decision in its favour. The special disadvantages of a federal arrangement under Colonial conditions are clear;

* Colonial No. r73. 
the great distances between the constituent colleges would mean that the university would not be a society but a machine for conducting examinations and granting degrees. The university would lack personality, and the colleges, not the university, would influence the character and outlook of the students. Moreover, to the degree to which the colleges specialised in various directions, to that extent the students would lose the benefit of association with an institution of wide interests. It would therefore be a matter for regret if a departure from the unitary arrangement was made inevitable by local conditions.

\section{CHAPTER IV}

\section{ACADEMIC LIFE AND RANGE OF STUDIES}

We consider it no part of our duty to prescribe in detail the courses which should be established at Colonial universities or colleges. Each of them will, it is hoped, develop its particular traditions and special lines of study. We are conscious, moreover, that the areas with which we are dealing differ widely from one another, and that the variations in conditions which bring about the individual characteristics of universities in Great Britain are immensely greater in the Colonial Empire. We shall therefore confine ourselves in this section of the report to suggesting certain general guiding principles, and to stating some of the problems which will face the academic authorities in the Colonial institutions.

\section{Relation between professional and other studies}

In the first place, it is of the greatest importance that a balance should be maintained between two extremes of purpose. The education provided must be neither rigidly directed to the training of recruits to the professions nor so disdainful of practical needs that its products are unequipped for useful service to the community. As we have already observed, there is pressing need for men and women trained to undertake work in social administration, in medicine, in the teaching profession, or in one of the other several fields of service. If the choice lay between the two extreme objectives to which we have referred, there are some who might be inclined to regard this need as paramount; for the production of an educated or semi-educated class divorced from the community as a whole and unlikely to secure employment in it, would be disastrous. We are convinced nevertheless that concentration on professional training would be almost equally regrettable. It would fail to achieve one of the main objects set before us, the preparation of Colonial peoples for self-government; it would not meet the genuine desire of these peoples for easier access to education at a university level, and it would defeat its own purpose, for it would lead rather to the production of technicians than to that of educated men and women proficient in professional subjects.

The task of keeping the balance will be impossible unless certain general principles are followed. In the first place the universities should include teaching in a fairly wide range of subjects. The presence in the same institution of medical, engineering or veterinary students with those taking courses in subjects normally included in Faculties of arts and science, provides for both groups of students an opportunity for exchange of ideas, and this is an important part of the education of all undergraduates.

It may be useful if we suggest what is the minimum range of subjects for the study and teaching of which provision should in our opinion be made. They fall into three categories: $(a)$ some subjects in the Faculty of arts, 
(b) some in the Faculty of science, (c) one or more of those subjects which have been classed for convenience as professional. Considerable variety is possible under each of these heads, particularly under $(a)$ and $(c)$, but this variety does not affect the general principle which we have laid down. This fairly wide range could, indeed, be justified readily enough on the single basis of the provision of training for the various forms of service of which the Colonial communities are in need. It can, however, be justified also as necessary for the provision of what we should regard as the essentials of a general education. Every student, whatever subject or subjects he is studying in his regular course, should be given an opportunity to become aware of certain great conceptions. He should know something of the place of science in modern civilization and the use of scientific method; he should have learnt something of what is meant by sociology, so that he is aware of the other elements and forms of civilization. He should be enabled to gain some apprehension of what is involved in philosophy in its widest meaning, and some sense of the past as expressed in great literature and in the record of history. If his time at the university does not open his eyes to the existence of these great forces in modern life, the student, however expert in his own work, will have missed one of the great advantages which the university can offer him.

In achieving the balance to which we have referred above, the provision of adequate facilities for research is also in our opinion of great significance. We refer to this matter in chapter VI of our report, and it is enough to say here that research in subjects of diverse character is as important from the point of view we are now considering as is the provision of teaching.

\section{Other essential characteristics}

A second principle is closely associated with the first. The universities should be residential. Several considerations lead us to this conclusion: the widely scattered areas from which students will come, the nature of their home background and of the secondary schools where they will have obtained their earlier education, the unsuitability of the accommodation available to students outside the university itself. There is further the important point that a residential college affords greater opportunity for adequate supervision of the student's health. It is also true that no other single condition can serve so well to give the students a broader outlook or a higher general level of education. Nothing could minister more effectively to a spirit of unity where communities are divided by racial or sectional differences. Our third principle needs no elaboration. The universites should be open to all classes, without distinction of wealth, and without discrimination on the ground of race, sex or creed. The criterion of entrance should be one of academic achievement and of personal suitability to profit by the courses offered. We deal in chapters X and XI with entrance tests and with scholarships, and our recommendations on both those questions are directed to secure the general principle which we have stated here. Lastly, the staff responsible for teaching the students and for the tutorial duties essential in a residential institution must be adequate in numbers and of high quality. We deal more fully with this subject in chapter $V$. We only wish to emphasise here that if the quality is not high neither expert training nor general education will be possible. Adequacy in numbers is almost equally important. An overburdened academic staff cannot find time for the multifarious activities which contribute to the provision of a university education in the broader sense. These activities range from the provision of general courses of lectures open to all students, irrespective of their particular Faculty or subject, to informal discussions and debates, and the equally important maintenance of individual contacts. 
In Part II of this report we deal in some detail with special considerations that arise in connection with certain professional subjects: medicine, agriculture, veterinary science, law, engineering and the training of teachers. We are therefore confining our comments here to problems associated with subjects other than these, that is to say to those commonly covered by Faculties of arts and science, including among them the social sciences.

\section{The Faculty of arts}

Considerable variation is possible in the selection of subjects which might be included in a Faculty of arts, and we do not propose to comment upon all those from which the choice might be made. Some, however, seem to us essential, and among them one must have a special place, English language and literature. This special place arises from the fact that in many areas English will be the medium of instruction while at the same time it is not the inherited language of common speech. Where these conditions prevail departments of English should be specially strengthened. The teaching of this subject will involve the detailed instruction normal in departments of foreign languages in this country, and it is important for this purpose that additional members should be appointed to the, staff. We refer in chapter XX to the advisability of a special study of phonetics. The subject of English will be for many students the readiest means of access to the study of literature, and it is essential therefore that its teaching should be maintained at a level comparable to that of university courses in this country. While therefore we consider that the appointment of a professor of English language and literature is essential in every university institution, we should also maintain that he should be given an adequate staff qualified in various branches of the work of the department.

It would be convenient to assume that the special need for the teaching of English could be met by the neglect of other languages. This however would be inadmissible for several reasons. In certain areas the linguistic background makes it desirable that the study of those classical and modern languages which are appropriate to the region should have a prominent place in the curriculum. Wherever these conditions prevail we should recommend strongly that full provision for the teaching of these languages should be made. In others there may be a place for the study of linguistics. In our view this is a subject better suited for research than for undergraduate teaching, and we should urge that facilities for research should be provided wherever it is appropriate. Further, we would consider it essential that provision should be made for the study of at least one European language other than English. The close inter-relation of European literatures would be a sufficient justification in itself for this recommendation, but we may add the further consideration that the students would otherwise be deprived of access to the background of much of the conditions of modern life. Where the conditions of the area do not indicate the need for the study of non-European ianguages we should recommend that provision be made for two European languages, classical or modern, other than English. At the same time we should urge that in the teaching of languages it is particularly important to maintain the principle that it is better to provide adequate facilities for a smaller number of subjects than inadequate provision for many.

History, geography and the social sciences would naturally be included in every scheme for courses in the Faculty of arts, and all three have their special appropriateness in Colonial regions. They form an essential background to much of the work that students will be undertaking later and an essential part of the educational framework. There is one general point which in our view is applicable to all three. It is important to secure, wherever possible, that due attention is paid to local conditions. Our West Indies 
Committee has recommended that a special lecturer should be appointed to deal with the history of the West Indies, and we are much attracted by this recommendation. We hope, too, that in all subjects adjustments of syllabus may make it possible to direct the more specialised part of the students' work to aspects particularly relevant to their regions. But here we must make one qualification. The study of any particular region must be carried out against a much wider background, and the exclusive study of a Colonial region is as undesirable as would be its neglect. In relation to many local aspects of history, geography and the social sciences much research and publication are still necessary before the literature available for their study is adequate in amount and quality for undergraduate training. We therefore regard as most important the institution at the outset of posts wholly or mainly devoted to research in these fields. We considered a suggestion that there should be an institute entirely devoted to research in the social sciences which, while linked with the university, would possess a large degree of autonomy. This plan has the advantage that the claims of teaching could not encroach upon the time for investigation, but for more than one reason we do not favour it. If a semi-independent institute were responsible for this important field of research, the authority and prestige of the university would be diminished; furthermore the result would almost certainly be to create an inappropriate distinction between teachers and research workers in the social sciences. Therefore we favour the institution of a strong department or school of the social sciences within the university, so amply staffed that the proper claim of teaching would not impede investigation. There might be posts in which teaching duties are relatively light; but in any case, all members of the staff of the department should be encouraged to pursue their lines of enquiry and should have sufficient opportunities of so doing.

It follows from what we have said that in our opinion well-staffed departments are needed for English, at least one or two other languages, history, geography and the social sciences. There is one other subject for the inclusion of which we should press. We should like to see in every Colonial university a senior lecturer or professor of philosophy. Even if his work were in some cases confined to the provision of courses and discussions open to all students, we should consider that his presence for this purpose would be of great importance. Moreover he will have a place also in the courses provided for students of the social sciences together with the teachers of economics and sociology who will be responsible for the main part of the work of this department.

\section{The Faculty of science}

The subjects included in the Faculty of science call for less comment, because the possibility of variations of choice is less marked. Fully staffed departments are obviously necessary in mathematics, physics, chemistry, botany, and zoology. In some cases a department of geology will also be needed. In many of the institutions these departments will fulfil a double purpose. Their work will be essential as the basis for the study of medicine or engineering or agriculture. At the same time the pursuit of these subjects is essential to the provision of a scientific training, and in some of them opportunities clearly exist for the building up of active schools, of research in the universities. In all these subjects the general principle applies that where there is a professor there should also be one or more lecturers, and in the experimental sciences adequate provision of laboratory technicians is essential.

We cannot leave this brief discussion regarding the teaching of the physical and biological sciences without some reference to a peculiarly important function which graduates, well trained in science, may have to perform in certain Colonial areas, notably in Africa. Where there are large sections of the population still living under primitive conditions the impact upon them of 
modern scientific ideas and methods may have an effect at once stimulating and disturbing, stimulating in the possibility it holds out for improved methods of production, disturbing in the demand it may impose for sweeping changes not only in habits but even in fundamental beliefs. Interwoven as such beliefs are in so many ways with social relationships, accepted obligations and even domestic and agricultural processes, they require skilful and sympathetic handling when the need arises for adjustment to modes of life governed by scientific ideas.

\section{The provision of libraries and laboratories}

The development of the universities will depend to a large extent upon the provision of fully equipped libraries and laboratories. Considerable capital grants will be needed in the first instance, and again whenever the addition of new departments involves the establishment of a new laboratory or a new section of the library or when the development of new lines of research requires expensive new equipment. Annual maintenance grants are also necessary on a substantial scale. In both cases the aim should be to provide both for the efficient conduct of undergraduate courses and for the development of research. We note elsewhere that the possibility of fundamental research is greater in some subjects than in others, and in the provision made for both libraries and laboratories this fact will no doubt lead to greater demands in some directions. It must be remembered, however, that in all subjects the members of the staff will depend upon the library provision made in the university to a far greater extent than is the case in this country. It will be impossible for them to keep in touch with research undertaken in other countries if its published results are not available for their use. We cannot emphasise too strongly the paramount importance of the equipment of laboratories on a scale comparable to that of the universities in this country, and of the building up of a university library worthy to rank with university libraries elsewhere. The library will need a fully qualified librarian with an assistant staff. We appreciate the great difficulty which may be experienced by the new institutions in building up an adequate library from the beginning and we hope that they may be able to look for assistance in this task to the Inter-University Council whose creation we recommend in chapter VII.

\section{Buildings}

In connection with both the library and the labotatories some considerable importance is to be attached to the size and character of the buildings and their location in the general plan of the university. The possibility of expansion is an important consideration, as is also the close proximity to one another of departments whose work is nearly associated. It is no part of our task to plan an ideal assembly of buildings, but we would suggest that in the consideration of their planning the advice of experts in university buildings should be obtained. Second only in importance to laboratories and libraries we should place the provision of union premises and of halls of residence for students. We should emphasise also the importance of securing that members of the staff have adequate rooms in which they can themselves work and receive students to advise them upon their studies.

\section{Extra-mural activities}

We have thought of the university so far as a centre of research and of the teaching of undergraduates. We hope that it will also take a leading part in the development of adult education in the region. The measures we propose must be limited in their immediate influence; they will affect those who are now children, but, without adult education, they will not touch anyone older. Something should therefore be done for those who would have profited by university education, but have passed the age for it. Otherwise genera] progress and fresh educational advance will be gravely hindered by mass 
ignorance in the older generation. They too should be helped to lead their lives and do their work with more knowledge and intelligence. The fostering of extra-mural studies would in particular do much to guard against a* danger, of which we are fully conscious, that the university graduates might become a separate community within a Colony, divorced from the concerns and aspirations of their fellow-citizens. The development of a self-contained group of this kind is certainly no part of our purpose. The universities as we conceive them have on the contrary a vital contribution to make to the development of the community as a whole. We should therefore urge that from the earliest stage in their evolution, the university colleges should maintain direct contacts with those members of the population whose studies must necessarily be restricted to the leisure left from their other work. There is, further, another reason for the special importance which we attach to extra-mural courses. The university institutions must in the early years be few in number. The areas they serve will be extensive, and will stretch in many cases far beyond the boundaries of the Colony in which they are situated. The proportion of the Colonial populations which can come into direct contact with them must perforce be small. Local centres for extra-mural work will extend the influence of the university to the outlying parts of the region. We consider, therefore, that in every Colony served by a university, there should certainly be one centre for extra-mural studies, and that there should be similar centres wherever large urban or industrialised localities provide opportunity for part-time study. We have been impressed by the evidence given to us of the activities of the Hebrew University of Jerusalem in this direction, and we consider that a strong and fully staffed department of extramural studies should be regarded as one of the normal features of a Colonial university. We hope too that opportunity may be given, through refresher courses and "summer schools " to persons engaged in administrative work, teaching, the health services, agriculture and other activities, to refresh, extend and bring up-to-date their knowledge, and to think, learn and study anew.

\section{CHAPTER V}

\section{THE STAFFING OF UNIVERSITIES}

\section{The factors of environment}

As we have already observed, the provision of an adequate staff is one of the major problems which have to be faced in the development of the new Colonial colleges. No matter how liberal the provision of material facilities and finance may be, the key to successful development lies in the building up of academic staffs adequate in number, quality and experience.

We feel it necessary to preface our recommendations on this subject by a brief reference to the particular needs and difficulties which may be encountered by the teaching staff in the-early years of the development of a college in the Colonies. In the first place, in areas where the numbers receiving English education are as yet few, even though the student possesses the same formal entrance qualification as the corresponding student in Great Britain, he is in certain respects less well prepared to embark on university courses. This is inevitable, for his secondary education has been in English, which to him is a foreign language; he may rarely hear English spoken save during his hours of schooling. The environmental factors which are associated with the English background and which contribute subconsciously yet so materially to education in this country are largely absent. His study of English thus tends to be an isolated and, so to say, exotic episode, rather than an intensification of his education which merges into his life as a whole. 
There is the further difficulty that he will often have received instruction from teachers to whom English is also a foreign language. Teachers have frequently suffered from the limitation of having been insufficiently trained for their work. Their teaching must inevitably lack breadth, and too much emphasis is laid on success in examinations. We do not criticise either the teacher or the pupil; indeed we admire the measure of the success which has been achieved in spite of all the handicaps. It is consideration of these particular difficulties that have influenced us in making our subsequent recommendations in regard to the adequacy of the academic staff in the new colleges.

Colonial colleges themselves have had to face other limitations. The Governments have been handicapped in the development of the colleges by the limited revenues at their disposal. In Great Britain the expenditure on education from central and local authority funds amounted in r938 to $E_{1} I_{3}, 205,000$. In the same year, the total net revenues available to the Governments of all the Colonies and the Sudan to meet expenditure on administrative charges, material development and the full range of social services amounted only to $f 79,552,000{ }^{*}$ In many cases, therefore, the staffs of existing institutions have inevitably been insufficient in number.

There are special obstacles which may be encountered by the men and women who have been recruited for the staffs of the colleges from Great Britain. There must be more tutorial teaching than is common in this country, owing to the relative immaturity of the students, and this fact adds to the burden on the teacher, while the general work of building up the life of the college also consumes much time. There is consequently little or no time available for original work or research.

Perhaps most important of all, is the fact that the colleges normally suffer from lack of contact with academic life in Great Britain or elsewhere, and have none of the advantages of frequent interchange of thought which are largely the driving force in the life of our home universities. The young men and women who have devoted themselves to the development of the Colonial colleges have in fact largely cut themselves off from the main stream of thought when they have taken posts in institutions which are too little known in Great Britain; their contact with the home universities has been limited to their visits to this country during their biennial or triennial leave. Whatever may be the effect of climatic conditions on physical vigour, it is clear that intellectual vigour can be maintained only by avoidance of the isolation which service in the Colonies may often involve.

\section{The position of part-time teachers}

Usually members of the staffs in arts and science subjects and in the preclinical subjects of medicine, have been directly recruited for the purpose; in other cases the teaching has been given by men seconded to the college from the appropriate government departments. Such men may have had no experience of teaching, or little experience of teaching at university level. These seconded teachers may be full-time or part-time; if they are full-time, they may look forward to their return to their original posts. If part-time, they teach with the consciousness that their primary duty and perhaps their major interests lie elsewhere. Nor with staff limited in some subjects to a single member, can the essential continuity of teaching be maintained. During the absence of a member of the staff on leave, a new temporary teacher must be introduced, with all the disadvantages which this entails.

We recommend a departure from the practice under which the teaching in certain professional subjects has been given by officers of the different government services seconded for part-time or full-time duty. Higher

n This figure excludes surpluses and deficits on self balancing departments. 
education in the Colonies owes much to the work of the men who have acted in this capacity and we do not underestimate their services. We feel, however, that the growth of the future universities must depend on their having in the principal subjects of study a nucleus of full-time members of staff with appropriate training and experience of university life.

The departure we advocate is not, however, to be interpreted as meaning that the work of the colleges should be divorced from that of the different government services. Indeed, the help of the members of the staffs of these departments will be as necessary as ever in the provision of much of the part-time teaching in special aspects of medicine, agriculture and similar subjects; equally the facilities for practical instruction in government hospitals, in agriculture and forestry and the like will be not less essential. We would hope also to see members of the staff of the colleges collaborating with the officers of the government departments in many of their research problems.

\section{Recruitment and the conditions of service}

In order to obtain staffs of appropriate standing and experience the majority of the posts in the new colleges must for some time be filled by recruitment overseas. Success in filling them will come only if a number of conditions are satisfied. In the first place, we regard it as of high importance that the universities of Great Britain should take an active interest in the staffing of the Colonial colleges and in the other important directions which we discuss subsequently in chapter VII.

There is a second point of no less importance. In the past, the salaries attached to appointments in the colleges of the Colonies have followed the general pattern of those of the different government departments. In our view this practice should be modified. The conditions of service in the colleges of the Colonies should be related to those in the home universities. Many of the senior posts in the different subjects should carry the title of professor, and all the posts should be given an appropriate academic grading. Further, only if the salaries are comparable with those in Great Britain will staff of the appropriate quality and experience be attracted from overseas.

Thirdly, we consider it is of great importance that the other conditions of service should not be such as to hinder the subsequent appointment of members of the staffs to universities in Great Britain, nor the appointment of members of home university staffs to serve in the Colonies. At the present time, the practice regarding pension schemes varies in different Colonies, and the fact that the colleges, with the exception of the Imperial College of Tropical Agriculture in Trinidad, do not participate in the Federated Superannuation Scheme of the Universities of Great Britain may be an obstacle to mobility. We recommend therefore that the Colonial institutions should seek admission to this scheme for staff recruited from overseas. We recognise that its application to institutions in the Colonies which are largely tropical may present some special problems, but the provision of similar and transferable superanuation rights is important.

Our fourth point concerns the question of leave. In the past, members of the staffs of the colleges have followed the practice obtaining in the local government services. In West Africa, leave of three months is taken after each eighteen months of service ; in Malaya, of six months after each three years of service. Such long absence from contact with university life in Great Britain is undesirable. There is no doubt that it limits the number of those coming forward for appointment; equally it has undesirable effects on the vigour and enthusiasm of those working .in tropical conditions. It is essential that the members of staffs should be refreshed by frequent visits to Great Britain in order that they may keep abreast of developments not only in their own subjeots, but in general university thought and life. We 
therefore recommend that there should be a liberal provision of free passages for the use of members of the staff during vacations. Air travel will make this provision advantageous even from the Far East. The good effects of a system of annual leave are to be seen from its working in Khartoum and at the Imperial College of Tropical Agriculture, Trinidad. In addition, men appointed to the permanent staffs should have the opportunity of extended study leave of six months to a year perhaps every fifth year.

\section{Rates of pay for overseas and local staff}

The question of salaries raises a difficult problem which has caused some concern to our West Indies Committee, and will undoubtedly arise in other parts of the Empire. It is the problem of differential salaries for staff recruited overseas and for those appointed locally.

The argument in favour of differential pay is based upon three propositions which should first be briefly stated and will then be discussed:-

(I) It will be essential to recruit the great majority of the staff from over-

seas during the first period of university development in the Colonies.

(2) It will be necessary to pay high salaries to attract staff of the required quality.

(3) It will be unnecessary and inequitable to the taxpayers and restrictive to the growth of the university to pay salaries at the same rate to locally recruited staff.

The first two points may be discussed together. The whole future of the university may well depend upon the intellectual standards, the wisdom and experience in academic administration of those who mould the college into a university, and carry the university through its first years. It will not be easy in the period after the war, when there will be a shortage of academic teachers at the very time when universities in this country and in the Dominions will be expanding, to obtain sufficient men and women of the right quality to take up positions in the Colonies. We have referred already to some of the professional difficulties which may stand in the way of possible candidates. There are others of a personal nature that may make it necessary for them to consider the financial conditions carefully, such as the need to make a new temporary home while, it may be, some members of the family remain behind for reasons of health and education. It is thus clear that, to put the matter in its plainest financial aspect, the Colonies will have to make their bid in a highly competitive market at a time, too, when British salaries are likely to rise. It will thus be necessary to pay at least the salaries which will be paid in this country.

Turning to our third proposition, we look forward to the time, which we hope will be very soon, when men and women of the Colonies will begin to replace the overseas staff. There would be no. necessity to grade the new appointments at the same rate, since there would be no question here of the teachers uprooting themselves from their own regions and climate and interrupting their careers. The market, moreover, instead of being open and highly competitive, would tend to be closed and sheltered.

The argument that, for reasons of prestige and equality, it would be desirable to continue to pay all salaries at a level considerably above the rate justifiable on economic grounds, is based upon the immediate interests of the very few people involved. As the overseas staff began to diminish, it is very possible that the university would have reached a stage demanding expansion; reduced rates of salary would allow of more new appointments being made than might be possible in many Colonies with restricted resources. To maintain a uniform salary scale for all appointees irrespective of whether they are recruited locally or come from overseas would restrict the whole development of the university. 
There are, however, even wider considerations bearing upon this question. It would not be equitable to ask the British taxpayer to subsidise the payment of salaries at a level that could be justified only for the special purpose and limited period which has been defined above. Equally it would be unjustifiable to ask the Colonial taxpayer to shoulder the same unnecessary burden, all the more since an inflated level of salary for one group tends to re-act upon that of other groups in the same region. It would be socially as well as economically improper to support one small group at the level fixed by British standards of life. As Colonial standards of living rise, the disproportion between local and overseas rates will be progressively adjusted.

It would be a complete misreading of the financial factors involved to regard the proposed distinction as being in any sense a racial discrimination. Two considerations alone should dispel this idea. One is that the same problem presents itself, and has to be met in the same way, wherever a country with a shortage of persons with special expert qualifications is obliged to attract candidates from a distant country overseas. This happens where European countries employ people of other nationalities, especially where the conditions of living are very different or in any way less congenial than in the home country of the imported expert. Even within the Commonwealth it has often happened that when a Dominion university has wished to engage a teacher of repute from this country a special salary has been paid for the overseas appointment. The other consideration that should make it clear that an overseas salary rate has no inherent relation to race, is that a local rate would apply equally to those Europeans who are domiciled in the Colony. This would obviously be true, for example, of the West Indies.

We are aware that the problem thus created is to some extent of a general character, and that more than one suggestion for its solution has come under consideration. We confine ourselves to considering the method which appears most appropriate and practicable in the particular field with which we have to deal. It is one that has been discussed in the report of the West Indies Committee. Under this scheme there would be a basic rate of salary paid by the university to all members of staff, and any supplements necessary for the recruitment of teachers from overseas would be provided by the United Kingdom, under special arrangements made for their administration. There are several ways in which this could be carried out, but in order to show the practicability of this proposal we will briefly indicate one method. Part of the money which the United Kingdom Government may be prepared to devote to Colonial higher education should be paid into a special fund under the control of the Inter-University Council whose creation is recommended in chapter VII. The proper authority of each university or college would make its own appointments, but where an overseas teacher was appointed he or she would then apply to the Council for payment of the supplement, which would be made upon a settled scale, though adjustment to meet special cases might be made by the Council in consultation with the appointing authority. A slight modification of this scheme might allow the authorities of the Colonial institution to pay a regular expatriation overseas allowance at a modest rate which would cause it no financial or other embarrassment, the sum payable from the fund at the disposal of the Council being adjusted accordingly. The payment of the expatriation allowance would have the value of reminding the Colonial authorities of the financial advantage of resorting to local recruitment as soon as this should prove possible.

The establishment of such a fund would allow of further proof that the overseas allowance had no racial significance. As the Colonial universities 
advance towards maturity we hope that they will produce, from among their own members, scholars with a reputation which will make them desired acquisitions at other universities of the Empire and Commonwealth, though from the historical background of the situation this reverse movement is not likely for a long period to be so large in volume as the other. Anyone thus appointed to a home or another Colonial university from a Colony would be eligible to claim an overseas supplement designed to compensate him for the disturbance of his life and career. The home Government and those operating the scheme centrally would thus have the satisfaction of promoting at its most influential level the intellectual solidarity of the Empire.

\section{Secondment of staff}

While the institution of new salary scales and conditions of service will remove some of the existing barriers to recruitment, these proposals alone will not provide a complete solution of the staffing problem in the immediate years ahead. It is essential in our view that the colleges and universities of the Colonies should be brought into the intellectual stream of university life in Great Britain. Only by such means can the isolation from which Colonial institutions have tended to suffer in the past be overcome.

We shall discuss in chapter VII the many directions in which the home universities could further the policy of Colonial university development. Here we confine our remarks to the problem of staffing. It is not unnatural that young men shbuld be unwilling to leave the resources available to them in the home universities in order to take posts in Colonial institutions of which they have little or no knowledge and from which the chances of return to an appointment at home have hitherto been remote. In our view, the solution lies in the institution of a scheme under which men and women of varying seniority in teaching and research may be seconded from the home universities to the staffs of the colleges with a reasonable prospect of return to their home university at the end of their period of service, withont loss of seniority. We make this proposal in the light of much evidence both from Great Britain and from the Colonjes. It would be facilitated if arrangements were made as previously suggested for the continuance of policies under the Federated Superannuation Scheme for Universities. As we subsequently show, the adoption of such a secondment scheme would make some contribution to a solution of the problem of recruitment of the permanent staffs. We recognise, however, that the seconded staff could not, without some loss to the institutions of the corporate spirit necessary to their development, contribute more than perhaps a quarter of the total staff.

It is unnecessary to define in detail the conditions of secondment, which will need discussion in each particular case. Here we need only say that we have in mind periods from one to three years, and that the scheme should be open to members of staffs of all grades of seniority. It would apply most readily perhaps to junior lecturers of some teaching experience; less frequently, though with great profit to the Colonies, to the men who had reached the status of senior lecturer or professor. We intend that all seconded members of the staff should be considered as full members of it. Besides taking the part-assigned to them in teaching, they should share like other members of the staff in the administration of the college.

It is clear that the ease of application of such a scheme would vary greatly from subject to subject. But in our judgment there is no doubt of the great impetus to the development of the future colleges which this scheme, which has been described as " intellectual lease lend," would provide. On the 
one hand, the sense of intellectual isolation felt by members of the staff would be greatly lessened. On the other, some of those seconded would find the conditions of life or the opportunities presented sufficiently attractive to make them desire to join the permanent staff, and as a result the building up of a permanent staff of suitable quality would be facilitated. Lastly, after a period of secondment and return to their home universities, some of the younger men might wish later to apply for appointment to a post as professor or principal at the college in which they had served or at some similar institution in the Colonies.

The institution of a secondment scheme would entail certain sacrifices on the part of the home universities in agreeing to some of their best men being temporarily released for work in the Colonies, and in making arrangements which would ensure that these men could return to posts without loss of seniority. But the great service which they would so render would not be without recompense. Anything which provides new academic experiences for the members of a university staff is an advantage to the academic body as a whole. From this point of view our own universities would benefit in a different degree but in much the same way as would the colleges which they would be endeavouring to help. It is not for us to suggest methods whereby the home universities should ensure the carrying on of the work of members of the staff who may be seconded. Serious practical difficulties will have to be faced; but we hope that in view of the high importance of the measure we propose, every effort will be made to overcome them, and we are encouraged in this hope by the sympathetic attitude shown by representatives of various home universities with whom we have discussed this problem.

Any such scheme which brought the universities of the Colonies into intimate relationship with those of Great Britain would also have not less important results of a wider nature. Some of the regrettable ignorance which exists in this country regarding the Colonies might in the course of time be dispelled. Knowledge of the Colonies would first permeate the universities through the return to them of men who had seen Colonial service. Inevitably this knowledge would be reflected in the teaching in different subjects and the students' interests would be widened. Later, through the teachers trained in the universities, it would reach a wider circle in the schools. Further, the opportunity for students to discuss the question of service in the Colonies with teachers who have had personal experience themselves, might help to remove the doubts which often deter men from entering the Colonial services.

\section{Local recruitment}

As regards the appointment of local members to the academic staffs, the staffs of the institutions already contain a varying number of members drawn from the Colonies, mostly holding junior posts, and appointed usually after study in the universities of Great Britain. It is dearly desirable that their numbers should be increased as soon as men of quality become available. We suggest that graduates of promise should be appointed for a period of one or two years to posts such as that of demonstrator and research assistant, and that they should then be given the opportunity of a period of postgraduate study in Great Britain. We do not think that they should be appointed to any post of responsibility unless they have successfully completed a course of postgraduate study. With the passage of time, suitable local graduates will establish reputations which will justify their appointment to the more senior posts, until ultimately the universities will be staffed mainly by members of the communities whose territories they serve. 


\section{General}

We give below in chapter VII some indication of the range of the problem of stafting in respect of the numbers likely to be required. The plans we have framed can fairly be described as ambitious and far-reaching, and we realise the difficulty of recruitment on the scale which they indicate. We are mindful that this difficulty will be increased by the expansion of the home universities and other institutions of higher or specialized education which may follow as a result of the greatly increased grants recently made for the purpose, or which is likely to form part of a post-war programme. But while we fully realise these difficulties, we remain convinced of the paramount necessity of promoting a healthy and effective development of the Colonial universities and university colleges, and are equally convinced that this cannot be achieved save by measures on the scale we have indicated.

\section{CHAPTER VI}

\section{THE PLACE OF RESEARCH}

In the course of outlining in chapter IV the character which in our view the new Colonial colleges and universities should possess, we indicated that we attached great significance to their recognition not only as agencies for instruction but as centres of research. We have again, in chapter $V$, when dealing with the measures necessary to mitigate the effect of the intellectual isolation and of absorption in a continuous routine of instruction from which members of the teaching staff of a Colonial institution are liable to suffer, emphasized the value of affording them the opportunity to undertake original study in their own special field of knowledge. It is not to be expected that all teachers can devote themselves to research of a fundamental type, but all must have opportunities for such reading and enquiries as will broaden their own knowledge, and enable them not only to have greater competence as teachers, but also to gain greater intellectual authority vis à vis the student. But apart from this, the subject of research seems to us of such general importance as to justify a more extended examination of the position which it should occupy in the life of the Colonial colleges and universities.

\section{The university as a seat of learning}

The original impulse which led to the founding of universities some eight centuries ago was search after knowledge; for that purpose scholars banded themselves together and round them gathered young people who sat at their feet; these young people followed the discussions of their seniors in the hope that one day they would gain for themselves recognition as scholars. Thus originated the familiar distinction between staff and students. Search after knowledge is the continuing inspiration of universities, and if conditions in institutions of higher education are such that this inspiration is baulked or stifled, these institutions whatever they are named, will be continuation schools and not universities. This is a statement of an ideal, and in what follows in this chapter, we are concerned with its implications. We are aware that in no university is the ideal attained, but the closer any university approaches it, the more nearly does it fulfil the true purpose of a university.

The first point to secure in the organization of an institution of university rank is recognition of an cbligation upon those appointed to the staff to forward the study of their special field of knowledge. Such furtherance of knowledge in a special field rests upon individual work which varies in kind in different disciplines and different circumstances. It includes the essential duties of keeping constantly in touch with the results of research and of 
preserving a continual readiness to consider new ideas and to make the adjustments of outlook that follow from the acceptance of new data. It includes much that furthers appreciation as well as investigation, and may lead as naturally to attempted synthesis as to the extension of factual knowledge. The pursuit of such independent intellectual activities is a paramount need if university departments are to retain their vigour and to discharge their proper obligations in a university society.

This obligation resting on the staff involves a complementary obligation resting upon those who control universities, whether directly as members of the governing body or indirectly as providing the finance, to ensure for the staff sufficient time and adequate facilities to pursue investigations of their choice. But this will only be achieved if two conditions are fulfilled. In the first place, those who control universities must understand what search after knowledge as undertaken in a university implies. It means that the knowledge sought is desired for its own intrinsic value; the motive proper to a research worker is to extend the boundaries of charted knowledge in his own field wherever extension is intellectually most satisfying. Research of this kind is called fundamental research, and it is fundamental research which is proper to a university. It follows that utilitarian results must not be demanded from the research activities of members of the staff of a university and that their work must not be judged by its immediate bearing upon practical problems.

In the second place, those who control universities must believe wholeheartedly that fundamental research is an essential feature of university life and that in the long run universities will be judged by the contributions which they make to fundamental knowledge. Unless the importance of providing facilities for research, in the shape both of time and of material requisities, is kept steadily in mind, it is inevitable that under the pressure of circumstances the duties connected with teaching and organization will grow and eat into the time which is required for research. The universities have to comply with demands from many new classes of students, and in a world of increasing complexity are bound to make their own internal organization more elaborate ; the easy but dangerous-indeed ultimately fatal-solution is to allow new duties to be placed upon the staff at the expense of reducing facilities for research. As the duties placed upon universities multiply, the staff must be strengthened.

Even if reasonable opportunities for research are secured, all has not been achieved. There is a subtle danger which threatens all universities, and will be especially formidable in the Colonies. A university is not a continuation school in which the staff have time for research ; it is an organ of higher learning inspired throughout by devotion to search after knowledge. Outwardly the daily ordering of life at a university may be similar to that found at a school, as seen for example in required attendance at lectures and classes and in the preparation for examinations ; but inwardly the situation is of quite another character. The school pupil is inevitably in large measure a passive recipient as he acquires the necessary elementary techniques and the indispensable basic facts ; the university student should be an active participant in the studies of the place, and in so far as it is possible for him at his particular stage of academic progress, he must be a fellow seeker. Indeed a university may be said to be a society embracing students as well as staff which is devoted to search after knowledge.

The parts played vary ; the professor is initiating important research ; the young teacher is learning to assume similar tasks; the graduate is assisting ; the senior student is following with considerable understanding; while the 
new entrant is becoming aware for the first time what investigation means. If university teachers, for any reason such as the type of student sent to them or the nature of the work they are called upon to do, have to adopt the attitude of instructors rather than of guides to junior, very junior it may be, seekers after learning, they are subjected to a strain that they should not be required to bear. Moreover, if the university teacher cannot appear before his students in his true guise as a searcher, he is precluded from exerting through them a particular form of influence upon society that he is especially qualified to spread and which it is most desirable for society to experience.

\section{The field open for research}

It was suggested above that those who engage in fundamental research seek to extend knowledge for its own intrinsic interest, and it may appear that to research workers in Colonial universities opportunities for investigation are unduly limited. But it must not be forgotten that the choice of subjects for research is nowhere unconstrained by circumstances which may make some desirable projects difficult or impossible to attempt. In the Colonies certain constraints will be very obvious, at least for some considerable time to come. It will be long before libraries can be built up to a point at which there will be a possibility to undertake many forms of historical and literary research; the same applies, though with less force, to some kinds of economic and sociological research. It will not be possible at the outset to equip laboratories with expensive apparatus which is more especially needed for research in the physical sciences. Indeed, for some time to come, difficulties of obtaining laboratory equipment will tend to impede research in all the natural sciences, while the inevitable poverty of library resources will be an obstacle to all forms of research in the social sciences and the humanities.

On the other hand, tempting and little explored fields lie to hand for the students of social data, anthropologists, archaeologists, students of political science and applied economics, educationists, students of languages and others. It would be difficult to exaggerate the wealth of opportunity available in the Colonies to those engaged in social study; the variety of cultures, the impact of western ideas, the swift changes, all offer chances for observation and investigation which it would be hard to equal in this country. Much the same might be said of the opportunities awaiting the zoologists, botanists, ecologists, parasitologists, geologists, meteorologists, and many specialists in branches of natural science. As regards students of medical science generally we invite reference to what we say subsequently in chapter XIV. The novelty and attractiveness of the problems which await enquiry in such fields may well outweigh the difficulties arising from paucity of laboratory and library resources. Moreover, it is likely that improvements in ease of travel and communication will soon be such as to lessen these difficulties. While it would be obviously misleading to imply that opportunities for research in the Colonies will be at all similar to those at home, or that adjustment of interests and methods will not be necessary on the part of those who join Colonial universities, it is nevertheless true to say that fundamental research can be successfully pursued in many subjects under conditions presented by the Colonies. It is indeed possible that the necessary adjustment to new problems and new conditions may in itself form a welcome and valuable stimulus.

\section{The function of a university in respect of the applied sciences}

The course of historical development has been such that the territories of Colonial status are even more in need of the application of scientific knowledge 
to their problems than are those of most of the more advanced sovereign countries; the urgent need of using science to improve health, agriculture, or industry in the Colonies is so obvious as to require no emphasis here. But it is not the function of universities directly to provide this kind of help; to require universities to do so would be to divert them from their proper purpose; to expect them to do so would indicate a fundamental misapprehension of the place of research in universities. This does not mean that the universities have no part to play in the fostering of applied science in the Colonies. It will be at the Colonial universities that scientists will be trained, many of whom, it is hoped and expected, will find a career in applying their scientific knowledge to practical problems. They will be trained in institutions where fundamental research is pursued, and it is important to understand that training in that atmosphere is as essential for one who aspires to be an applied scientist as for one whose aim is to pursue fundamental research. In short, it is an important duty of the university to train students to become applied scientists.

Again, it is customary in this country to associate with a university persons working on specific or practical problems. So situated, the research worker, while not a member of the university staff, has the great benefit of the advice of the staff, who may be expected to take a friendly interest in his problems. It is hoped that this practice will be widely followed in the Colonial universities. It may also be deduced from what has been said as to the abundance and attractiveness of local material that the university research worker, though untrammelled by the need to produce utilitarian results, will in fact not infrequently devote himself to enquiries which will have considerable practical significance. Thus the indirect contributions of the Colonial universities to the furtherance of applied science will not be small.

\section{The relations between institutes of applied science and the universities}

Nevertheless provision for most of the work in applied science must be made outside the Colonial universitics in institutions or other organisations specially set up for that purpose. Many organisations of this kind exist and others will no doubt be created. Just as benefit is derived by an individual research worker engaged on a practical problem who is associated with a university, so benefit would be similarly experienced by workers employed by one of these organisations if it were located near a university. They too could obtain help and advice; further, the benefit would be mutual, for it is stimulating to a member of a university staff to be directly aware of the problems and difficulties of applied science. Moreover, scientific workers tend to suffer from the effects of isolation, and derive stimulation from contact with a group or society of persons sharing their general interests, outlook and way of life. When the site of a research organisation is considered, it may be found that there is little freedom of choice; a marine biological station must be on the coast. But there is generally considerable freedom, and it is to be hoped that when this is so, the advantages of a site near the university will be carefully borne in mind. The advantages so derived may well outweigh in the long run the reasons, administrative or other, which at first sight would seem to suggest another location. When research organisations cannot for good reasons be near universities, it may prove possible and beneficial for some link to be formed between them and the university; the opportunities offered to students of biology in this country to study in marine and fresh water biological stations has been of great benefit to them and has not been without some corresponding advantages to the stations. 
CHAPTER VII

\section{AN INTER-UNIVERSITY COUNCIL FOR HIGHER EDUCATION IN THE COLONIES}

\section{The general role of the home universities in the development of higher education in the Colonies}

As we have already observed, the success of any scheme for the development of higher education in the Colonies depends on the active interest and cooperation of the home universities. The universities of Great Britain have as a whole made their contribution to Colonial development through the training of graduates who have entered the various Colonial services. Some of them have rendered a more particular service by concerning themselves with the training of Colonial students in Great Britain; others with research into special Colonial problems such as education, medicine, social science or political administration. We desire here to pay tribute to the special interest in Colonial education shown by Durham University through its long standing and intimate connection with Codrington College in the West Indies and Fourah Bay College in Sierra Leone. But as we see it, the policy under which large sums are now being made available for the development of the Colonies offers a new and effective field for a close partnership in the realm of university education. We would recall that in spite of the widely varying conditions in the Colonies the diversity in their economic, social and religious backgrounds and in their mother-tongues, higher education in almost all the territories is conducted through the medium of English. It is then in the development of institutions of higher education that peculiar opportunity exists for the forging of the permanent intellectual links which are so desirable in the world to-day. The recommendations which we now make are directed to the immediate problems of university development, but we have no doubt of the importance of their bearing on this wider objective.

\section{The creation of an Inter-University Council}

We recommend the creation of a new body, the "Inter-University Counci] for Higher Education in the Colonies ". The Council would be a co-operative organisation of the universities of Great Britain and the Colonies charged in general terms with the two distinct tasks of co-operating with existing Colonial universities and of fostering the development of Colonial colleges in their advance to university status. In recommending that this new body should be constituted, we do not overlook the valuable work that is being done in a more general field by the Universities Bureau of the British Empire. We believe, however, that a new body such as we now suggest may be more appropriate for the discharge of the special function to which we shall refer below and which will have considerable bearing on the development of the new universities and university colleges in the Colonies at the earlier stage of their existence.

As regards the composition of the new Council, each of the home universities should be invited to nominate a member. We might venture to hope that a tradition would be established that representatives so nominated would not only be of weight in their own universities, but would have a special interest in Colonial affairs. Provision might also be made by co-optation for the representation of university colleges and institutions of comparable status which have a special interest in Colonial students or in Colonial subjects of study. Each Colonial university and university college should also be invited to nominate a member. Such members might be able to attend meetings only as occasion served, but they would provide a valuable channel for communication and for making known in the Colonies the opportunities provided 
by the work of the Council. In order that the Council should be kept in close contact with developments in school and other forms of education in the Colonies, it is desirable that the Adviser on Education to the Secretary of State should also be a member. The Council would appoint its own Chairman who might or might not be chosen from among the members of the Council.

The Council would doubtless carry out much of its work through an Executive Committee which might find it necessary to form standing or ad hoc committees. The members of these committees, all of whom would not necessarily be members of the Council, would be chosen by regard to the subjects of which they possessed special knowledge rather than by regard to their representative capacity. The Council would require a permanent secretariat, with a full time secretary of suitable distinction and appropriate experience and adequate office accommodation. We suggest that the appointment of members to the Council should be for a period not normally exceeding five years, but that the appointments should be so balanced that no undue proportion of the members retire in any year.

\section{The chief functions of the Inter-University Council}

The first task of the Council would be to acquaint itself with the present position and needs of the Colonial university institutions. We attach great importance to its acquiring first hand experience of the Colonies by short visits of some of its members. Evidence from the Colonies has shown that such visits are greatly valued by the Colonial institutions. Some of us who have had the privilege of visiting the colleges and universities at various times will always remember the welcome we have received and the interesting discussions and exchange of information and ideas which took place. Visits of this type will have a special value since they will provide the staffs of the colleges with an opportunity of discussing not only general policy but problems of teaching and research encountered in their own subjects and in mitigating their sense of isolation. We shall subsequently refer to the benefits which have been derived by the Kitchener School of Medicine, Khartoum, from the regular annual visits of men of high distinction in medicine.

As has already been indicated in chapter $V$, the Council would have a specially important part to play in connection with the staffing of the institutions. Here it is desirable to give some indication of the range of the problem of staffing. While we are unable to make any precise estimate of what may be the requirements in regard to staff, we anticipate that in the West Indies and West Africa alone some 90 posts of status not less than that of senior lecturer would be created within the next few years. To these must be added the needs of East Africa, where under our proposals the requirements for medicine, agriculture and veterinary science will not be less than those of West Africa. Later there will come the similar needs of Malaya, at least in the subjects of arts, science and medicine; and of Hong Kong. These estimates take no account of men who may be required for special research appointments either within the colleges or in institutions elsewhere.

In the normal course, appointments to the staffs of the institutions will be made by the institutions themselves and we would not wish to suggest that their responsibility for their own staffs should be lessened in any way by the work of the Council. But by virtue of its composition, the Council will be in close touch with all the home universities and it would no doubt be ready to make its services available to any Colonial institution which desires to consult it regarding the recruitment of staff whether for teaching or for research. The services which it may be able to render in this respect will 
be considerable; especially so when it is desired to fill appointments, as we recommend in chapter $V$, by the secondment of members of the staffs of home universities and colleges.

By following the progress of members of the staffs of the colleges the Council would gather experience as to the type of men who prove most successful. Where a member of the staff of a Colonial institution desired a change, the Council might use its good offices to assist him. Above all it would foster the feeling that for those who go to the Colonies there exists at home an authoritative academic body interested in their careers.

A further function of the Council should be to facilitate arrangements by which institutions in the Colonies can receive visitors annually, the number of whom would no doubt vary from year to year, concerned with one or other of the subjects or branches of study of which they have special knowledge. These visits would be arranged by the Council in consultation with the authorities of the institutions to be visited. Correlation with the visits of examiners sent out by the University of London in connection with the scheme of examination to which reference is made in chapter IX will be ensured through the member of the Council representing that University. In certain subjects such as agriculture and medicine there would be an additional advantage if these visitors could learn something of the problems of the particular government departments by visits to research and similar institutions.

We should not wish to see such visits limited to the Colonial colleges. If the existing Colonial universities so wish, we suggest that visits should from time to time be made to them also, and that a similar arrangement should be made to enable visits to be paid to the universities in Great Britain by members of their academic staff.

The question of the financial provision to be made for the work of the Council will be discussed in chapter XIII, but here we would say that the cost of visits arranged by the Council seem, in our opinion, to be a proper charge on United Kingdom funds. If grants for capital or recurrent expenditure are to be made from these funds, the visits might help to ensure that the grants have been wiscly spent and assist in the assessment of future needs. In chapter VIII we recommend that one or two seats on the governing bodies of a Colonial college and future Colonial university should be filled by the Inter-University Council.

The Council would advise the Colonial institutions on any matter of academic policy or research on which they sought its help. Arising from the special relationship with London University which we outline in chapter IX, there will be many points on which collaboration with that University may be of great value. In subjects such as medicine, agriculture, or veterinary science, the Council would interest itself in the question of the recognition of the local diplomas by bodies such as the General Medical Council, or of their acceptance by the home universities as conferring a qualification for entering upon postgraduate study in this country or obtaining exemption from the earlier stages of undergraduate courses.

\section{Its functions in connection with Colonial students in the home universities}

The Council would we hope take an active interest in the placing of Colonial students in the home universities. Full information could be obtained by the visitors through personal interview and discussion with the teachers concerning any student who was hoping to come to this country. In the light of this information, the Council would be able to advise the intending student which university would be best fitted for his proposed studies. Such a method would help to overcome the difficulties which have been experienced in the placing of students in the past and provide the home universities with more 
reliable information than has hitherto been available as a basis for dealing with applications for admission from students. The Council would thus ensure that the places available in the home universities, which may at least in some subjects be limited in the next few years, will be allocated to the best advantage. while the students themselves will come to Great Britain knowing that a personal interest had already been taken in them.

We have given considerable thought to the question whether the Council should be responsible for the welfare of Colonial students coming to Great Britain for study, a matter which is at present in the hands of the Director of Colonial Studies, an official of the Colonial Office. The question is complicated by the fact that many students come to Great Britain for a variety of training purposes in institutions other than universities, and for this as well as other reasons we feel that the problem of their welfare is not one appropriate to the Council.

The problem of welfare of students and their proper guidance is not easy of solution. We hope, however, that one of the results of the more active interest and co-operation of the home universities will be the development within each university of special provision for their welfare and advice.

\section{The relation of the Council to schemes for financing higher education from United Kingdom funds}

We have also given some thought to the question whether the Council should be asked to render advice on the allocation to Colonial universities and colleges of grants from United Kingdom funds. We have decided not to recommend a function of this character, apart from the suggestion which we have made in chapter $\mathrm{V}$ in regard to the administration of the funds provided for supplementing the pay of overseas staff. We consider that the Council would have greater influence with the Colonial institutions if its function were in the main confined to consultation and advice on the academic aspect of any projects of development put forward. We have therefore decided to recommend the establishment of a separate body, the Colonial University Grants Advisory Committee, to the composition of which we shall refer subsequently in chapter XIII. The Inter-University Council should however be represented on the Grants Committee, and we assume that it will be consulted, as a matter of course, on the desirability from the academic point of view of the projects for which financial aid is sought. In the knowledge obtained through the work of its visitors, the Council will be able to advise the Grants Committee not only on general principles but on the needs of particular institutions. Indeed it will be able to anticipate needs which are likely to develop in the near or more distant future, and any views put forward would no doubt be of assistance to the Secretary of State and to Colonial Governments. We anticipate that occasions may arise when it will be desirable for the Council to arrange special visits to the Colonies to discuss problems of this character.

\section{The functions of the Council in regard to the promotion of Colonial studies in home universities}

We feel that the Council may also have an important function to perform in regard to the encouragement of Calonial studies in the home universities. A number of the universities have chairs, readerships and lectureships in subjects which have a particular reference to the Colonies, and we hope to see the number of these posts extended. Their holders will be able to make a valuable contribution to the literature on Colonial problems, and to stimulate among their students an increasing interest in Colonial affairs. It will be for each university to decide how far it would 
wish to bring the further study of Colonial problems within the scope of its activities. But we hope that as the work of the Council makes these problems better known, there will be an increased desire on the part of the universities to take a part in assisting in their solution.

\section{Relations between the universities of the United Kingdom, the Dominions, India and the Colonies}

Although the immediate objective of our proposals is the promotion of institutions of higher education in the Colonies, the machinery which we have recommended would be available for the development of co-operation with the Dominions or India, and if other schemes are forthcoming (as we believe they may be) for closer co-operation in certain aspects of higher education, for example, postgraduate work, there would be nothing to hinder the InterUniversity Council from taking a part in them.

\section{CHAPTER VIII}

\section{THE GOVERNING AUTHORITY OF COLONIAL UNIVERSITIES AND COLLEGES}

\section{The importance of autonomy}

In our view it is essential that Colonial universities should be autonomous in the sense in which the universities of Great Britain are autonomous. This does not mean that they should not be under certain obligations. They should be required, for example, to publish an annual report accompanied by a financial statement, and wherever grants are sought either from the United Kingdom or from Colonial funds it is reasonable that periodical visitations should take place by a properly constituted authority. We have in mind the analogous visitations of the University Grants Committee in this country. The Colonial universities should, in effect, have full freedom to manage their own affairs, though placed under the obligation to present an account of their stewardship. Only if autonomy so understood is allowed, can that degree of freedom of teaching and research be secured which is fundamental to a university; only in these conditions can the highly expert task of maintaining proper academic standards be carried out.

\section{Practice in this country}

The newer universities of this country have constitutions which, while varying in detail, follow the same general plan. This plan has been found to work with success, and we recommend that it should be followed in the Colonies. In this scheme we find two chief offices, those of Chancellor and Vice-Chancellor, and two chief organs of government; the names given to these organs vary, but there is always a supreme organ of government which we shall call the Council and a body of purely academic composition which we shall call the Senate.

This scheme of government is also applicable to university colleges though they do not have a Chancellor. The officer corresponding to the ViceChancellor is the Principal, and the body corresponding to the Senate is usually known as the Academic Board. It may be observed that if it were found desirable to have an officer at a university college with the status and powers of a Chancellor, other than the power of granting degrees which is not possessed by a university college, he might be called the Visitor. 
In order to secure the required degree of autonomy it is not enough to have these officers and these organs of government. Two further conditions are indispensable. The Senate must possess full authority in purely academic matters; otherwise, however independent the university may be, academic issues, which should be the sole responsibility of the academic staff, will be subject to determination by the Council, a body in which the representatives of the academic staff will be in a minority. In other words, a proper measure of autonomy for the academic staff within the university is necessary. It is of equal importance that the members of the Council nominated or elected by any one outside organisation or institution shall not be in a majority; otherwise the university may become a mere creature of that organisation. The composition of the Council should therefore be well balanced; moreover, the method whereby outside organisations appoint members to the Council should be such as to secure as far as possible that these members are not so much representatives of outside interests as persons well qualified for the task of forwarding the true aims of a university.

\section{Outline of constitution for Colonial universities}

We now offer a sketch of the broad outlines of a constitution suitable for Colonial universities; while retaining the main constitutional principles found in our newer universities, we have attempted to take account of the special situation which will face universities in the Colonies. The Council is the supreme governing body ; it is the trustee of the property of the university, and it authorises all expenditure. It appoints the Vice-Chancellor and fills all non-academic posts. We consider that the power to appoint the Chancellor should rest with the Crown. To the Senate are assigned all academic matters relating to curricula and examinations; it is responsible for the control and discipline of students; it is empowered to make regulations. In certain spheres the two bodies co-operate ; the Council promotes statutes and frames ordinances after consulting the Senate, and it makes all academic appointments on the recommendation of the Senate. There is an appeal to the Council on matters in dispute in the Senate, and to the Chancellor on matters in dispute in the Council. The Charcellor is the final arbiter in all matters which may be referred to him.

\section{Composition of the Council}

As already indicated, the composition of the Council is a matter of great importance. It should not be too large a body; it would be well if its numbers did not greatly exceed twenty. For the members other than the representatives of the Senate will be drawn from different walks of life and sometimes from different Colonies and will not normally be known per. sonally to one another. If they are to form a body between the members of which there can grow up a certain degree of intimacy, as is most desirable. they must not be too numerous. The methods of attaining seats on the Council will be various, some will hold seats ex-officio, others will be elected. nominated or co-opted.

The two chief officers of the university will be members of the Council ex-officio. When present the Chancellor will preside, but he would not normally be expected to attend. It might be laid down that the ViceChancellor should be chairman of the Council in the absence of the Chancellor: thus exercising the power of the Chancellor in this as in other spheres when the Chancellor is not present, or it might be thought best for the Council to elect its chairman. The Vice-Chancellor should be chairman of the Senate ex-officio, and since much business comes forward from the Senate to the Council it may be easier for the Vice-Chancellor to present this business to the Council if he is not also its chairman. 
Not less than one third of the seats on the Council should be held by members of the academic staff. It is a great convenience if the deans of the principal Faculties are members of the Council; they should therefore be members ex-officio. But a majority of these seats should be filled by election by the Senate, and the restriction on total numbers which we have suggested may mean that not more than three of the deans could be members ex-officio. Provision is sometimes made for one or more of these seats to be filled by members of the non-professorial staff; but in the absence of such a provision the non-professorial staff would not be excluded from membership if our subsequent recommendation that the non-professorial staff should have seats on the Senate is adopted.

We now approach the question of the presence on the Council of persons who are not members of the university. We would assign up to one third of all seats to persons nominated or elected by the Legislatures and by the Executive Governments in the area served by the university, but it is to be desired that the majority of these seats should be filled by representatives of the Legislatures. The filling of seats by the Legislatures would be a method of enabling the people in the areas served by the university to take a share in the direction of university policy, and it is appropriate that they should be in a position to do so. While we hold that the university should neither be directly controlled nor appear to be controlled by the government we consider that on many grounds it is advisable that the executive Government should have some representation on the Council.

As regards the remaining seats we should like to see provision made for the nomination by the Chancellor to a certain number of seats to provide for those who may be qualified by experience or who possess personal qualities which might be of assistance to the Council. We would hold that for this purpose members of the government services should not necessarily be excluded, but they would be nominated on their personal qualities, not as representatives of Government. We would like to see formed an organisation of the graduates of the university, which might be called either the Guild of Graduates or Convocation; this body should be represented by at least two members on the Council. In our opinion such a body might be of much assistance to the university, and not only by electing members of Council while it would have no other formal powers, it would enable graduates to keep in touch with developments and to offer advice; in short it would focus the loyalty of graduates to their university.

Finally, we propose that one or two seats should be filled by the InterUniversity Council. We realise that these members will seldom be able to attend, though we hope that they would visit the university once a year and be present for at least one meeting of the Council. But we think that the provision of these seats would be useful because those holding them would receive all the papers of the Council of the university and would be able to keep the Inter-University Council fully informed of the current business of the university. They would also, no doubt, convey their views on current business in writing to the Vice-Chancellor for communication to his Council.

We realise that it may be difficult to secure the regular attendance of a majority of the members of the Council so constituted and it may be necessary for it to arrange that its business may be transacted either through an executive committee with sufficient powers to avoid the delay of current business or by a suitably balanced quorum of its members. 


\section{Composition of the Senate}

The composition of the Senate is a less difficult problem. It would consist of the Vice-Chancellor, who would be ex-officio chairman, all professors, all deans of Faculties, heads of departments who are not professors, and certain officers, as for example, the librarian. In addition there would be representatives of the non-professorial staff elected by the members of that section of the staff; these representatives should not form more than a sixth of the total number composing the Senate. Under the Senate there would be Faculties to whom power to determine certain matters would be assigned.

\section{The Chancellor and the Vice-Chancellor}

Some indication has been given of the mode of appointment and of the powers of the Chancellor and the Vice-Chancellor. The former office is honorary and the holder should be a man of distinction and experience. It is hoped that he would preside on ceremonial occasions. He would be available for advice but would not intervene in the affairs of the university unless invited to do so, as for instance, by arbitrating in a matter of dispute. In the absence of the Chancellor all his powers would be exercised by the Vice-Chancellor who should be a man of good academic standing and administrative experience.

\section{Initial stages}

In order to bring a constitution of this kind into being, special arrangements would have to be made; moreover the body first to be set up would be a university college and not a university. The first Principal might be appointed by the Crown and the initial appointments to the academic staff will no doubt be made after consultation with the Inter-University Council. It would only be after the university has been in operation for some years that there could be a Guild of Graduates of the new university; it might be arranged that graduates of any United Kingdom or Dominion university resident in the area concerned should be members of the Guild until a certain number of years after the grant of a charter to the university. Since these are matters of detail rather than of principle, we have not thought it incumbent upon us to consider further the necessary transitional arrangements.

\section{CHAPTER IX}

\section{THE PERIOD OF TRANSITION FROM COLLEGE TO FULL UNIVERSITY STATUS}

\section{The significance attaching to the standard and character of degrees}

There may be more than one test of the value of the contribution which a university makes to the life of the society which it serves. But as a centre of instruction and learning the test which must be applied is the extent of the recognition accorded to its degrees in the academic world. The problem of the standard and character of the degree to be awarded at the end of the normal undergraduate course is one which every university rightly regards as of the first importance. There is no simple formula for its solution. The degrees awarded by universities in this country vary among themselves in many important respects. Different universities establish individual traditions which become recognised as peculiar characteristics of their own, and it would be idle to deny that there are variations in standard in the work demanded in specific subjects. At the same time a rough equality of standard is maintained sufficient to permit a general recognition of the value of a degree; the differences are one aspect of the 
freedom of university institutions on which great store has long been set in this country. The new Colonial universities will, it is hoped, in course of time build for themselves similar traditions and individual characteristics. At the same time it is most important that the general standard maintained in this country should prevail also in them.

Developments of this nature must of necessity take time. It is inevitable that in the initial stages of the growth of Colonial institutions attention will be concentrated on securing for the Colonial graduate a qualification whose significance is clear. The degrees obtained by students must rcpresent both academic attainments of the standard associated with success at a degree examination in this country, and an intellectual training comparable to that obtainable in a home university; for the qualification must be acceptable to Colonial Governments and other appointing bodies as the equivalent of degrees granted by universities at home; and it must, at the same time, be acceptable by universities in this country as an adequate preparation for postgraduate work. These are the two tests which will commonly be applied in the Colonies themselves as the criteria by which the value of their university institutions is measured. There is ample evidence that Colonial opinion is already crystallised on this point.

These considerations apply with equal force to all the branches of study in which degrees may be granted. The problems involved in finding the solution differ indeed in detail. In medicine, for example, the General Medical Council by its system of " recognition " of qualifications to practise provides a valuable test of the standard of achievement. The special problems relating to this and other professional subjects may call for individual solution, and where this is the case they are considered in Part II of our report. The discussion that follows here is particularly applicable to degrees in the Faculties of arts and science, although it may be found in many cases to have wider application.

\section{Possible alternative methods of awarding degrees in the initial period}

We have examined in detail three possible methods for the awarding of degrees in the initial period of the growth of Colonial institutions:-

(a) that students should enter for the London extcrnal degrees in continuance of the practice followed hitherto in several of the Colonial colleges,

(b) that the Inter-University Council should be empowered to grant degrees,

(c) that degree giving powers should be conferred at once upon the authorities of the Colonial institutions themselves.

\section{(a) The external degree system of London University}

The external degree system of the University of London offers opportunity to persons who are not students of any of the colleges of that University to follow the same curricula and to be examined by the. same standards as the internal students of the University itself; examiners are appointed to examine both internal and external students and they are specially charged to maintain equivalence of standards. This system allows persons who, for one reason or another, cannot attend courses at a degree-giving university to acquire a degree of deservedly high prestige. It has been of great service to isolated students in this country and in many parts of the Empire, and it has encouraged the spread of higher education among large numbers of persons whose desire or opportunity for learning has come at a comparatively late period in their lives. It has further contributed substantially to the growth of the newer universities in this country. As these institutions developed they became universities with the power of conferring their own degrees; in several cases, 
however, there was an earlier period when their students obtained their degrees through the London external examinations. At the present time students of the University Colleges of Nottingham, Exeter, Southampton, Leicester and Hull sit for London external degrees. A similar evolution has. already taken place in Ceylon, which was until recently a university college most of whose students worked for London degrees and is now a degreegranting University. The value of the London external degree in the development of higher education in different parts of the Empire is indeed wellrecognised, and London examinations have been taken widely both by the "private" student working in isolation and by students of the various colleges not yet of university rank.

The system has, however, disadvantages from the Colonial standpoint, and we have examined carefully the points of criticism which have been raised with us from various sources. Differing conditions in the Colonies involve problems wholly distinct from those experienced in providing common examinations for students in various parts of Great Britain. The differences are partly geographical, with the accompanying variations in the materials available for the study of the biological sciences; they are partly the result of the broad distinction between communities at different stages of social and economic development, distinctions of great importance in relation to the study of the social sciences. There is further the problem of the approach to the study of language in those large areas of the Colonial Empire where the English tongue is not the inherited language of the people, and the linguistic background of their speech differs fundamentally from that of Europe. The authorities of London University have recognised many of the implications of these differences. Special provision is made for the substitution of an oriental classical language for Latin or Greek in the case of students born in Asia and Africa. Variations have been permitted in syllabuses in the biological sciences, in history and in geography. But these special provisions, helpful though they have been, do not wholly meet the needs of Colonial students. The differing background and educational needs of the peoples of the Colonial Empire demand a greater measure of variety in courses and curricula than has hitherto characterised the London external degree.

There is another important point. The judgment of students in an examination designed and controlled by an authority some thousands of miles away is, indeed, a system admirably devised to secure impartiality of treatment and the maintenance of sound standards of academic achievement. Still more does this become apparent when it is remembered that the examination, with a few minor variations, is the same as that taken by students working in Great Britain itself. But these advantages, which have benefited alike the "private" student and the students of the Colonial colleges, have carried with them some drawbacks for the latter. The system, as we have been informed, has led in practice to over-emphasis on the importance of examinations in comparison with that of the training received during the students' course. It is easy to see that teaching in these circumstance may become too rigidly directed to the examination. Again, in practice, the minimum requirements laid down in university regulations may come to be regarded as upper rather than lower limits ; regulations may indeed obtain an importance which should be reserved for the more nebulous objective of sound learning, and the letter of the law may be exalted to the detriment of the spirit.

We realise fully that for the "private" student the external system as it exists at present provides opportunities which otherwise would be wholly lacking, and we have learned with interest of the further methods for helping such students with their work afforded by the development of an Advisory Service for external students as part of the activities of London University.

$(44.67)$

B 4 
We are, however, concerned primarily with the system of examination for the students of the Colonial colleges, and for these colleges we sinould desire a relationship with the degree granting authority of a different character, one above all which permits dinect contact between examiners and teachers and a full adjustment of examination requirements to the geographical, linguistic and economic characteristics of the Colonial areas.

\section{(b) Possibility of recognising the Inter-University Council as a degree-giving body}

With these considerations in mind we have examined the possibility that we should seek for the Inter-University Council the power of conducting degree examinations and conferring degrees. This solution to our problem would have one outstanding advantage. It would give to all the participating universities in this country a direct concern in the determination of the character and standard of the degrees. It would put the awarding of degrees into the hands of that organisation which, if our recommendations are accepted, will have an interest in the other aspects of the work of the colleges. It would facilitate the adjustment which we desire to secure between degree examinations and Colonial conditions.

The proposal appeared to us at first sight to be an attractive one, but on careful consideration we have reached the conclusion that there are decisive objections to it. In the first place, it would involve the setting up in this country of new and elaborate machinery for dealing with curricula and examinations. In the second place, it would mean that the degrees obtained by the students were those of an authority not only newly created, but also having no precedent in the university world, an authority moreover brought into being to deal only with students of Colonial colleges. For this reason the plan might well fail to fulfil the aspirations of Colonial students, who, it is reasonable to suppose, would value a degree either of an established university or of their own college when it haf risen to university status, but not a degree emanating from so novel a source. In short, when it is examined, the proposal is seen to involve a cumbrous innovation for which those whom it is designed to benefit would probably feel no enthusiasm.

\section{(c) The possibility of the immediate grant of degree-giving powers to Colonial colleges}

The ultimate desideratum is not a Colonial degree system, but a degree of each of the various Colonial universities, each with its own diversities and traditions comparable to those existing in universities at home. This fact led us to consider with great care the third of our possible solutions, the immediate grant of degree-giving powers to the Colonial colleges themselves. We were agreed from the outset that the early grant of these powers was desirable, and that this was essential to the free development of higher education. We have learned with interest of the system for the grant of college diplomas at certain of the existing Colonial institutions, as, for example, at Makerere College and at Gordon College, Khartoum. This system gives opportunity for the free planning of courses and the conduct of examinations by the staffs of the Colleges. It permits valuable experiments in the adjustment of academic curricula to local needs. It provides a qualification for students the value of which we fully appreciate. We desire in every way to encourage experiments on these lines, and regard them indeed as an important part of the ground work upon which later a degree system can be based. We are of opinion that the practice by which these courses terminate in a college diploma should be maintained for the present. The colleges must be given time to develop so that their degrees when they are granted will have immediate recognition. No greater disaster 
could befall a university than that it should start its history with a system for the grant of degrees which failed to secure ready acceptance as proof of a high standard of achievement and a sound course of training. If our recommendations were to lead to this result, we should have done harm rather than good to the cause of education in the Colonies. A period of probation is in our view essential, and in this interval the interest of the students requires that some means should be open to them for proving their capacity for academic achievement. It has been our concern to find a way by which these means can be provided without what we have described as the disadvantages of the external system as it works at present.

\section{Recommendations in favour of the grant of degrees by London University}

The solution of this problem has been made possible by the successful termination of negotiations into which we entered with the University of London. The University has set up a special committee of the Senate in accordance with a scheme, the object of which will be to establish a new relationship between the Colonial colleges and the University. The University has stipulated, and we recognise not only the justice of the stipulation but its advantages from our standpoint, that the Colonial colleges which participate in the scheme must have reached a certain stage in development. In order to participate, a college must, for example, have an adequate staff, whose control of academic work is constitutionally established; it must be adequately equipped and must have satisfactory standards of entrance requirements. It will be noted that these conditions will in fact be fulfilled if our recommendations are carried into effect. The degrees awarded to the students of the participating colleges will be those of London, and will therefore carry with them the reputation which those degrees possess.

We fully realise that in these circumstances the final word in the ditermination of the standards of the examination and the syllabuses prescribed for them, and in the appointment of examiners, must lie with the London Senate. The decisions taken by the Senate, however, aim at the removal of the special disadvantages of external system when it is applied to Colonial areas. In particular it may be noted that the new committee of the Senate will have the following aims prominently in mind:

(i) the establishment of direct and easy co-operation between the Academic Boards of the Colonial colleges and the Senate of the University,

(ii) the institution of a regular system of consultation between the authorities of the University and the staffs of the colleges upon questions of syllabus and examination requirements,

(iii) the promotion of personal contact between the external examiners appointed by the University and the teachers in the colleges, in part by visits of the examiners to the colleges,

(iv) the participation of members of the staffs of the colleges in the actual work of examining their own students.

It is clear from our communications with the University of London that it is the intention of the Senate that the new system of co-operation should have wide implications, and in particular that the consultation on questions of syllabus and examination requirements should result, where it is found desirable, in substantial adjustments to local conditions. It will be open to the academic authorities of the colleges to make their own proposals direct to the University, and these proposals will clearly be welcomed. This practice will give to the teachers in the colleges full opportunity for making their views effective by direct communication with the University: The visits to the colleges of examiners from this country will make possible a far 
closer co-ordination than has been the case hitherto between the examination requirements and the work of the colleges themselves, and the gradual introduction of members of the staff of the colleges as assistant examiners will make this co-ordination still more secure. The University has moreover expressed its readiness to participate in giving help and advice to the colleges in relation to their diploma courses, and in doing so has recognised the importance of these courses as the foundation of the later degree system. Further the University has indicated its willingness to receive suggestions made by the proposed Inter-University Council, whose direct contacts with the colleges will, it is intended, be frequent. In our opinion this scheme is admirably designed to remove the difficulties and misapprehensions inherent in the normal system for the award of external degrees, and we therefore recommend that the Colonial colleges should be invited to avail themselves of it.

We are aware that the scheme of examinations which we recommend will be of necessity an expensive one. Special syllabuses involve separate examination papers, and the visits of examiners to the colleges will require special provision. We are of opinion, however, that the results which we seek to achieve are of great importance, and have included in the financial statement in chapter XIII a recommendation that special grants should be made to the University of London to cover the costs which the new system involves.

\section{The stage at which Colonial universities will grant degrees}

This scheme has been devised by the University of London and is recommended by the Commission as an interim arrangement pending, the grant of degree-giving powers to the Colonial institutions themselves. We regard it as part of our duty to indicate in broad outline the conditions which should prevail before the interim period is ended. The colleges which enter upon the new relationship with the University of London will be, if our recommendations are put into effect, already on their way towards university status; for in them will be found the control of academic matters by an Academic Board or Council, the achievement of substantial progress in the equipment of laboratories and libraries, the possession of an academic staff adequate in numbers as well as in quality, and the insistence on satisfactory standards of entrance requirements. The process of development to full university status under the scheme recommended will begin as soon as our recommendations become operative, but the interval before it is complete will no doubt vary with different institutions. There are three conditions whose fulfilment is essential. The staff must have had a few years' experience of university work in the Colonial institutions; their conditions of work must be of a nature to permit the active prosecution of research; and there must have been already a substantial number of students who have completed satisfactorily courses for degrces. These students, morever, should show some variety in academic training, some taking a course in one subject or group of subjects and some in others, some in the Faculty of arts, for example, and some in the Faculty of science. A reasonably well-balanced academic backgtound is, in our view, essential in a university. When these conditions have been met by any of the Colonial colleges-a matter concerning which the proposed Inter-University Council will be able to express a view_the transfer to full university status will be sought by making an application for an appropriate charter.

The transformation of the Colonial college into a Colonial university may involve certain minor changes of nomenclature. The Principal would become a Vice-Chancellor, the Academic Board a Senate. The university will have 
unquestioned control over its entrance requirements, its curricula and its degree examinations. It will appoint its own external examiners. We may here express a hope that under these new conditions the universities may continue to seek the help of external examiners from this country, as well as from universities elsewhere, so that the close links that will have been established will not be broken. The universal practice in the universities of Great Britain of inviting examiners from other universities to take part in their degree examinations is one which we hope will become equally the practice in the Colonies. It does much to achieve the general acceptance of a rough equality of standard in the degrees of different universities, despite the many variations between them. The change will involve too a new relationship with the Inter-University Council; but we have already indicated our hope that the Council may continue to be of use to the Colonial universities in maintaining close links with this country and in giving help when it is needed in matters such as staffing and equipment on which the friendly assistance of universities at home may be of value.

\section{CHAPTER $\mathrm{X}$ \\ ENTRANCE QUALIFICATIONS}

The problem of the selection of students for admission to the Colonial colleges (and later to the universities which will develop from them) is one of vital importance to the institutions themselves. The standard adopted for the minimum entrance qualifications will have a direct influence on the standards of work in the college, and unless a reasonable level is maintained its evolution to university status will be undesirably postponed. At the same time there is another danger against which it is necessary to guard. The qualifications required for entrance to the college will have repercussions on the work of secondary schools, and care is needed to secure that this influence is favourable to the development of sound teaching at this stage.

We fully recognise that the conditions prevailing in the Colonies.demand special consideration and that they vary greatly in different areas. The University of Ceylon imposes a standard of admission closely similar to that which we recommend here. Our West Indies Committee found that conditions in the West Indies made this standard equally applicable to that region. In Africa on the other hand different circumstances require separate treatment. Secondary school education is not nearly so fully developed; the pupils have, moreover, the additional disadvantage that their education is conducted in a language which is not their mother-tongue. In some areas English is not even the pupils' second language but their third. Such pupils cannot be expected to pass school examinations at the age normal in this country and attempts to make them do so would result in undesirable cramming and overwork. This difficulty cannot be wholly overcome by the improvements for which we hope in the secondary schools. We have given full and sypathetic consideration to the problems raised by these conditions, and make special recommendations for their solution. One or two of us, indeed, feel that these problems are so vital that our recommendation as a whole should be directed primarily to meet them. Most of us, however, are of opinion that we ought to state in the first place the principles which we think should be maintained wherever circumstances permit, and follow this statement by a separate discussion of the possible ways of meeting special difficulties.

\section{General Principles}

There is a large measure of agreement among university teachers in this country as to the general level which it is desirable that students should reach before they are admitted to courses in the Faculties of arts and science lead. 
ing, in the normal period of three years, to a degree. This level may be defined as that achieved as a result of two years' work in a sixth form, two years, that is to say, after the successful entry for a School Certificate examination. In English schools these two years are frequently given to preparation for a Higher School Certificate examination. While, however, there is agreement as to the value of work in the sixth form, there is some diversity of opinion about the suitability of the particular form of test now associated with the Higher School Certificate examination. We are moreover aware that the whole system of school examinations is at present under review, and we do not therefore wish to express an opinion as to the desirability of encouraging pupils in Colonial secondary schools to enter for this examination as at present constituted. We should prefer to emphasise our view that these pupils should wherever possible, like their contemporaries in this country, have the opportunity to spend two years in a sixth form.

This recommendation involves certain consequences. In the first place, the normal age for transfer from school to college would be not less than 18 . In the second place, the preliminary studies necessary before a student starts a university course would be carried out at school, and time at the university college would not be wasted in making good the deficiencies of earlier education. This second point is an important one. We should strongly deprecate a practice by which students are admitted to classes for which they are not properly fitted. In the Faculties of arts and science for example the normal first year course terminates in an Intermediate examination. No student should be admitted to this course who does not satisfy two conditions; he must have already completed the requirements for matriculation and he must have attained a sufficiently high standard to make it probable that he can reach the level of the Intermediate examination in one session. The crowding of the first year courses by students who are manifestly ill-equipped is wasteful and academically unsound. The conditions of entry to the degree courses must be framed in such a way as to secure that this danger is avoided.

In those colleges where the students will take the degrees of the University of London, in accordance with the system which we have described in the preceding chapter, the minimum entrance qualifications for the degree course will be determined in the first place by the requirements for matriculating at London. There are several methods of meeting these requirements. The usual method for students of the normal undergraduate age (i.e., about I8) is the entry at school, at the age of about 16 , for the School Certificate examination conducted by one of the eight schools' examining authorities in this country. Success at this examination with the requisite number and distribution of "credits" qualifies the student for exemption from any special matriculation examination. It is to be noted that the obligation to obtain " credits" is a matter of some importance. In 1939, for cxample, at the midsummer examination I4,575 candidates "passed" the London School Certificate examination, while the number obtaining the " credits " necessary for matriculation was 7,634 .

Representations have been made to us that the restrictions at present in force as to the choice of subjects necessary in order to fulfil the requirements of matriculation weigh unduly on Colonial students, and the question is one of those to which the Senate of the University of London has agreed to give sympathetic consideration. We attach considerable importance to the adapting of syllabuses and restrictions as to subjects to meet conditions in the Colonies at this stage as well as for higher cxaminations, and we have learned with interest of the substantial progress already made in this direction by schools' examining authorities, and in particular of the modifications of syllabuses made by the Cambridge Schools Examination Syndicate. It is, 
however, a general principle which we cordially endorse, that such modifications are subject to the limitation that they must not imply any lowering of standard. Moreover, the proposals at present under discussion for changing the basis and character of schools' examinations are likely to lead in the direction of raising rather than lowering the present minimum requirements for matriculation in this country. The minimum statutory requirements must therefore be taken as a bare minimum below which no admission should be made.

There is a further point. The minimum qualifications do not in this country constitute any claim of entry to universities or colleges. This is a point of some importance in considering the applicability of the normal practice to the Colonies. Grants and scholarships to enable pupils at secondary schools to proceed to a university are given at a stage in their education which may generally be described as two years after the securing of minimum qualifications by successful entry for a School Certificate examination. The figures given above for the numbers successful at the London School Certificate examination are significant from this point of view, particularly if it is remembered that this is only one of the eight schools' examinations conducted regularly in this country. Only a small proportion of the students qualified for matriculation in fact proceed to a university in Great Britain. The normal entrant to a university has substantially higher qualifications than those prescribed as the statutory minimum. Each college in the University of London, for example, settles its own standard of admission provided that this does not fall below the minimum statutory requirements, and we recommend that from the beginning the same practice should be applied in Colonial colleges. The normal method of testing qualifications is by an entrance examination. In using the term "entrance examination " we do not intend to imply a written examination only; intervicws (or viva voce examinations) form an important part of entrance tests, and the scrutiny of school records is also valuable.

\section{Entrance requirements for degree courses}

We recommend therefore that direct entrance to courses leading to a degree should be limited to students who fulfil the following conditions:-

(i) the securing of the necessary number of " credits " at a School Certificate examination (or at whatever schools' examination may later be substituted for this);

(ii) the passing of a special college entrance examination, designed to test the results of work at the level commonly associated with a sixth form in a secondary school (in connection with this, students should be interviewed and their school records scrutinised).

Our recommendations in favour of a college entrance examination instead of the acceptance of results of a public examination are based upon the belief that a special examination can more readily be directed to the specific end of testing the capacity of candidates to profit fully from a degree course. It can also be designed with a full knowledge of the type of work which can reasonably be expected from the secondary schools in the region.

\section{Special conditions for entrance in certain areas}

We have stated already that we are aware that the conditions which we have recommended are not possible of fulfilment in all Colonial regions. In some areas, it is hoped, the development of secondary schools will make them possible in the future. One of the objects, indeed, to which our recommendations are designed to lead is the encouragement of the growth of secondary schools. In these regions as clsewhere it is essential to our purpose that the university colleges should frame their policy and state their requirements in ways which give full weight to the circumstances of the region which they serve. 
There are several ways in which adaptation to these circumstances could be made. One obvious policy is for the university colleges to institute preliminary courses designed to enable the student to reach at college, at the end of one or two years, the standard of attainment which we have indicated in the preceding paragraph. In connection with it we would, however, suggest one warning. The time spent on these preliminary courses must be added to the normal period of the degree course. We should, morcover, recommend strongly that the preliminary course should be conducted separately from the normal first year's course designed to lead to the Intermediate examination. This method of dealing with the problem has an obvious drawback. It would prolong the courses of students at the college and thus postpone the time when the effects of our recommendations can be felt in the teaching and other services for which trained men and women are urgently needed.

A different policy is already in operation in some of the Colonial colleges, and we hope that it may be further developed. This policy is that of providing alternative courses terminating in a diploma given by the Colonial college itself. The development of these courses would make it possible for students who can spend only three years in all at a university college to follow a course planned as a coherent whole, a point to which we attach considerable importance, and framed on a system which takes fully* into account the entrance qualifications which it is reasonable to impose. The urgent need of the Colonies for trained men and women leads us to the view that a qualification resulting from a course of this kind may be invaluable in the immediate future. It might be possible in some cases to combine the two policies, by permitting students admitted to the diploma course to transfer to a degree course at a specified stage should the record of their work justify it.

It is at the same time of vital importance that the entrance requirements to the college for students of whatever category, should not be set too low. If a three-years' course for a diploma is provided it may well be that students taking it will have a large part to play in the task of bringing secondary school education to a satisfactory level. We recommend therefore that the conditions imposed should be as stringent as the circumstances of the Colony permit. In no case should students be admitted to the college below the age of I7, and wherever possible the normal age of I8 should be maintained. The students should in all cases be required to have passed before entry to the college a School Certificate examination with a "credit" in English and a prescribed number of other subjects. They should moreover be tested by the college by a special entrance examination designed to show their suitability to profit from a university course.

\section{Provision for over-age students}

There is one other class of student for whom special provisions may need to be made; the students who seek to enter the college af an age substantially above the minimum age after a period spent in employment since they left school. Some of these students may not have the necessary School Certificate qualifications.

\section{CHAPTER XJ}

\section{SCHOLARSHIPS AND FINANCIAL ASSISTANCE}

\section{Scholarships as a mark of academic distinction}

The difference between scholarships as a mark of academic distinction and grants of financial assistance to supplement the means of students has been developed very clearly in Britain during the last twenty-five years. This 
distinction is of special importance in the Colonies, where it is probable that in most areas an unusually large proportion of the students will be unable, without considerable help, to undertake higher education.

Little need be said here of entrance scholarships as rewards for academic ability. Those who win them should receive the status of scholar or of exhibitioner, and, as frequently in this country, they should have the first claim upon financial assistance in proportion to their needs. Some might argue that the time has come when the practice of recognising intellectual distinction through scholarships should be allowed to lapse, but it is probable that the Colonies will wish, in this matter, to follow the practice in this country, and there is no doubt these awards stimulate energy and rivalry among the schools. That this rivalry may in certain conditions have unhealthy effects has been shown in the report of the West Indies Committee; the solution must be found in arrangements made to regulate the standards for entrance, to which reference has been made in chapter $\mathrm{X}$.

\section{Assistance to meet the financial needs of students}

The question of assistance given to meet the financial needs of students may arise at more than one stage.

The first is that at which the student is entering a university or university college. We have recommended in chapter $\mathrm{X}$ that the colleges should conduct a special entrance examination. A selection having been made of students of the required standard, appropriate grants, as far as funds are available should be allocated after such confidential inquiry as may be practicable into their financial position. An adequate fund for this purpose is an essential part of the provision for Colonial universities, since without it there will' be no possibility of filling the available places with the best candidates, or, perhaps, of filling those places at all. It is probable that grants of money will be forthcoming from other sources than the university. As in the West Indies and in Africa, Colonial Governments may vote funds for students from their own territories and Native Administrations may wish to do the same.

It would be most undesirable to discourage provision of this nature which may be voted readily under the impulse of local patriotism, but it would obviously be necessary for the conditions under which assistance is given to be worked out in consultation with the academic authorities. We may say here, and we elaborate this point in the succeeding chapter, that we hope that, except where special conditions warrant, the present practice of giving scholarships for undergraduate education overseas will be brought to an end, and that scholarships available for postgraduate work will be extended.

We attach much importance to this latter point. Although it is desirable that in future the great majority of Colonial students should receive higher education at institutions in the Colonies, we hope that policy will be directed to securing that an increasing number of these will be able to take in Britain or the Dominions postgraduate studies or special courses of training which are not available in the Colonies. Financial provision will be required for this purpose, and the question arises how these funds should be administered. The Colonial Governments will wish to play their part, since in many and perhaps in most cases, they will be in the best position to know in what directions trained staff is most needed and will also themselves be employer's. On the other hand, the university authorities will best be able to judge of the qualifications of the students and probably of the most suitable overseas institutions in which to place them: As we have suggested in chapter VII, the Inter-University Council may also be able to give assistance in this respect. 
It is not for us to prescribe in detail how this situation should be met, but we anticipate that both the university and the Government will have funds from which to finance this further training and will set up joint machinery for the selection of those students who are to be assisted directly by the Government. It is possible that Colonial men and women might be selected for studies abroad at a further stage when they have shown their qualities through some years of work in their professions. In these instances the balance of the decision will clearly be with those who are directing their work, but even here their record as undergraduates might usefully be taken into consideration.

Experience in the home universities has shown that there may be need for additional help at a third stage in special cases. After they have entered upon their courses, students sometimes meet with unforeseen difficulties which make it hard or impossible for them to continue their education. There should in each institution be arrangements for meeting these special cases where the performance of the student justifies such assistance, either by special grants or by instituting funds from which loans without interest can be made and which therefore operate as a revolving credit. It is important that no student should be allowed to contract the obligation of a loan until he has shown himself in all respects capable of bearing it. It is therefore desirable that loans should not be given, before the calibre of the student has been shown and in no case before he has entered upon his undergraduate career.

\section{The indenture system}

The further question arises whether those to whom the Governments award grants in order that they may obtain undergraduate or graduate training to fit them for the Colonial Services, should be under any legal obligation to enter these services and remain in them for some specific period. It is clear that they are under the strongest moral obligation to the tax-paying community to act in this way, but experience in Britain with regard to the obligations imposed upon teachers whose training has been subsidised from public funds has shown the difficulties of this method. The McNair Committee* in its report has indeed recommended that the system whereby young students in this country are required to sign a declaration committing them to take up work as teachers in return for the grants received by them should be abandoned as soon as possible. Here again, we cannot dictate to Colonial Governments how they should meet the problem, but we must express our doubt as to the efficacy of the legal contract in this sphere. In the Colonies many of the government services are so attractive in point of prestige and in the prospect of security that the question is scldom likely to arise.

\section{CHAPTER XII}

\section{COLONIAL STUDENTS IN THIS COUNTRY}

\section{The number of Colonial students studying in Great Britain}

There will be found in the Appendix figures of the number of Colonial students studying in various institutions in this country at the end of January, I945. We are informed that the figures may not be complete, since the Colonial Office does not necessarily come into contact with all students, and we are also informed that since that date nearly a hundred students have arrived in this country. To some extent these figures may be abnormal and reflect the result of war conditions. But the numbers are in any case

\footnotetext{
* Report of the Committee appointed by the President of the Board of Education on
} Teacters and Youth Leaders, p'iblished by the Stationery Cffice (April I944) 27-260. 
considerable, and it is likely that with the progress of post war development in the Colonies the numbers of students seeking university education will show a substantial increase.

\section{Considerations regarding resort to this country for undergraduate studies}

The whole tenour of our report has pointed to the conclusion that the undergraduate education of Colonial students should wherever practicable be carried on in Colonial universities. This opinion is not dictated merely by the negative factor that universities in this country will be faced in the post war period by unparalleled numbers of applicants for admission and will find it increasingly difficult to make room for undergraduate students from overseas, but by conviction that the development of Colonial universities has great positive advantages. We note that our West Indies Committee, as the result of evidence taken in that region, are strongly of the same opinion.

As we have already suggested in general terms, we believe that the development of a university is the educational concomitant of political, and, indeed, of economic advance. A university should become a focus for the intellectual self-expression of the people. By receiving their higher education together in their own country, Colonial students will be encouraged to direct their new knowledge and ideas to the understanding of the character and problems of the country in which they are working. Moreover, "they will be able to make a substantial contribution to the development of unity in regions where its attainment is made difficult by geographical, racial and cultural barriers.

In comparison with the positive gains to the Colonies which should come with the development of their own universities, the loss appears very small. We do not deny that many young students who happen to have been well fitted in intellect and character to make the best of higher education overseas have greatly profited from their courses, especially where they have been able to share in the life of residential colleges or halls of residence. But there has been another side to this picture, one of failure of adjustment to new conditions overseas, or of re-adjustment to old conditions upon return home.

A further advantage will be that a local university will give those responsible for filling posts a better opportunity to assess the capabilities and special characteristics of candidates than would be possible if they had been studying abroad. It will also be much easier to make a proper selection of students to pursue postgraduate studies overseas and to advise them as to the courses they should study.

\section{The pursuit of postgraduate studies overseas}

We hope, therefore, that undergraduate study for Colonial students in this country will, as their own collcges develop, be confined mainly to those few who wish to study exceptional subjects for which there is no local provision. We may quote here from the report of the Inter-departmental Committee on Medical Schools (I944)* which, after stating that it is preferable in most cases that Colonial students should qualify in their own country, goes on to say, "Future policy should be in the direction of . . . . making good provision in this country for suitable Colonial practitioners to obtain the postgraduate training and experience they desire ". Many of the doubts about the advantages of sending Colonial students to overseas universities will not apply to mature students seeking postgraduate education. It should be borne in mind that it is amongst them that staff may be found for the Colonial colleges. The experience of sending locally qualified doctors who have served for a period in government service to take a special diploma in this country suggests that

* Report of the Inter-Departmental Committee on Medical Schools issued by the Ministry of Health and Dept. of Health for Scotland. 
in some other studies also the postgraduate course can with advantage be deferred until the Colonial student has gained some experience after taking his degree.

We have emphasized, particularly in chapter IX, the desirability that degrees awarded as the result of study at Colonial universities should be of a standard which has the recognition of the home universities, so that a Colonial graduate may be qualified to take up postgraduate work in this country. The academic bodies of the home universities have necessarily been conservative in their recognition, particularly for the purpose of postgraduate study, of courses for degrees and diplomas substantially different from their own courses. It should be remembered that the university authorities in this country expect those entering for higher degrees involving research to have shown a high standard of ability; in some subjects, a first class or, at the least, a good second class honours degree is essential.

We conclude with the hope that wherever possible Colonial postgraduate students may be accommodated in colleges or halls of residence and given every opportunity to enter the corporate life of the university in order that they may derive the fullest benefit from their visit.

\section{CHAPTER XIII \\ FINANCE}

\section{Difficulty of preparing estimates of expenditure}

It is unfortunately not possible for us to give a reliable estimate of the cost likely to be involved in our proposals for the development of institutions of higher education in the Colonies. Exact estimates for each region would demand a local investigation, such as that which has been carried out in the West Indies by our West Indies Committee. Further, two of the regions with which we are concerned, Malaya and Hong Kong, are still in enemy hands. Nevertheless we believe that we can provide on the basis of the estimates prepared by the West Indies Committee, some indication of the range of expenditure which may have to be contemplated in particular directions.

\section{The finances of existing universities or university colleges}

The Royal University of Malta now provides courses for degrees in a number of Faculties with a wide range of subjects. Owing to a variety of factors such as the method of its evolution, the limited number of students except in medicine, and its lack of financial resources, the greater part of the teaching of the University has to be carried out by part-time teachers. Its total income is no more than some $£ \mathrm{I} 6,000$ of which rather more than $£$ II, 000 is provided in the annual estimates of the Government of Malta. Lack of resources has also prevented the modemisation and extension of its buildings.

The University of Hong Kong received $£_{2} 65,000$ from the Boxer Indemnity Fund and more recently a grant of $f 46,000$ from the Rockefeller Foundation for the establishment of chairs in its Medical School. The Hong Kong Government made considerable contributions to its endowment fund and provided it with an annual grant of about $£ 22,000$. The University has always suffered from lack of adequate buildings and equipment, and its financial position deteriorated rapidly in the years preceding the present war owing to the fall in revenue from investments in China.

The estimated expenditure of the Hebrew University of 'Jerusalem for I943-44 was $£ I 75,000$, part of which was met from interest on its endowment fund of $£ 500,000$. This fund, as well as the remainder of its recurrent expenditure and the cost of its extensive lands, buildings and equipment have 
been provided from contributions from Jewish organisations and individual donors; the University has hitherto received no financial assistance from the Government of Palestine. Its expenditure will increase substantially if the plans which it has recently put forward for further development are carried out.

The University of Ceylon does not possess endowment funds and derives the larger part of its income from a grant voted annually by the Ceylon Government. In I942-43 its total income was $£ 97,263$ the major items in this sum were the grant from that Government of $£ 73,909$ and income from tuition and examination fees which amounted to $f 22, I 64$. In I924, the Government of Ceylon established a building fund by a vote of $£ 225,000$. From this fund the cost of the new University site near Kandy and the initial stages of development of the site have been met. At the end of 1942 , the building fund stood at $£ 352,705$.

As regards institutions which have not yet attained university status, the Government of Uganda has provided Makerere College both with its site and with funds for capital expenditure, $f_{105}, 000$ has been expended in buildings and equipment. Income, which in I943 amounted to $£ 30,900$, is derived from three sources:-

(a) interest on invested funds which in 1943 amounted to $f \mathbf{1} 8,750$. (These funds consist of an endowment of $£ 500,000$, not available for capital expenditure, comprising $£ 100,000$ contributed by the United Kingdom," $£ 250,000$ by the Uganda Government, £I00,000 by the Tanganyika Government and $£ 5^{\circ}, 000$ by the Kenya Government; the balance of the original grant from the Uganda Government for capital expenditure $€ 65,000$, which has remained temporarily unexpended because of war conditions; and $£ 8,278$ provided by the Native Administrations for the building of a hall of residence for women students).

(b) an income of $£ 5 ; 460$ derived from a system under which the East African Governments reserve places at the College in proportion to their original contribution to the endowment fund, by annual contributions of $£ 30$ for each place.

(c) revenue from fees, $£ 6,690$.

It is difficult to present any comparable account of the finances of Gordon College, Khartoum, in view of the changes which are being made in the character of the institution. We understand, however, that the Sudan Government has in the current year made a grant in aid of $£ 73 ; 896$ to the College and the schools now being associated with it, and that the College received $£ 2,500$ from the Gordon College Executive Committee in this country.

The relevant figures regarding West Africa will be found in the report of the West Africa Commission. The Prince of Wales' College at Achimota has been financed by the Gold Coast Government. Capital expenditure has amounted to $f^{6} \mathrm{I} 7,000$. The Government makes an annual grant of $£ 54,000$; about one-sixth of this sum is spent on post secondary education. The income of Fourah Bay College in Sierra Leone in I942-43 was $£ 3,755$, derived from various sources. The expenditure of the Higher College, Yaba, Nigeria, for the year 1944 was estimated at $f I 7,444$. The provision for the Medical School at Yaba in $1943-44$ was $£ 12,855$.

For Malaya, we can do no more than record the position described in the report of the Commission on Higher Education in Malaya which visited that country in I938. The buildings of Raffles College, Singapore, cost $£_{192}$, I50, the expenditure was met from a fund of $£ 268,000$ subscribed by the Governments of the Straits Settlements $(£ I I 6,667)$ and of the Federated Malay States $(£ 23,333)$ and by private persons and commercial firms $(£ 128,333)$. The income of the College in 1937 was $£ 36,167$. It was made up of (a) annual 
grants from different Malayan Governments of $f 18,083 ;(b)$ income derived from investment of the balance of the capital fund mentioned above, and from other invested funds, and $(c)$ income from fees, $£ 8,167$.

The cost of the buildings of the Medical College, Singapore, cannot be stated, but could be taken as similar to that of the buildings of Raffies College. Its income was derived partly from the investment of endowments for specific purposes, such as the grant of $f$ I 4,000 from the King Edward VII Memorial Foundation for a Chair of Physiology, and the gift of $f_{40}, 833$ by the Rockefeller Foundation for Chairs of Bacteriology and Biochemistry. The main part of the income was provided from Government funds, since the Medical College was part of the Government Medical Department, and the staff consisted largely of medical officers carrying out part-time teaching duties. The total income was $£ 33,717$.

The two Singapore Colleges may thus be regarded as having possessed buildings which cost some $£ 380,000$ and a joint income of $£ 69,884$ together

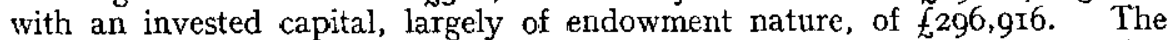
proposals made in the report on Higher Education in Malaya recommended the fusion of these two Colleges as the first step towards the creation of a University of Malaya. These proposals contemplated heavy capital expenditure and a substantial increase in recurrent expenditure for the provision of further buildings and increases in the numbers of the academic staff.

\section{Estimates of further expenditure}

The West Indies Committee has recommended that the University College shall comprise Faculties of arts (including education), science and medicine and has estimated that the capital expenditure for bouldings and equipment will be $£ \mathrm{r}, 130,000$ and the recurrent expenditure $£ \mathrm{I} 39,690$. These estimates should prove, for two reasons, a useful guide in calculations which may be made in respect of other regions. They represent the estimated cost of a college containing Faculties of arts, science and medicine only, Faculties which must be found in any university in the Colonies. Secondly, while capital expenditure for similar provision elsewhere may differ on account of variations in building costs, the recurrent expenditure is unlikely to do so, for the greater part of it is attributable to the salaries of the academic staff, and the cost of this is not likely to vary substantially in different areas.

It may at the same time be helpful to make a number of other observations regarding this estimate. In the first place the figure for capital expenditure does not include the cost of the site, which the West Indies Committee hope will be the gift of the Government of Jamaica, and while allowance has been made for the cost of a medical school, financial provision has not been made for a teaching hospital. Secondly, while the scheme contemplates the teaching of the basic sciences to students of agriculture, the instruction in agriculture will be given at the Imperial College of Tropical Agriculture at Trinidad, and its cost will not be a charge on the funds of the University. We note however that if the Imperial College undertakes the functions proposed for it in the report of the West Indies Committee, addilional funds will be required by it. Thirdly, no provision is made for the teaching of veterinary science and animal health, which may well be required in other regions ; the teaching of physiology, anatomy and pathology to such students could, however, be readily given by an extension of the work of a medical school without considerable increase in capital cost or recurrent expenditure. Lastly, we suggest in a later chapter that the economic development of many areas of the Colonial Empire may demand the provision at an early stage of schools of engineering, which must involve considerable expenditure on equipment. 
As regards West Africa, we may refer to the recommendations of the West Africa Commission.

We are unable to give any estimate of the ultimate requirements or Makerere College. We are informed however that the Council of the College nas in the last few months made application for a grant from the United Kingdom of a capital sum of $£^{167,500}$ to meet the cost of further academic buildings and residential facilities for staff and students; and for a sum ot $£ 85,000$ to meet the aggregate of new recurrent expenditure which will result up to the end of the College financial year in r95o, if the increases in the number of its academic staff which it considers desirabie are authorised. Comparison with the estimates made in the West Indies report suggest that this forecast of recurrent expenditure is of a moderate nature.

We understand that the University of Jerusalem has put forward a scheme of development which will involve tresh capital expenditure of about $£ 500,000$ and will require about $f I 50,000$ a year new recurrent expenditure.

We have not before us specific tigures as to the cost of the developments which are now contemplated in Malta, but we have reason to believe that the University will require substantial financial assistance.

We are unable to make any estimate of the needs of Malaya and Hong Kong.

We anticipate that demands for expenditure may anse as a result of proposals which may later be formulated for higher education in the Western Pacific, the East Mediterranean and Mauritius.

\section{Expenditure on scholarships for study in Great Britain}

There is another source of expenditure to which we direct attention. As an interim measure before local facilities for professional training up to degree standards are available, it will be desirable and in some subjects essentral that Colonial Governments should provide a certain number of scholarships tor students to come to Great Britain for undergraduate study. Further we have suggested that there should be a substantial increasc in the number of scholarships available for postgraduate study by Colonial students in Great Britain. The scale of scholarships now provided for students to come to this country varies widely, from $£ \mathrm{I} 75$ to $£ 500$ a year with free passages and an allowance for medical expenses. The cost varies according to the course taken but on the average a sum of $£ 350$ to $£ 400$ a year may be required. The provision to be made for the total number of students sent annually from all the Colonies will therefore amount to a considerable sum. The financial provision for overseas undergraduate scholarships will, we hope, largely disappear as the Colonial universitics develop, but scholarships tor posigraduate work will be a permanent charge.

\section{Expenditure by the Inter-University Council and the University of Londou}

There remains the recurrent expenditure which will result from our proposals regarding the Inter-University Council and the special part whicn the University of London will play in the conduct of examinations in the colleges of the Colonies. As suggested in chapter VII, the Inter-University Council will require a permanent secretariat with a secretary of appropriate standing and experience. Funds will be required to enable the Council to send out visitors to the Colonial institutions; and for the supplements tc salary which we have suggested in chapter $V$. The University of London will need reimbursement of expenses which will result from the conduct of examinations under the scheme described in chapter IX; and from time to time, it will wish to send its examiners to the Colonies. 


\section{The source from which finance should come}

In approaching this subject, it is of some interest to note the sources from which the universities and university colleges of Great Britain have derived their support. The following figures are taken from the returns from universities and university colleges in receipt of Treasury grants for the academic year I938-39 issued by the University Grants Committee*:-

\begin{tabular}{|c|c|c|c|c|c|c|}
\hline $\begin{array}{c}\text { Total } \\
\text { Income }\end{array}$ & $\begin{array}{l}\text { Endow- } \\
\text { ments }\end{array}$ & Donations & $\begin{array}{c}\text { Local } \\
\text { Author- } \\
\text { ities }\end{array}$ & $\begin{array}{c}\text { Parlia- } \\
\text { mentary } \\
\text { Grant }\end{array}$ & Fees $\dagger$ & $\begin{array}{l}\text { Other } \\
\text { Services }\end{array}$ \\
\hline$, 712,067$ & $\begin{array}{c}\text { per cent. } \\
\text { I5.4 }\end{array}$ & $\begin{array}{c}\text { per cent. } \\
2.6\end{array}$ & $\begin{array}{c}\text { per cent. } \\
9.0\end{array}$ & $\begin{array}{c}\text { per cent. } \\
35.8\end{array}$ & $\begin{array}{c}\text { per cent. } \\
29.8\end{array}$ & $7 \cdot 4$ \\
\hline
\end{tabular}

These figures illustrate the very considerable percentage of the income which is derived from public funds and the relatively small percentage derived from endowments. We may observe too that a considerable proportion of the fees included in the above schedule represents the results of grants to scholarship holders and other students from the State or by local authorities.

It has not perhaps been generally appreciated how largely the home universities idepend on Government or local authority funds for their income. In the Colonies it is clear that at the present stage of development the greater part of the recurrent expenditure of university institutions can be met only by direct grants from Colonial Governments or from United Kingdom funds. This statement applies with equal force to capital expenditure. The buildings and much of the equipment of the universities of Great Britain have come into being as a result of large benefactions made over long periods of time by public spirited individuals and private bodies; they do not owe their existence in any considerable measure to funds provided by the State. On the other hand, while we recognize that private benefactors have already helped to promote the development of university institutions in some parts of the Colonial Empire, such as Palestine, Hong Kong and Malaya, it seems to us inevitable that capital expenditure, particularly in the less prosperous regions, must largely come from Government funds.

It is not for us to attempt to assess what proportion of the required funds should be contributed by the Governments of the different Colonies or by His Majesty's Government. We are, however, convinced that the policy which we recommend can only be carried out if very substantial financial assistance is made available from Great Britain. We note, for instance, that our West Indies Committee recommends that the whole of the capital expenditure involved in its proposals, $£_{1}, 130,000$, should come from United Kingdom funds, although it hopes that the recurrent expenditure of $f 139,690$ in so far as it is not met by fees or other sources of income, will be met by votes from the different West Indies Governments.

\section{Creation of a special body to advise on allocation of funds}

In view of our conviction that the development of higher education in the Colonies must depend on the grant of substantial financial aid from Great Britain, we have considered the question of the nature of the body which should advise on the allocation of such funds. As already stated in chapter VII, we do not advise that the Inter-University Council should act in this capacity, and we recommend the creation of a new committee, which would act as an advisory committee to the Secretary of State, and which would be known as the Colonial University Grants Advisory Committee.

- Returns from Universities and University Colleges in receipt of Treasury grants for academic year 1938-39, Stationery Office Publication (70-152-0-39).

$\uparrow$ It is understood that these comprised tuition, examination, graduation, matriculation and registration fees, and included the Board of Education grant for teachers in training. 
The considerations which prevailed with us when discussing in chapter VII the position of the Inter-University Council in this relation would, we consider, apply also to the case of a committee largely composed of members of the Council, even though reinforced by additional members with special experience of finance and Colonial administration. On the other hand, it is clear that no financial body could adequately advise on the allocation of grants from United Kingdom funds, unless it had at its disposal expert opinion as to the merits of the proposals for academic development on which the application for those grants were based. This expert opinion will be at hand in the Inter-University Council.

As regards the composition of the Colonial University Grants Advisory Committee, we should hope that it would include a representative of the Committee of the Vice-Chancellors of the home universities; the Chairman of the University Grants Committee and one other person chosen for his wide knowledge of home university matters; two members with special knowledge of the Colonies, the one with administrative experience, the other with personal experience of higher education in the Colonies; two representatives of the Inter-University Council, together with the Adviser on Education to the Secretary of State. The Inter-University Council and the Grants Advisory Committee might with advantage be served by one secretary. In considering applications for grants the Committee would normally seek the advice of the Inter-University Council; it would also seek the assistance of any other persons who had special knowledge of the problems which came before it.

We hope that the Inter-University Council and the Colonial University Grants Advisory Committee will be created at the earliest possible moment, as schemes involving substantial financial help from the United Kingdom are already coming forward and others will doubtless follow in quick succession. We may perhaps add that in our recommendation for the institution of a Grants Committee we have been largely influenced by recognition of the part played in Great Britain by the University Grants Committee in the development of the home universities. In our opinion, it would be unwise not to profit by the experience which has been gained from its working.

\section{The provision of a separate fund for higher education in the Colonies}

Since the development of higher education must entail the provision of substantial financial help from Great Britain over a considerable period, we suggest that it may be justifiable to set aside for this purpose an appropriate part of the funds to be made available under the Colonial Development and Welfare Act. The number of schernes of different types for which grants are sought under that Act will inevitably increase, and the position is likely to arise when these schemes are in competition for the available funds. If a special provision is assigned to university development, the expenditure to be met from it should include both recurrent grants and capital sums.

\section{The need for continuity in university finance}

This brings us to comment on two general aspects of university finance. It will be agreed in the first place that the orderly conduct of any university institution is dependent upon the stability of its income. This stability has been largely assured in Great Britain by the system under which each university receives, on the advice of the University Grants Committee, an annual Treasury grant which is fixed for five years and which is reviewed at the end of that period in the light of the amount of the funds then made available to the University Grants Comnittee.

The provision of an assured income which is not subject to reduction even in times of emergency is one of particular importance in the Colonies. In times of economic depression the financial position of a Colony deteriorates 
more rapidly than does that of a highly industrialised country, and it is perhaps natural that at such times education should appear to offer a ready field for temporary economy. We fcel it desirable therefore to emphasizc that a decision to reduce the grants to university institutions at such times is to be deplored.

Our observations on this general aspect of university finance bear on the question as to the form which grants from United Kingdom funds to university institutions in the Colonies should take. Any recurrent grant must be made with the realisation that it must continue until such time as the sum involved can be borne from the revenues of the Colony or Colonies concerned. Until the Colonies concerned reach the stage of full economic development, grants of this nature may remain a charge on United Kingdom funds and further may need to be increased from time to time as the institutions grow.

In our opinion, it is desirable that endowments should be built up by the Colonial colleges as soon as possible. Endowment for specific purposes is particularly valuable to a university. It enables it to develop special activities and to foster interests which may have no immediate wide appeal. It acts as an insurance against the retrenchment of such activities at a period of stress. We should hope that as time goes on the Colonial institutions will be the recipients of private benefactions for these purposes. But we realise that to provide these institutions at the outset with adequate endowment funds would involve a large addition to the initial provision required for their establishment. It is for others to decide whether sufficient grants could be made with this object. We confine ourselves to suggesting that the total income of each institution, whether drawn from local or United Kingdom sources, should be such that a sum of perhaps $f$ I0,000 a year should be allocated specifically for endowment purposes, thus providing the necessary basis of an endowment fund. In this way, the desirable objective of gradually building up an endowment fund would be achieved.

\section{Io. The case for expenditure}

We are fully aware that the rccommendations which we are making contemplate the expenditure of very substantial sums both from United Kingtom and from Colonial funds. University education is necessarily expensive, it involves large initial capital grants for buildings and equipment and requires a considerable recurrent grant for upkeep, for the payment of salaries and for the provision of scholarships. Our proposals, indeed, are not lavish; they presuppose, on the contrary, the same kind of prudent and watchful economy that is practised in university institutions in this cointry. We are aware that questions may arise in some minds as to whether we are justified in recommending the creation of universitics in the Wcst Indies, in East and West Africa, when this recommendation of necessity involves the grant of large capital sums from the Exchequer. Even the figures for annual expenditure may scem high. The average cost of educating each student in the Colonial universities will be, indeed, little more than half the average cost of sending a student from one of these distant territories to a university in Great Britain. but it will be, at the same time, substantially higher than the cost of the education of an English student in most English universities. There are several reasons for this. The university unit in the Colonies will, at least in the early stages, be small. The universities will be residential; we state in an earlier chapter our reasons why this should be so. They will contain a high proportion of students working in the relatively more expensive subjects, such as medicine, for the study of which expensive equipment is essential. The universities must, moreover, in the nature of their situation, be self sufficing from the standpoint of libraries and equipment to a greater extent 
than would be necessary here, for both staff and students will be compelled to rely wholly on the provision made for them in the university itself. Again those of our recommendations which are directed to the breaking down of intellectyal isolation contemplate special expenses which add to the total cost.

All these things we freely admit. But we do so without any sense that our attitude needs excuse. The university education which we seek to provide for the Colonial citizens of the Empire must be fitted for the purpose for which it is designed. Its aim is to give to these Colonial citizens an opportunity for self-development which will enable them to fit themselves for the management of their own concerns; to train themselves for their future responsibilities by gaining the expert knowledge necessary for the service of their own communities; and finally to take their place among those who are contributing to the intellectual life and scientific progress of man.

\section{PART II}

\section{SPECIAL PROBLEMS INVOLVED IN THE PROVISION OF PROFES- SIONAL AND VOCATIONAL COURSES IN THE UNIVERSITIES AND UNIVERSITY COLLEGES}

\section{CHAPTER XIV \\ MEDICINE}

\section{The expansion of the Health Services in the Colonies}

In considering the special needs of the Colonies in respect of the provision of facilities for professional and vocational instruction, it is not unnatural that we should give priority to education in medicine. The standard of health of a people goes far to determine its ability not only to make the fullest use of its available resources, but to create new resources. More than one factor makes for improvement in the health of a community-better nutrition, progress in sanitation, the influence of the spread of education on antisocial custom and unhygienic habits. But clearly one of the most important factors, especially in Colonial conditions, is the adequate provision of men qualified for employment in the field of curative and preventive medicine and in medical research.

In the Colonies, the deficiency in this respect is so generally recognized as to need no comment from us. In Great Britain, we note that the ratio of doctors to inhabitants is approaching one to $x, 000$, and the number of doctors is likely to be increased as a result of the programme of social reform on which the country is now engaged. We cannot hope to see a similar standard attained in the Colonies, but some of the figures of the provision made there are of interest. In Malaya the ratio was one doctor to every ro,000 people: At the other extreme is Nigeria, where the ratio is one doctor for every 100,000 , and in certain districts one doctor for an area containing $1,000,000$ people. It is enough to say that there is, in the great majority of Colonies, an urgent need for the expansion of the existing medical staff, and of the ancillary health services for whose training and supervision the medical staff must be responsible.

\section{The creation of medical schools in the Colonies}

There is a general agreement that the need for expansion of the medical and health services of the Colonies can be met only by the provision of centres of medical education with material facilities and standards of teaching comparable ultimately with those available in the medical schools of Great 
Britain. In the first place, there is the outstanding consideration that the medical schools of Great Britain are able to accept for training only an insignificant proportion of the Colonial students whom it will be desirable to train. Even before the war there was difficulty in the way of the admission of all approved prospective students of British origin and this difficulty will clearly be greatly increased in the immediate post-war years. We accept in full the considerable body of evidence which we have received in this regard, and recognise that, in spite of their sympathetic attitude to the requirements of the Colonies, the medical schools of Great Britain will be unable for some years to contribute appreciably to the solution of the problem of providing undergraduate medical training for students from the Colonies. Provided that facilities of adequate standard are made available in Colonial medical schools, and if, as we suggest below, particular emphasis is laid on clinical training in diseases peculiar to the tropics, doctors trained in these schools should actually have a better equipment for their future work than if they were trained in Great Britain. Even the acquisition of a postgraduate diploma such as the D.T.M. and H. acquired in Great Britain, following an initial medical qualification obtained in home medical schools, cannot in our opinion confer on the holder that background of knowledge which clinical training and experience under tropical conditions can supply. It is to be expected that Colonial medical schools, associated as they will be with universities and medical colleges in this country, will in time establish their own traditions of professional conduct.

\section{Recognition by the General Medical Council}

The present provisions for medical education in the Colonies may be classified in accordance with the qualifications available, into three groups :-

(a) The Universities of Malta, Hong Kong and Ceylon, the medical degrees of which are recognised by the General Medical Council.

(b) King Edward VII Medical College, Singapore, which was not as yet part of a university conferring its own degrees, but awarded a local medical diploma neceiving recognition by the General Medical Council.

(c) Medical schools in which education has not yet reached the standards necessary to obtain recognition by the General Medical Council and the diplomas of which entitle to local practice only. Of such are the Medical School of Makerere College, Uganda, the Yaba Medical College in Nigeria and the Kitchener School of Medicine, Khartoum. There is also the Native Medical Practitioners' School in Fiji, which is, for a number of reasons, in a special class and is not included in our subsequent recommendations.

We consider it important that steps should be taken at the earliest possible date so to improve the quality of the teaching provided in medical schools which have not yet received recognition by the General Medical Council that such recognition shall be accorded. Recognition by the Council is important from several points of view. There is everywhere evidence of the desire of the Colonial peoples to demonstrate their capacity to reach the same standards of academic performance as those achieved by the European. This desire is shown nowhere more keenly than in medicine. The desire that a local diploma should receive recognition from the Medical Council has its roots more decply in the opportunity for demonstrating intellectual equality than in the privileges of practice which registration confers. The progress of medical education is retarded in those areas where the schools have yet to receive recognition. In its absence pressure is brought to bear on Colonial Governments to provide scholarships to medical schools in the United Kingdom. Not only is the prestige of the local diploma thus lowered, but the best students, whose presence would contribute greatly to the general elevation of standards 
are not retained where their presence is most needed. Moreover, recognition by the Council is important in that the diploma thereby becomes acceptable to the universities and medical schools of Great Britain for the purpose of direct entry into postgraduate courses without the necessity of further undergraduate study. Again, the more able students who owing to the absence of Council recognition would tend to seek their training in Great Britain, may be driven by the growing pressure on accommodation in the home schools to resort to other countries. Difficulties then might arise in connection with the question of the local registration of foreign degrees. Finally, the difficulties of admission of Colonial students to medical schools in the United Kingdom might mistakenly be attributed to discrimination.

In passing, we wish to pay tribute to the service rendered to medical education in the Colonies by the General Medical Council, which through its visitors has done much to foster development of the right kind. The task of these visitors is to assure themselves that the required standards have been achieved, and the constructive suggestions which they have offered have proved of the greatest value. We accordingly hope that the Council will feel able to continue to send its visitors to inspect the medical schools of the Colonies. In the past the Council has doubtless been faced with difficult decisions in respect of the conferring of recognition; but if the proposals made in this report are carried into effect these difficulties should be appreciably diminished.

\section{Studies in medical schools in the Colonies}

The recent reports of the Inter-Departmental Committee on Medical Schools (I944) and the Planning Committee on Medical Education of the Royal College of Physicians (I944) stress the need for certain changes in emphasis in undergraduate teaching. In concurrence with these recommendations we suggest that greater prominence should be given in the pre-clinical period to the study of the co-ordination of function in the human and animal body and to nutritional physiology. Early instruction in some of the vocational applications of anatomical and physiological knowledge is also desirable and should increase the interest of these subjects without detracting from their value as scientific disciplines. We also suggest that in the clinical period social and preventive medicine should receive increasing emphasis. If the need for such changes in medical education is becoming apparent in Great Britain, an even greater noed exists in countries in which tropical and nutritional diseases are rife and the standards of general education, hygiene and sanitation are at present low. To perpetuate in these conditions a system of medical training in which, as we see it, too great a stress is already laid on the pathological and technological aspects of medicine at the expense of a sound clinical discipline and socio-medical teaching would be unfortunate.

The views which we have expressed may give the impression that we feel that a special curriculum should be adopted for Colonial medical colleges. Such a departure, which would doubitless present great difficulties to the General Medical Council, is not in our minds, for we believe that what we consider desirable can be accomplished by me-arrangements in the teaching without alterations in the curriculum. The changes proposed need not be such as to raise doubts as to the suitability of the training as a qualification for that right to practice in Great Britain which recognition by the General Medical Council confers.

The opinion is sometimes held that, for teaching purposes in Colonial hospitals, there is an insufficiency of those types of disease which are prevalent in England. This question is, however, related in part to the existing 
lack of hospital accommodation. At present there is an unavoidable preponderance of acute cases in the wards of hospitals in the tropics, with the result that the chronic cases, which are also necessary for teaching, are excluded. If large hospitals specially adapted for teaching purposes are created, as we recommend elsewhere, the clinical teaching material available in Colonial medical schools should become both varied and plentiful. A main emphasis should however be maintained on those diseases which are locally predominant.

We recognise the multiplicity of problems presented by conditions obtaining in the several Colonial regions and we consider that elasticity should be allowed in arranging particular teaching and the forms of final examinations for diplomas or degrees. A too "British" emphasis in pathological or clinical teaching would be inappropriate in a Colony where tropical, nutritional and florid venereal diseases loom much more largely, and gastric ulcer and the psycho-neuroses of city life are less in evidence. On the other hand diseases consequent upon the impact of European civilisation and industry on less advanced peoples may come to provide a fruitful field of study and furnish the indications for enlightened preventive action. Increased emphasis on the social and preventive aspects of medicine need not, in our vicw, imply any neglect of basic pathological and clinical studies, which can in fact be rendered more valuable and realistic in the broader setting.

\section{Staffing and institutional facilities}

Medical education in the Colonies will make substantial progress only if at each centre there are up-to-date laboratory facilities for the pre-clinical subjects and a hospital specially designed or carefully adapted to meet the needs of a teaching hospital. The staffs both of the medical school and of its teaching hospital must be adequate in numbers and quality. Facilities and time for research must also be at their disposal.

As regards staffing, the practice adopted hitherto has been based on the general pattern of the medical schools in Great Britain, necessarily modified in the light of Colonial conditions. In Great Britain the pre-clinical subjects are taught by full-time members of staff; in the clinical subjects (except where whole-time clinical units have been established) the teachers are usually honorary members of the staff of the teaching hospitals. In the Colonies the teachers of the first year science subjects (biology, chemistry and physics) have, as a rule, been full-time teachers; often, though not invariably, the teachers of anatomy and physiology and its related subjects are also full-time teachers; the teachers of the clinical subjects are sometimes appointed on the model of the medical schools of Great Britain, but more usually they are officers of the Government Medical Service seconded to the schools for part-time teaching duties.

If the development of medical education in the Colonies to the standard which we have indicated is to be achieved, a change in this system will be necessary. A government medical officer is often at a disadvantage in carrying out part-time academic work; his real interests often lie elsewhere; he is called upon to undertake teaching under conditions requining a. type of cxperience which he may lack. In making these comments we do not underestimate the debt which Colonial medical education owes to the men and women who have contributed so much to its progress, usually under conditions of great difficulty. We believe, however, that the new sense of urgency in the field of medical education demands that a proportion of the clinical teachers should be full-time members of staff. It will be recalled that the report on Higher Education in Malaya recommended that there should be created in the Singapore School full-time chairs in the three clinical subjects, 
medicine, surgery and obstetrics with gynæcology, and a chair in preventive medicine and tropical hygiene. The Inter-Departmental Committee on Medical Schools (I944) has recommended that in the medical schools of Great Britain it is now desirable that there should be a proportion of fulltime clinical teachers, a recommendation which involves a fundamental change in a long tried and highly oherished system. The case for their introduction into the medical schools of the less developed regions of the Colonial Empire appears to us overwhelming.

We now record more precisely our views on the staffing of a Colonial medical school with an annual intake of 40-50 students. For the subjects which follow the first or pre-medical examination there should be senior posts in anatomy, physiology, pathology, medicine, surgery, obstetrics with gynæcology, and in tropical medicine and hygiene. The title of these posts would vary ,with the particular stage of development of the school; they might be professorships or lectureships, but for ease of description they may be referred to as professorships. A department of physiology should include a lecturer in pharmacology and should work in close consultation with a department of biochemistry. A department of pathology should include a lecturer in bacteriology. The professor of every subject mentioned should be assisted as soon as possible by at least one senior and one junior assistant. In the earlier stages the teaching of such subjects as anæsthetics, orthopædics, pædiatrics, mental diseases, forensic medicine and toxicology, would need to be given by such whole-time or part-time staff as were available. In many of these subjects, however, highly specialised teaching is better deferred until the postgraduate period, and in the undergraduate period the teaching might well be given by the senior full-time assistants in the clinical departments.

With a possible reservation in favour of strictly limited consultant practice (in which case a major proportion of the fees received might suitably be contributed to the research fund of the department) clinical chairs should be whole-time appointments. All other chairs and senior lectureships, including those in the subjects of pathology and bacteriology, and all junior and research posts which may be created, should in our opinion be whole-time without reservation.

In order to obtain staffs of adequate calibre the posts should be filled in the first instance by recruitment from home and Dominion universities. As soon as possible, appointments to the junior posts should be filled by graduates of the developing Colonial medical schools who have also carried out postgraduate training or research in Great Britain or the Dominions. Ultimately senior posts would be similarly filled.

The appointment of heads of departments' should be on a long-term basis. Appointments to junior posts should be for three years in the first instance, with adequate allowanoes in respect of special study leave. Ample provision should be made for leave and in the case of senior posts for sabbatical years. In the case of junior appointments the fullest use should be made of opportunities which may present themselves for exchange with home and Dominion universities. We recommend in particular the filling of these posts so far as practicable by the secondment system to which we have referred in chapter $V$.

\section{The provision of hospital facilities}

The provision of material facilities should not fall below standards which are considered appropriate elsewhere. Our West Indies Committee has recommended the creation of a new medical school in the West Indies; we understand that the West Africa Commission will recommend that the Medical School at Yaba should be replaced by a new school at Ibadan; a new medical 
school to replace the existing arrangements at Makerere College is also contemplated. A new hospital for teaching purposes will be required at Ibadan, while that adjacent to Makerere College ought to be replaced by a modern building. The provision of suitable hospital facilities for the new medical school in Jamaica will likewise call for early discussion.

The location of the medical school and hospital in each existing or proposed university centre will need to be considered in full discussion with representatives of all special interests in the region. But cven more important is the desirability that any new medical school or teaching hospital should be planned only after full consultation with expert opinion in Great Britain and elsewhere, and with careful provision in respect of future expansion. We attach the greatest importance to this recommendation. Each new medical school should be planned in regard to its future annual intake of students, and in our opinion that normal intake should not exceed 80 students a year. On the standards recommended by the Inter-Departmental Committee already mentioned in this chapter, a teaching hospital of about $I, 000$ beds would be required. The hospital must be designed with special attention to its use for teaching purposes.

We recognise that these recommendations will prove costly. None the less we feel that more modest proposals would not meet the urgency of the situation; nor would they prove less expensive in the long run. It is to be remembered that the medical schools which we have in contemplation are few in number and are to serve large areas and populations - the West Indies (3 million), East Africa ( 16 million), West Africa (26 million), Malaya ( 5 million) -and we believe that it is more fruitful to concentrate on the provision of a few first-class centres of medical education and research than to disperse effort and money in smaller centres serving more restricted areas. We recognise also that our recommendations for staff may seem excessive in those areas where the number of students coming forward for medicine is for some time likely to be limited. That position will however change with the extension in secondary education which is likely to occur in the post-war pcriod. The provision of at least two members of staff in addition to a professor for each of the principal subjects, is in our opinion justified from the start. The building up of a medical centre must be the result of a process of steady growth, and this is only feasible if there is a sufficiency of full-time members of staff who are devoting themselves to the problem.

But apart from this, the subject of medicine presents in the Colonies particularly fruitful opportunities for research. There are many research problems which can be pursued without elaborate provision of material facilities, provided time is available. Research material is at hand in the teaching hospitals, and in much of the work the teachers of the pre-clinical subjects can co-operate with the clinical teachers. If the time of the teachers in the first few years is not occupied with teaching to the extent which may occur in teaching centres elsewhere-although in this connection the principle that teaching must become more personal and tutorial is to be remembered-we belicve that this would be advantageous because it would enable the building up of traditions of research at the most crucial time in the development of a school. We recognise that in all stages teaching and its sound organisation must, nevertheless, be the first consideration and that applications for research funds must be judged in the light of this consideration.

\section{The provision of hospital assistants}

For many years to come, and this particularly applies to the African Colonies, there will be a need for large numbers of a grade of medical staff with training inferior to that of a qualified medical practitioner but more extensive than that of a nurse. Such staff might be known under the name of "medical 
aid " or hospital assistant. By the term "medical aid" we mean a person who has been given a full course of training as a nurse, a sound knowledge of elementary hygiene, sanitation and pharmacy, and instruction, particularly on the practical side, in the diagnosis and treatment of the commoner diseases of the country. He will have been taught to give intravenous and intramuscular injections and to carry out minor surgical operations under supervision. It is of importance that a clear distinction should be kept between the qualified medical practitioner and the medical aid. For this reason the latter should be trained in a school distinct from that used for medical students; his course of training should not approach the medical curriculum either in content or length; and he should be given no title which would imply claims for consideration as a qualified doctor.

\section{The transition to the stage at which the university grants a medical degree}

The first step to be taken is to raise the standards of teaching so that the local medical diploma obtains recognition by the General Medical Council. The final stage would be reached when the centre of which the medical school is part becomes a university awarding its own degrees. Between the first and final stages there will be a period in which we hope that the more able of the students would be afforded opportunities for taking the degree of a home or Dominion university; we would in particular support the proposal that arrangements should be made available for such students to become candidates for degrees of the University of London.

In this connection we are aware of the concession which has been made by the Royal Colleges under which students who have obtained the diploma of the Kitchener School of Medicine, Khartoum, are permitted to sit for the final Conjoint Board examination, provided they carry out a further year of clinical study in Great Britain. We appreciate the motive which lies behind this concession. We feel, however, that the immediate need is that students shall be able to obtain in their own Colony a diploma or degree acceptable in Great Britain, so that the best of them may later be selected for a period of postgraduate study in Great Britain or one of the Dominions.

Very considerable benefits have resulted from the annual visits to the Kitchener School of Medicine of eminent medical men, and we recommend that each of the medical schools should be visited annually under arrangements made by the Inter-University Council and that these visitors should assist the staff of the medical schools in the conduct of examinations.

The selection of students for admission to a medical school should be on a basis of promise and aptitude and not in respect of scholastic achievement alone. The schools should be open to students of both sexes and of all nationalities. They should be entirely residential, and in no case should students be allowed to live in lodgings. As the universities come into being it is also desirable that there should be no segregation of students of medicine from those of other subjects. An exception might be made during certain appointments in the clinical period when residence in or near the hospital carries special advantages.

If the medical courses in the schools are to be equivalent to those in Great Britain they must be of at least the same length. We are in favour of a postqualification but pre-registration year to be devoted to house appointments or other forms of supervised training.

\section{Postgraduate education}

While it is desirable that facilities for certain types of postgraduate work should ultimately be provided in the Colonial medical colleges, we recognise that in the earlier years suitable provision will not be possible. It is therefore 
necessary that scholarships should be made available to cnable carefully selected graduates to proceed to a home or Dominion school or research institute for periods of not less than two years and with a view, not so much to acquiring a higher degree or special diploma, but rather to obtaining experience in research or teaching methods. Such scholarships should for the most part be for the purpose of study in approved home or Dominion universities or research institutes but in special circumstances a foreign university should not be excluded. It would be an important function of the InterUniversity Council to supervise the proper placing of postgraduate students and to obtain for them such advantages and amenities as should be open to all full members of a university centre, including the holding of full time appointments in teaching hospitals and special clinical units.

\section{Io. The medical school as part of the university}

We are in full agreement with the view of the Inter-Departmental Committee on Medical Schools (I944), that medical schools should be integral parts of universities, and that full participation in the life of universities and close association with those following other branches of learning, will provide the greatest stimulus to teachers and will encourage medical students to develop those qualties of mind and character which go to the making of a good doctor. We would particularly emphasise the importance of drawing attention throughout the student period, both by direct precept and example, to the need for ethical observances and the maintenance of high standards of professional conduct. The Committee has pointed out that a university medical school presents the most favourable conditions for maintaining educational standards; for securing a consistent selection of students; for attracting teachers of the highest calibre; and for keeping alive their enthusiasm. It should also be borne in mind that the teaching of the preliminary sciences necessary for the study of medicine requires the services of a scientific staff not exclusively devoted to the interests of the medical student. Nor do we need to emphasise that advances in medicine depend increasingly on the application of chemical, physical and biological methods to research problems, and that without intimate collaboration between those who work in other fields of science the progress of medical research will incvitably be hampered.

\section{The Colonial Governments and the medical schools}

In the less developed territories the administration of medical schools has inevitably been largely the concern of the government medical departments. We fully recognise that the development of these schools can proceed only if there is the closest collaboration between their staffs and the medical departments. This is necessary both in hospital administration for the provision of clinical facilities and, as we have pointed out elsewhere, for the teaching of the special subjects by members of the Colonial Medical Service. Nevertheless these schools, destined as they must be, to become an integral part of a future university should as far as possible be free from Government control. Each medical school will, as a constituent part of a university or university college, have its Faculty or Board of Study which will be responsible to the Senate or Academic Board of the university or university college. The membership will be drawn from the full-time teachers, both preclinical and clinical, whose appointment we have recommended. It will include also a senior teacher in one of the preliminary scientific subjects together with a suitable proportion of the part-time clinical teachers who will at first be usually members of the Colonial Medical Service or locally qualified doctors who are members of the teaching staff. 


\section{The teaching of dentistry}

Whereas in medicine a start has already been made in the provision of medical schools, there are at present no facilities for the training of dentists in some of the less developed areas of the Colonial Empire, and facilities for dental treatment, whether in government hospitals or in private practice, are virtually non-existent. While we fully recognise the urgent need for the provision of dental treatment in large areas of the Colonial Empire, the health of the people as a whole will be best served if in the earlier years the students available should be trained as doctors and not encouraged to elect for specialisation in orodental disease. Further the building up of a medical school of high standard is, under Colonial conditions, a task of considerable difficulty, and it is in our opinion desirable that the medical schools should ibecome firmly established before dental schools are created. Once medical schools are established, the provision of professional courses in dentistry, the first two or three years of which are largely common with medicine, will be accomplished with ease. The available students will in the meantime have increased in number.

Nevertheless a beginning should be made to provide opportunity for dental treatment in the hospitals of the larger towns. We suggest that scholarships available in this country might be awarded to a number of selected students each year so that on return to their Colonies, they may provide the nucleus of a future government dental service. The provision of hospital dental departments and later of dental schools, facilities for the training of dental mechanics and hygienists and the establishment of dental clinics would need to be considered simultaneously. Since we understand that the whole future of dental education and research in Great Birtain is now under review, it might be premature to make specific recommendations in regard to the type of dental education which should be available in the Colonies. We urge that the early co-operation of leading members of the dental profession should be sought in deciding the best policy to be adopted as each new Colonial medical school comes into being or existing schools become firmly established. This could be effected through the Inter-University Council.

\section{r3. General recommendations}

The above recommendations relating to medical education are to be considered as applicable in the main to the Colonial regions which are the subject of our more immediate concern. Special considerations will arise in the case of individual Colonies or groups of Colonies, and our West Indies Committee has given an indication of the importance of paying regard to local needs and interests and of viewing territorial and other requirements in their proper perspective. The relationship of existing medical research institutes to medical schools or colleges and projected universities will clearly call for careful consideration in certain Colonies; we have already suggested in chapter VI that, wherever geographical and other circumstances permit, the closest association is desirable.

We would hope that both the research activities and the diploma courses of the London and Liverpool Schools of Tropical Medicine may become more closely linked with the work of the Colonial medical schools and research institutions. The award of a British D.T.M. and H. might, for instance, become contingent eventually upon a final period of training in a Colonial centre. The interchange of ideas and personnel thus brought about would assist the advancement of tropical medicine and bring benefits to medical education alike in Great Britain and the Colonies. 


\section{CHAPTER XV}

\section{AGRICULTURE}

\section{The importance of agriculture as a subject of instruction.}

If instruction in medicine can provide one of the most practical contributions which the new university institutions can make to social progress in the Colonies, education in agriculture would seem to afford an opportunity for a contribution of great significance to progress in the economic field. Eighty out of every hundred of the world's two thousand million inhabitants are engaged. in primary production, and the proportion is possibly even higher in the Colonies. The overwhelming importance which attaches to adequate preparation for such an industry or mode of life needs no stressing.

In many of the Colonies, the cultivation of marketable crops has already superseded purely subsistence production; but there are at the same time large areas where a self-sufficing economy is still the prevailing feature in rural life. The improvement of traditional practices in subsistence production by the application of scientific methods is of the highest importance, for this is the most direct means of ensuring better nutrition and a more balanced diet for large numbers of people. Adam Smith's dictum that " subsistence is in the nature of things prior to luxury " remains fundamentally unassailable. As populations are increasing in most Colonies, pressure on land steadily grows. To meet the demand for more and better food improved methods of peasant farming and especially modifications or avoidance of shifting cultivation will become essential. It is, however, mainly to the expansion of marketable production that we must look for an improvement in the general standards of living. That development is likely to gain impetus in the postwar years; and like the improvement of subsistence cultivation, it will call for the most careful guidance by experts of high technical and scientific ability and possessing full knowledge of local conditions.

It may assist in the consideration of this matter if we explain the extent of the existing provision of specialists engaged in the various problems connected with the development of agriculture, and the manner in which they are recruited. The Colonial Agricultural Service, members of which occupy the great majority of posts of higher responsibility in the agricultural departments of the Colonial Governments, comprised in I944 some 440 officers. Out of these, 28 held the post of Chemist or Soil Chemist, 27 the post of Entomologist, 43 the posts of Botanist or Plant Pathologist, and 3 that of Agricultural Economist; the remainder were designated as Agriculturists. These numbers do not include officers attached to the Imperial College of Tropical Agriculture, the tea, rubber and cocoanut research schemes in Ceylon or the Rubber Research Institute in Malaya. The Colonial agricultural departments were also served by a very large number of officers, mainly locally recruited and trained, who held posts of lower standing, ranging from that of Agricultural Assistant to that of Farm Supervisor or Crop Demonstrator.

As the figures given above will show, recruits for the Colonial Agricultural Service are of two types: $(a)$ the agricultural officer and $(b)$ the specialist officer. In regard to $(a)$, recruits destined to become agricultural officers may either have obtained a degree in agriculture or a degree in pure science. Those having a degree in agriculture are given one year's postgraduate training in Cambridge and one year's postgraduate training at the Imperial College of Tropical Agriculture in Trinidad. Those who have a degree in pure science also have a year's training at each of these centres, but their courses in the Cambridge year are naturally different. The object is to bring 
them both to the same level at the end of the two years" graduate training, the agricultural graduate having been strengthened on the scientific side and the science graduate having been taught to a competent level in agriculture and in the agricultural sciences. The scheme is flexible, and one of the postgraduate years may, in certain circumstances, be dispensed with or spent at a special centre.

Recruits for $(b)$, the posts of speciallst officer are, save exceptionally, not taken from among graduates in agriculture but only from those having a degree in pure science. They also spend one year in Cambridge followed by one year in Trinidad, the object of this year's postgraduate course being to give them a knowledge of agriculture suited to specialist work in some branch of agricultural science, and also to give them special knowledge of the agricultural science to which they will particularly devote themselves, with a more general knowledge of the agricultural sciences closely cognate to it. This scheme is also flexible, admitting of suitable variations.

At the present time, a diploma in agriculture (other than a postgraduate diploma), i.e., a qualification below degree level, is not ordinarily accepted for any branch of the Colonial Agricultural Service. We understand that the Colonial Advisory Council of Agriculture, Animal Health, and Forestry has recently submitted proposals for the raising of the qualifications required of recruits who are to become specialist officers. It lays special stress on the advantage of a term in a research institution concerned with research in their own special subject, in addition to formal postgraduate training. Proposals have also been made for important changes in the organisation of agricultural research in the Colonies, the most important of which contemplates the constitution of a separate cadre of research officers.

Apart from the officers employed in the government agricultural departments, there is a considerable number of trained agriculturists employed by private enterprises, such as the sugar, rubber and tea plantations, or the Empire Cotton Growing Corporation or (in the Sudan) the Sudan Plantations Syndicate. The Empire Cotton Growing Corporation has adopted a system similar to that of the Colonial Office, and insists on the same standards in its agricultural and specialist officers; the Rubber Research Institute in Malaya observed standards of the same nature in recruitment. In the majority of cases, the agriculturists employed by private enterprises connected with the production of cotton, tea, rubber, or cocoanuts, are specialists working in well equipped laboratories, and their work in investigation and research can in many cases compare with what is done in fields of a like character almost anywhere else in the world.

\section{Existing institutions for agricultural education in the Colonies}

The provision made for agricultural education in the Colonies was surveyed in a report issued by the Colonial Office in 1938*. In a number of the territories, instruction has been confined to practical training given by departmental officers at government farms and the like; others have provided agricultural schools in which a certain amount of theoretical instruction is combined with practical training. The courses at these schools usually run for two or three years, but in many cases it has been found that the development of the schools has been impeded by the fact that pupils come to them with as insufficient school training, particularly in science, to enable them to benefit by the theoretical instruction given. In only a few of the Colonies has provision been made for instruction at a higher level. Some account of the institutions offering such instruction may be of interest, as it has a bearing on the inclusion of education in agriculture among the activities of the universities or university colleges which we hope to see established.

\footnotetext{
* A Survey of Vocational Agricultural Education in the Colonial Empire; Colonial (44I67) No. 124 
In West Africa courses for the training of agricultural assistants are given at Samaru and Ibadan in Nigeria, at Achimota in the Gold Coast, and at Njala in Sierra Leone. A more advanced course leading to a diploma in agriculture is given at Ibadan. This course, which is attended by Nigerians only, takes the form of a two years' course in the 'basic sciences at Yaba Higher College, followed by two years training in agricultural subjects at Ibadan. In East Africa, Kenya and Tanganyika give instruction in agricultural schools with three years' courses, the pupils being normally of primary or middle school status, but it is intended that Makerere College shall constitute the centre for more advanced agricultural education in this region. For some time it has had a five years' course in agriculture, the first two years being devoted to prevocational studies (mathematics, English, chemistry, physics, botany and zoology), the third to a theoretical course in agriculture, and the last two years to practical training under Government agricultural officers at Bukalasa and Serere in Uganda.

In the Mediterranean region Palestine has made a notable development in agricultural education, largely as a means of meeting the demand created by the influx of Jewish immigrants who seek to make their living on the land but have no previous knowledge of rural life. The two Government and eight independent schools, which in 1936 had 896 pupils on their rolls, give a two or three years' course, but the circumstances are somewhat exceptional, in that a considerable number of the pupils have a higher background of education than is usual in many of the Colonies. There is a School of Agrin culture attached to the Hebrew University of Jersalem. The University of Malta does not include agriculture among its Faculties, but the Government of Malta proposes to give short vocational courses at its experimental and livestock farm.

In the East Ceylon has provided instruction at the School of Agriculture at Peradeniya; the course, which is given in English, is of two years, and pupils must have passed the Junior School or Cambridge Junior Local examination. The syllabus includes agriculture, horticulture, animal hus bandry, agricultural botany, chemistry and entomology, and agricultural mathematics and engineering; practical training is given at the Experimental station at Anuradhapura. The University of Ceylon contemplates taking over the School at Peradeniya, and proposes thereafter to set up a Board of agricultural studies. In Malaya provision was made at the School of Agriculture adjoining the Central Experimental Station at Serdang; the two year's course, given in English, embraced among other subjects estate sanitation and hygiene, book-keeping, agricultural economics and surveying. Agricultural Assistants and candidates for the Rubber Research Institute undergo a further training of about nine months duration. The School has accommodation for 80 students. Mauritius has a College of Agriculture at Réduit which is operated as part of the department of agriculture. Pupils must have passed the Senior Cambridge Local Examination or its equivalent; the three years' course leading to the diploma is mainly directed to meeting the needs of the sugar estates, and includes a course on the technology of sugar manufacture. Scholarships for further study in Europe are given periodically to selected diploma students.

The West Indies are distinguished by the possession of the Imperial College of Tropical Agriculture at Trinidad. Since I927 it has been the centre for the postgraduate courses in tropical agriculture given to cadets holding scholar. ships in the Colonial Agricultural Service, but we are concerned here rather with its function as a centre for the agricultural training of students from the Caribbean area. Its diploma course is of three years, and includes both theoretical and practical instruction. The number of diploma students has varied from I9 to 37 . Jamaica has a school at Hope Estate which is probably 
the oldest institution of the kind in the Colonies, having been founded in I9ro. Candidates must possess the equivalent of a Junior Cambridge certificate; the diploma course is three years, and among other subjects the syllabus includes farm mechanics, book-keeping and surveying.

\section{The functions of universities or university colleges in agricultural education}

There can be no question of the need for both an extension and an improvement of the scope of agricultural education in the Colonies. We understand that the Colonial Advisory Council of Agriculture, Animal Health and Forestry, considers that every Colony should have a well thought out programme of agricultural education designed both to improve the efficiency of existing farmers and fit the coming generation of farmers for their way of life. Our own problem, however, is to determine the part which universities or university colleges can play in this process. Agriculture stands in a somewhat different position from some other subjects of professional instruction. To the great majority of people in the Colonies it is a way of life to which they are committed by circumstances rather than a field which offers the prospect of a career, and for which the necessary qualification must be sought by professional study. By far the greater proportion of those engaged in agriculture are of the peasant type, and the methods which they practise are the result of a process of trial and error, not of scientific study. Agricultural education-using that term in its widest sense-has therefore two aspects. The first consists in introducing the cultivator to such improved methods as his resources, or the prevailing social factors in the nature of land tenure and the like, allow him to adopt; its success depends on the practical demonstration of its benefits, rather than on theoretical instruction in the principles of better farming. Education of this type is the function of the agricultural school, with its school farm, or of the employees of the agricultural departments engaged as demonstrators or instructors. If the university has a part to play in education of this type, it would mainly be by the inclusion of the subject in its extra-mural activities.

The second aspect of education in agriculture consists in the training of men who are qualified to apply the principles of modern scientific agriculture to the special circumstances prevailing in the Colonies, or to conduct research, both of the fundamental and "applied" type, into the problems which Colonial agriculture presents. The demand for men so trained will come chiefly from the state departments or from some of the more highly organised Native Authorities; but it may also be foreseen that there will be an increasing demand from private enterprises requiring managers or research workers, or from larger land-owners seeking expert assistance in developing their estates.

It is natural that we should now look increasingly to the Colonies as a source of supply of specialists of this class; apart from other obvious considerations, many of them will have the advantage of the familiarity with local conditions which is so essential to those engaged in persuading a native population of the value of new methods of cultivation. It is natural also that we should look to the universities or university colleges as a means of supplying this need. But there is here one difficulty. Unless the training provided is practical as well as theoretical, the degree given will not carry a value which will ensure ready employment to those who hold it. There can be no question that the university or university college can provide a suitable agency for giving the preliminary courses in natural science and such parts of the syllabus of agricultural instruction as can be treated theoretically, and as in the case of medicine, the student will have everything to gain from association with the general life of a residential institution of academic standing. But the organisation of an adequate Faculty of agriculture will also involve the 
possession by the institution of its own farm lands, with the staff and equipment necessary for practical instruction. Alternatively, it will be necessary that it should make such arrangements with a department of agriculture or a private organisation as will enable the student to complete his practical training under conditions recognised as justifying the grant of a degree. It is relevant to point out here that our West Indies Committee has suggested two avenues for the training of agriculturists at the university level: (a) a training in natural science in the proposed University of the West Indies followed by a diploma in agricultural science at a home university, or $(b)$ a training consisting of two years in natural sciences in Jamaica followed by two years at the Imperial College at Trinidad in a course which would be developed from the present diploma course. The Committee is opposed to the establishment of a Faculty of agriculture as part of the original foundation of the University. It suggests that at a subsequent date the Imperial College might be associated with a Faculty of agriculture in the University, if a degree in agriculture rather than a diploma is considered to be desirable.

While therefore we hope that the Colonial universities will take their share in the development of agricultural education, any scheme for the establishment by them of a Faculty of agriculture should in our opinion be judged in the light of the consideration we have just expressed. This consideration also adds force to a recent recommendation made by the Colonial Agricultural Advisory Council that state institutions for the study of agricultural problems, both on the research and on the experimenal side, should wherever possible be associated with local centres of higher education.

\section{The character of university courses}

In home universities there is considerable variety of practice in regard to the courses by which an agricultural student qualifies. In some cases, the student, after taking a science degree proceeds to the special course of studies prescribed for the diploma in agriculture. In other cases-and these seem to be the majority-students qualify through a different type of course, in which the science subjects and agricultural subjects are all studied concurrently. In Colonial conditions, there is, we consider, a certain disadvantage in the latter method, in view of the relative lack of grounding in science with which the student will normally come to the university. We should prefer to see the student take a two years' course in the necessary scicnce subjects physics, chemistry, geology, botany and zoology - followed by a three years' course for the agricultural degree, of which the first year would be devoted to studies of a more specialised character, such as crop husbandry, soil science, plant pathology and genetics, animal husbandry and agricultural engineering and economics, and the last two years to practical work based on the application of these studies. We attach particular importance to the study of agricultural economics during the third year. The association of the student in the science courses of the university, and his participation in its residential life, will have broadened his outlook. It is necessary also that he should be able to see the relation of agriculture to the secondary industries, and to other activities for the development of natural resources or the improvement of standards of living.

We have been interested to learn that Makerere College contemplates that all students " attempting higher studies " including that of agriculture, shall be required to take concurrently certain courses in the humanities. We have already made it clear that we are impressed by the undesirability of confining vocational training to an unduly narrow range of study, and should be glad to see agricultural courses so organised that they are part of a liberal education. 
But the question of the best way of attaining this is a general one, not restricted to the needs of the student in agriculture, and we must limit ourselves here to referring to the general observations we have already made on this subject in chapter IV.

As already explained, the Colonial Office has hitherto required the cadets in the Colonial Agricultural Service to take a postgraduate or associateship course at the Imperial College at Trinidad. We do not consider it to be within our terms of reference to discuss whether a similar course will be desirable if Colonial universities should develop Faculties of agriculture on the lines we have suggested. Whether candidates who have received their training at one of the Colonial universities should also take a postgraduate course at Trinidad must, we suggest, depend on the character of the degree courses given at these institutions and the extent to which they can develop on the side of research. The facts which we have given in an earlier section of this chapter regarding the composition of the existing government services show the importance attached to the employment of officers with "specialist " training, and it is obvious that they can only obtain that training in well developed centres of research. The opportunities for investigation in the physical, biological, economic, and social fields of primary production are nowhere more numerous and nowhere likely to be productive of greater results than in the Colonies. We ourselves hope that time will see the growth of centres of research in the Colonial universities themselves or in close association with them; but we realise that, at the best, some time must elapse before they can attain a standing comparable with that of the more advanced centres of research in the United Kingdom or the Dominions. When, however, this stage has been reached, we should hope that the course of training given at a Colonial university would qualify the student for admission to the Colonial Agriculture Service.

\section{CHAPTER XVI}

\section{VETERINARY TRAINING}

\section{The scope for veterinary services}

Education in veterinary science embraces not only the preventive and curative treatment of animal disease, but the range of studies which find their application in animal husbandry. It is unnecessary to dilate on the essential part which the veterinarian everywhere plays in agricultural economy. But many of the Colonies present conditions which give unusual importance to his services. The introduction of systems of mixed farming upon the greatest possible scale in now an accepted policy, and the use of stock which this involves is an important factor in maintaining and increasing soil fertility. The improvement of the stock and their produce, and their freedom from disease, are all vital to the economic and social advancement of the agricultural peoples. There are, however, very large areas in which stock must continue upon a ranching system and here far reaching improvements are essential. Mal-distribution of stock in the past, because of the disinclination of owners to remove with their herds from established settlements, or the withholding of potential grazing from lack of water, the presence of tsetse fly or other causes, has been a contributory to soil erosion. Better distribution, extended watering facilities and improved pastures, will open out the way for that improvement of stock which will make smaller numbers of more economic value than the larger and heavier herds of to-day.

The contribution which the veterinarian can make is therefore far reaching; but his success depends on the possession of certain personal qualifications

$(44,67)$ 
The treatment of disease demands a full measure of scientific training, including the preparation and use on a large scale of serological products; but experience has shown also the special value of acquaintance with local social custom when dealing with questions affecting domestic animals and the use of animal products. There is in consequence an unusually strong case for obtaining a considerable part of the veterinary service by recruitment from local sources.

\section{Existing facilities for veterinary training in the Colonies}

\section{(a) Departmental training}

For years training has been given in practical work in those territories, more particularly in Africa, where large scale preventive inoculations have been carried out. Africans have been taught to organise camps, bring in stock and carry out inoculations under the supervision of European officers. The instructional work connected with the proper flaying and drying of hides and skins has been carried out by assistants locally born and trained. Similarly, the work in the small dairies, which have been erected in districts and in dairies which serve as depots, has been carried out under the immediate control of Africans. Some 15 to 20 years ago, classes were commenced either at the headquarters of the department in each territory or at the laboratories, at which selected Africans were given courses. There are now in the majority of the territories schools at which courses extending to three years are given.

The system in Malaya was somewhat similar to that in Africa; in other Colonies, such as the West Indies and Palestine where general education has reached a high level, technical non-professional workers in the veterinary departments have proved of great value.

\section{(b) Schools}

About I5 years ago a school for the education of African Assistant Veterinary Officers was opened at Makerere College. The course is of five years, the first three years being common with the medical course; the course is then continued at Entebbe near which is one of the government stock farms. It has recently been decided that students should go to Kabete, in Kenya, for the final stages of the course, but they will remain students of Makerere and will return there to obtain their qualifications.

Three years ago a similar school was opened in Nigeria to serve the whole of the West Coast of Africa. The course, designed for the training of Assistant Veterinary Officers, comprises two years' education in the basic sciences at Yaba Higher College, followed by five years training in the Veterinary School at Vom, which is the headquarters of the Nigerian department of animal health. The Veterinary Research laboratory, the substantial new buildings of the School, and the extensive experimental farm provide first class opportunities for both theoretical and practical instruction.

Animal husbandry is included in the syllabus of the School of Agriculture at Peradeniya, Ceylon. Some veterinary training is given at the College of Agriculture, Mauritius, which is operated as part of the agricultural department.

\section{The part to be played by universities in veterinary education}

Veterinary education in Great Britain has been the subject of recent enquiry by the Committee on Veterinary Education appointed by the Secretary of State for Scotland and the Minister of Agriculture and Fisheries.* In a 6517.

- Cotmmittee on Veterizary Education in Great Britain (February, 1944) Cmd. I944. 
review of the existing facilities for veterinary education the Committee has pointed out that, with one exception, the veterinary schools in Great Britain are largely detached institutions providing complete courses of study and that their connection with universities is, in general, slight. It concludes that veterinary medicine will be able to play the important part which its place in the national economy demands only if veterinary education becomes the concern of the universities. It also expresses the view that veterinary teaching has been concerned far too much with animal sickness; and that it has lacked the necessary emphasis on animal health; the teaching has been too theoretical, and facilities for proper clinical instruction have not been available. The Committee therefore recommends that each school should be provided with a field station for the purposes of clinical teaching; that there should be substantial revision of the curriculum, not only in the pre-clinical subjects but particularly in animal husbandry and in clinical teaching.

The fact that veterinary education is in the early stages of development in the Colonies provides an opportunity for putting into practice the newer conceptions of its scope and the methods to be employed in teaching. We are agreed that higher education in veterinary science should as far as possible develop as an integral part of the activities of the future universities of the Colonies, rather than that it should be taught in separate institutions. Its teaching should be carried out on a general pattern similar to that given in medicine.

\section{The curriculum in veterinary medicine}

We agree with the Committee that the first three years should be devoted to the basic subjects on which the more professional teaching is founded. The Committee suggests that after the first year's study of the preliminary sciences, chemistry, physics and biology, the second and third years should be devoted to anatomy, histology and embryology, physiology and biochemistry, pathology, bacteriology, immunology and parasitology. Save for anatomy, much of the fundamental teaching in these subjects is common to medicine, and the veterinary student should take the same courses as the medical student; more applied courses for veterinary students can then follow on this fundamental teaching. It is clearly desirable that the student should make early contact with field work, and we suggest that he should spend two or three months of both the second and third years at the field station.

\section{Field stations}

Much of what we have said in chapter XIV regarding the facilities required for clinical teaching in medicine applies equally to veterinary medicine. Ideally each university or college providing instruction in veterinary science should thus possess its own field station from the start, situated near the university college at whith the teaching of the pre-clinical subjects will be carried out. Only in this way will the veterinary student be able to share throughout his course the life of the student community as a whole; and only thus will his teachers be in daily contact with those working in allied subjects a matter of great importance since problems of research will increasingly demand the collaboration of workers in these and other fields.

But we recognise that this ideal cannot always be achieved immediately. In West Africa, for instance, environmental conditions make it inevitable that the field station should be situated in the northern areas far removed from any suitable location for a university college. As we have indicated in East Africa, it is proposed to give the clinical teaching of the students of Makerere College at the government station at Kabete in Kenya. Here we feel that even if such an arrangement is desirable in the immediate future, plans should be made for Makerere College to possess its own field station; 
students from that station would doubtless profit from visits to Kabete during vacation. While separation of the veterinary students during their cinical years from the general body of the students is thus inevitable in East and West Africa at the present time, we hope that means will be found to overcome the disabilities presented by this position.

\section{Staffing}

For the reasons we have given in discussing medical education, we recommend that there should be two full-time members of staff in each of the subjects of veterinary anatomy, veterinary medicine, animal husbandry and the pathology group. These posts should be created even if, as at Kabete, the clinical instruction is for the time being given at a government station; their holders would thus be members of the staff of the College and their appointment, apart from other advantages, would pave the way for the later creation of the field station of the College itself. As in medicine, the co-operation of officers of the government dopartments will be essential not only for the imparting of specialised instruction, but also for collaboration on problems of research.

On the general question of the curriculum, we hope that the teaching in the different subjects will be given in the sequence recommended by the Committee on Veterinary Education already mentioned. Nevertheless it is clear that in tropical conditions particular aspects of subjects will demand special courses or fuller treatment than is required in Great Britain. As in the case of medicine, the desired modifications can be introduced without so altering the curriculum that it becomes too specialised for acceptance in Great Britain. This is important, since the aim of the veterinary schools should be, in the first place, to give courses leading to a diploma recognised for the purposes of post-graduate study at home and in the Dominions. Later the Colonial universities will doubtless award degrees in veterinary science.

The length of the present M.R.C.V.S. course is four years from the completion of the preliminary science examination, and this is the period also recommended by the Committee referred to. The course given in the Colonial veterinary schools should be at least of this duration, and may need to be somewhat longer.

\section{CHAPTER XVII}

\section{LAW}

\section{The need for qualified legal practitioners in the Colonies}

We use the term " legal education" as denoting the machinery which provides the necessary educational qualifications for practising the law in the Colonies. Some of those so qualified may practise as advocates in the Courts, others as solicitors, or as both; they will provide the local source from which the magisterial and judicial establishments and the legal departments of the Governments must be recruited; and they may fill other posts, such as those connected with the registration of deeds or land titles for which a knowledge of the law is required.

It is clear that in many of the Colonies there will be an increasing need for persons so qualified, as the result of developments which can now be foreseen. With improving standards of life the more simple methods of administering justice through tribal courts or the like will call for change, in some cases by the introduction of presiding officers trained in the law, in others by the substitution of a qualified magistracy. The range of matters in which the public will require legal advice will be enlarged by the emergence of new 
issues in commercial law or by the application of social legislation; land issues will become of increasing importance and complexity as land acquires a transferable value; industrialisation will create its own series of judicial problems. In the field of law and justice, as in other fields which we have surveyed, development will depend largely on the possibility of obtaining from local sources the requisite supply of persons with adequate training and qualifications.

It is relevant here to add a brief comment on the content of the law in which qualifications must be acquired, since this has a bearing on the recommendations we have subsequently to make. The diversity of conditions in the Colonies is reflected in a considerable variety of systems of law. While the concepts and practice of English law have largely determined the formation of Colonial law, the statute law is, with rare exceptions, that formulated in the ordinances of different Colonies, not the statute law of Great Britain. Criminal law and the law regulating judicial procedure have in most cases been embodied in codes, and there is not in this case any marked diversity between the law of different Colonies, nor does its acquisition present any difficulty to those who have been grounded in the principles and practice of English law. But there is a wide variety in those fields of civil law, such as that relating to succession, matrimony, testament or land tenure, which reflect local custom, the legal prescriptions of the Hindu, Muslim, or other religions, or the particular European legal systems such as RomanDutch or French law, which have from time to time been "received" in particular Colonies.

There is in Africa and some parts of the East an added complication due to the existence of a system of Native Tribunals, the jurisdiction of which is recognised by statute, but which mainly owe their form and composition to native custom. These tribunals administer the local customary law under their own traditional forms of procedure. The customary law is for the most part unwritten; it varies widely from place to place, and there is a great diversity also in the procedure adopted by the tribunals. In many of the African Colonies by far the greater proportion of civil issues, and most of the less serious criminal issues, are now dealt with by these tribunals. In some, areas the system of Native Tribunals is not integrated in any way with the system of Colonial Courts which, under the judicial control of a Supreme or High Court, administer the statute or other law of the Colony; in other territories it is integrated only at the point at which an appeal is provided from the Native Tribunals to those Courts. It is important to note, that when such appeal is made, the appellate Court is required to give effect to the local customary law in so far as it is not repugnant to natural justice or equity or incompatible with the law of the Colony.

While in almost every case the ascertainment of customary law is a matter of proof, some general knowledge of the usual or frequent principles of that law, varying and difficult of ascertainment though they are, and an acquaintance with the social conditions which it reflects, are desirable as part of the equipment of the judges or officers presiding over Colonial Courts and of the advacates who plead in such Counts. It is even more desirable in law officers who advise on the course of legislation. It is to the combination of a knowledge of the general principles of English law and of the general principles of native customary law that we must look for the development of a body of Colonial law which, while adjusted to modern requirements, is at the same time adapted to the needs of different Colonial communities.

\section{The conditions regulating the right to practise in the Colonial Courts}

We may note that in some Colonies the two branches of the legal profession distinguished in England as barristers and solicitors are distinct; but in a 
considerable number of others admission to practise qualifies the holder to act in both capacities. It may be noted that the latter is also the system prevailing throughout the greater part of British India; there are firms of solicitors in three Presidency towns; but elsewhere persons enrolled as advocates (a term which includes barristers) are entitled either to plead in Court or to render the services normally discharged by solicitors in England. In many of the Colonies developments have not yet been such as to create a wide need for the specialised service of the solicitor, much of which lies outside the strictly judicial field. At present, by far the greater number of the Colonial or Indian students who resort to this country for their legal education seek to be enrolled as barristers and comparatively few as solicitors.

In this section we deal only with the qualifications of persons admitted to plead in the Courts. We shall deal subsequently with the solictors' branch of the legal profession. We shall do so very briefly, not because we in any way underrate its importance, but because some of the main problems raised by the legal education of baristers wishing to practise in the Colonies arise to a very much lesser extent in the case of solicitors. For instance a problem is created in the case of barristers, by the fact that in the majority of Colonics, freedom to practise in the local Courts is conditional on a call to the English, Scottish, or North Irish Bars: whereas in the majority of Colonies freedom to practise locally as a solicitor is not conditional on admission as a solicitor by the English Law Society, or by the corresponding bodies in Scotland and Northern Ireland.

Persons admitted to plead in the Courts are known locally under a varicty of titles-" advocates", "legal practitioners", " pleaders", " solicitors" or " counsel " but it will be convenient here to refer to them under the general title of advocate. In the majority of Colonies, a member of a Bar of the United Kingdom is ipso facto entitled to admission to the local Bar, and in some a corresponding privilege is extended to a solicitor who has duly qualified as such in the United Kingdom. But to this rule there are some exceptions, and there is also a considerable diversity in the manner in which the rule is applied in practice. The details which we give below are not exhaustive, but will illustrate sufficiently the major differences which occur:

(a) In Malta no one can be admitted as an advocate unless he has obtained the degree of Doctor of Laws in the Faculty of Law of the University of Malta. His studies in law may have been conducted at the University of Malta or abroad, but in the latter case he must satisfy the examiners in the Faculty of Law that he has studied at an institution recognised by it and has a full knowledge of the language of the courts. After obtaining his degree he must attend the superior courts in Malta for a year.

(b) In Palestine advocates must (i) satisfy the Law Council that they have studied at the Jerusalem Law Class for five years and taken its diploma, or have the diploma of a university or law school recognised by the Law Council, and (ii) must have passed two years in the office of an advocate practising in Palestine. A partial exemption from (i) may be granted to barristers or solicitors of the United Kingdom, the Dominions or British India.

(c) In Ceylon (i) any person who has been called to a Bar in the United Kingdom may be admitted to the Ceylon Bar without examination; (ii) other persons must have qualified by completing the course of the Law College at Colombo, and they must also pass six months in the chambers of an advocate of ten years' standing in Ceylon.

(d) In Hong Kong, St. Lucia, St. Vincent, Grenada, Dominica, the Leeward Islands, Cyprus, Jamaica, Mauritius, Barbados, British Guiana, North- 
Borneo, and Trinidad, a call to a Bar in the United Kingdom constitutes the sole qualification to the local Bar. Nothing less will suffice and nothing more is required.

(e) In Bermuda and the Bahamas admission is granted (i) to persons called to a Bar in the United Kingdom and (ii) to persons who have qualified by serving for three years with a barrister in the Colony.

(f) In the four West African Colonies the qualification is a call to a Bar in the United Kingdom, but in addition it is necessary either (i) to have read for one year in chambers in the United Kingdom or two years in the Colony or (ii) to have practised for two years in the Courts in the United Kingdom or a British Colony.

(g) In Kenya, Tanganyika, Uganda, Northern Rhodesia and Zanzibar admission is granted (i) to persons who have been called to a Bar of the United Kingdom (ii) to persons entitled to practise before the Supreme Court in any Dominion or self-governing Colony or a High Court in British India; (iii) to solicitors of a Superior Count in a British possession to which section 35 of the Solicitors Act, I932, applies. Nyasaland admits in addition any persons certified as duly qualified by the judge of the High Court.

(h) In Aden the qualifications required are those which regulate practice in a High Court in British India.

(i) In Fiji admission is granted to persons who have (i) been called to a Bar in the United Kingdom or (ii) are entitled to practise in Australia, Canada, New Zealand or any other Dominion or Colony named by the Governor in Council.

(j) British Honduras admits persons enrolled as advocates in other Colonies, or persons who have served for five years with a solicitor (the term applied locally to all legal practitioners) in British Honduras and passed an examination prescribed by the court.

(k) The Straits Settlements and Federated Malay States admit persons qualified as barristers or solicitors in the United Kingdom to practise locally as advocates or solicitors, and also persons who have acquired local qualifications. They require, however, that persons who have qualified in the United Kingdom shall also have received instruction in local law in the office of an advocate or solicitor practising in Malaya, the period varying according to the time during which the applicant has read in chambers in the United Kingdom.

\section{The qualifications for acting as solicitor}

It will be sufficient to refer here only to the conditions in those Colonies which distinguish between the position of an advocate and that of a solicitor. Thus in Malta, in order to be admitted as a legal procurator (the local term for a solicitor) a person must have taken the special course given by the Law Faculty of Malta University for the diploma of legal procurator. In Ceylon (i) any person who has qualified as a solicitor in the United Kingdom may be admitted as a "proctor" and (ii) any person may be admitted who has completed the three years' course for the proctorate prescribed by the Council of Legal Education and has served as a clerk to a " proctor " of approved standing. In Barbados, British Guiana, Hong Kong, St. Lucia, St. Vincent, Grenada, Trinidad and Jamaica, solicitors of the United Kingdom can practise, but there is also a local qualification which can be acquired by serving a term of articles in the Colony and by passing an examination which in certain of these Colonies is conducted on behalf of the Colony by the Law Society of England. In the Leeward Islands and Dominica only solicitors who have qualified in England are admitted. In the Bahamas a person may 
be admitted as "attorney" after serving a term of articles locally and passing a local examination. Mauritius admits as " attorneys" (i) persons qualified as solicitors in the United Kingdom, and (ii) persons who have served for six years under articles to an "attorney" in Mauritius. It may be noted, as a general rule, that where persons are admitted on the strength of qualifications obtained in the United Kingdom, the Colonies do not stipulate (as many have done in the case uf barristers) for a further period of practical experience or of study in chambers, it being held that the five years spent in the United Kingdom as an articled clerk guarantee a sufficient acquaintance with the practice of law.

\section{Procedure for obtaining legal qualifications in the United Kingdom}

The preceding survey will have made it clear that in the majority of Colonies candidates for the legal profession, in particular those desiring to practise as barristers, depend for their qualifying legal education on institutons in the United Kingdom, and that only three Colonies-Malta, Palestine and Ceylon-have a fully developed system of legal ecucation designed to provide an alternative means of admission to the higher branches of the profession.

In Maita, as already explained, the Law Faculty of the University provides the courses both for advocates and procurators, and is the authority which controls admission to the legal profession. In Palestine, legal education is controlled by a Law Council presided over by the attorney general, which prescribes the syllabus and supervises the examination of the Jerusalem Law Classes. Ceylon, however, is the only Colony which possesses a fully orgamsed Law College. The Council of Legal Education in Ceylon is a statu. tory body, consisting mainly of judges of the Supreme Court and law officers; it supervises (through a Board of Studies) the studies at the Law College. The three years' course of the College comprises a preliminary, intermediate and final examination.

As we have observed, we must foresee that there will be an increasing need in the Colonies for persons with legal qualifications. Apart from this, it is necessary to realise that with progress in self-government, the Colonies may, like British India, be unwilling to continue to accept a position in which they are so largely dependent on the facilities for legal education provided by institutions overseas. We therefore feel called upon to contemplate a state of affairs in which universities and university colleges of the Colonies should eventually play a part in supplying these facilities, but before making more detailed recommendations on this point we desire to make some observations in particular on the conditions which have to be fulfilled by the student of law in the United Kingdom, to obtain a practising qualification.

Where a call to a Bar in the United Kingdom is a qualification for admission to a Colonial Bar, the call may have been to the Bar either of England, Scotland or Northern Ireland. For brevity and because it absorbs most of the students in question, we will consider the Bar of England only. The Colonial student like anyone else must, before he can be called to the English Bar, be admitted as a student to one of the four Inns of Court, and this, saye in the exceptional circumstances to be afterwards explained, involves a considerable period of residence in the United Kingdom. Broadly speaking, anyone is eligible for admission to an Inn of Court who possesses the requisite educational qualifications, which may be indicated roughly as a School Certificate or its equivalent, with the proviso that one of the subjects of the examination must be Latin. He must make certain payments, which together with those payable on call to the Bar, amount to about $f_{\mathrm{I}}$;o (of this sum no less than $£ 75$ goes in stamp duty). He must also tender a certificate of good character. 
After admission to one of the Inns of Court, the student in order to qualify for a call to the Bar must pass both parts I and II of the examination for call to the Bar; subject to this, that roughly speaking if he has obtained an honours degree in Law at any university he may be exempted from part I. The student must further " eat dinners " for three years at his Inn of Court; each year consists of four terms, in each of which terms as a general rule six dinners must be eaten. A student who takes a first class in part II of the examination, may obtain a dispensation of two terms.

It will be seen therefore that a student once admitted to the Inns of Court can obtain a call to the Bar by passing the Bar examinations and " eating dinners." No proof is required that he has attended any prescribed course of lectures or law classes. After call to the Bar an English student almost invariably reads for a year, or a minimum of six months, in chambers as the pupil of an established junior. There is no compulsion on him to do this, but no one who failed to do so would have much prospect of acquiring a practice.

During the war the conditions qualifying for call to the Bar have in the case of Colonial students been greatly relaxed. They may be admitted as students of any Inn of Court in absentia. With the co-operation of the judiciary and the educational authorities in the Colonies, arrangements have been made for examining students overseas, and subject to a necessary period of residence and study in this country (the length of which remains hitherto undetermined) they can be called to the English Bar in absentia.

From the information supplied to us it appears that the number of admissions to the four Inns of Court from the Colonies in the years I937 (taken as typical of the years immediately preceding the war) and 1943 (representing a year of returning normal conditions) was 43 and 82 respectively. The total number of admissions to the Inns of Court in I937 was 466; in I943 it was 358. The admissions from the Colonies during these years comprised:-

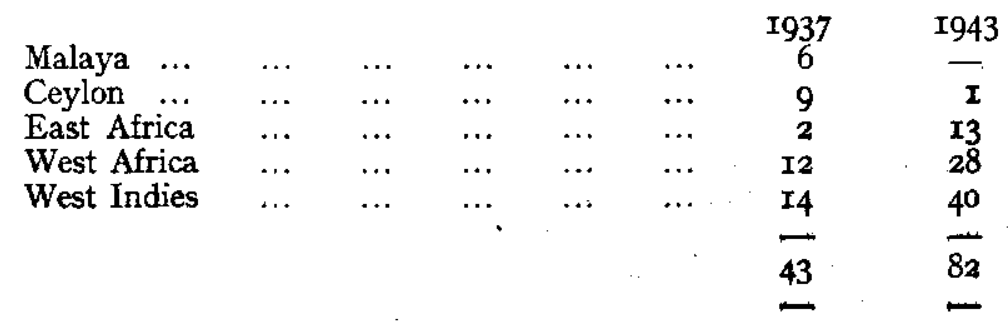

It will be seen that there have been no admissions from Malaya since the Japanese occupation and the number from Ceylon has also fallen off.

Though the extension of facilities for legal education in the Colonies may have its effect on the number of students resorting to the United Kingdom for call to the Bar, this development can only be gradual, and it is also possible that, as in the case of India, a number of students will still desire to be called to the English Bar, on account of the prestige which the status of barrister carries. We proceed, therefore, to consider whether the conditions which a Colonial student has to satisfy in order to be called to the Bar in England could not with advantage be modified: whether for instance he should be required, in addition to passing the Bar examinations to comply with some practical test-such as reading in chambers with a junior counsel in England or elsewhere or attending the Council of Legal Education's tutorial classes, which are designed to give practical training of the kind afforded to a pupil in chambers-before qualifying for practice at the Colonial Bar, is a question for the authorities of the respective Colonies involved. We have seen 
that the West African and some other Colonies have answered this question in the affirmative. If we may express an opinion on the matter which is perhaps strictly outside our purview, it would be to the effect that such requirements are reasonable, though difficult to satisfy so far as they demand that a Colonial student must have read as a pupil in English chambers.

As regards other requirements we feel that the Inns of Court might reasonably be invited to consider certain suggestions. We recognise that the Inns may feel difficulty in offering, and perhaps Colonial opinion in accepting, any sectional exemption from requirements which are at present generally imposed. We realise also that Colonial students may derive real value from a fairly prolonged contact with the buildings, libraries and traditions of which the Inns of Court are the owners or repositories. In the case of a Colonial Bar in the making it is impossible to exaggerate the importance of a high standard of professional conduct and honour, and, as things are, we know of no better or surer way of acquiring this than by a careful observation of the conduct of cases in an English Court of Justice, though the value of such experience is more than doubled if the student can peruse the pleadings and the brief of one counsel (as a pupil can) before going into Court.

Nevertheless, we feel that the requirements of three years of "eating dinners " may be over-exacting. The Colonial student of exceptional talent may be able to pass his Bar examinations in 18 months or two years, and although the cases in which this occurs are rare, it may not be desirable that a Colonial student (possibly with limited means, subscribed with difficulty) should have to remain for another year or I8 months in London with nothing further to do in the way of Bar examinations. No doubt he may employ this time to advantage, e.g., as a postgraduate student in an English university, or in studying in the Inns of Court, but there is nothing to compel him to make this use of his leisure and he may indeed employ it to less advantage.

Again, we feel that the continued possibility of passing part $I$ at least of the Bar examination in absentia would be a great boon to Colonial candidates. With less to do here in the way of examinations they would have more time to devote to their practical training, e.g., by attendance in Court, or at tutorial classes. The war experiment in this regard has, on the evidence given before us, proved a notable success.

We do not think it necessary to express any opinion on the standard of the English Bar examinations, and we appreciate the difficulty of imposing on Colonial students conditions either in respect of the standard for admission to the Inns of Court, or in respect of the Bar examination itself, which are different from those applicable to others. We feel at the same time that it would be to the general interest if, in order to obviate cramming and learning by rote, it were possible to demand a higher standard of general education and in particular a better command of English as a condition applying to all entrants to an Inn of Court, and some viva voce test in examinations for call to the Bar. We note with interest that in Ceylon the qualifications for entrance to the Law School as an advocate student is the London Intermediate Arts examination.

It is, of course, a matter for the consideration of the Colonial authorities whether they should take advantage of the proposals we make above in respect of the eating of dinners by overseas students or the grant to them of permission to pass one part of the Bar examination in absentia, or whether they would prefer to continue under the present system without modification. We believe that the Secretary of State has been in communication with them on the question of possible modifications.

The position of the Colonial student seeking qualification as a solicitor is materially different in that before entering for the examination prescribed by the Incorporated Law Society he acquires practical experience of the law by 
serving his articles with a practising solicitor. The period for which he must so serve is normally five years. We do not consider that we can usefully suggest any modification of this system in favour of Colonial students.

\section{Courses in the law schools of Colonial universities}

In contemplating the possibility of the establishment of law schools at the Colonial universities, where they do not already exist, we have assumed that graduates would be admitted to practice in the Colonial Courts on the same terms as those who have been called to a Bar in the United Kingdom. We hope also that when the Colonial law schools have been developed, a dualism which until I934 to some extent prevailed in this country may be avoided, a dualism which involved, in the case of persons who had obtained a law degree at a university, the superimposition of overlapping educational requirements by a Council of Legal Education. To-day this overlapping has largely been overcome; students who have obtained a good class in law at any of the well known universities are exempted from the whole of part I of the Bar examinations, and many of the main subjects covered by part II (the "final ") e.g. criminal procedure, equity, company law, conveyancing, evidence and civil procedure find no place in the university B.A. (Law) examinations.

To ensure these results it would be necessary for the Colonial universities to secure the collaboration of the judicial authorities of the Colonies concerned when laying down the standard for entrance to the law school, the curriculum to be followed, and the form of final examination for candidates for the diploma or degree. This might most suitably be achieved through the institution by the different Colonies in the region served by a university of a Council of Legal Education on which such judicial authorities would be represented.

We hope that the standard of entrance will be adequately high, and certainly not lower than that of the Intermediate examination of the university itself. It would be for consideration whether (as we have suggested for entrance to the schools of medicine) there should be a special process of selection of candidates seeking admission to the law schools, for they will follow a profession in which character and outlook are certainly not less important than technical qualifications.

Moreover in view of what we have said in an earlier section of this chapter, when dealing with some of the characteristic features of Colonial law, we are impressed with the need that the curriculum should not be confined to the formal study of law, but should be so framed as to enable the student to appreciate the social and economic factors underlying the formation of law and the part which law and the administration of justice play in the evolution of society.

\section{The prescription of additional requirements for graduates of law schools}

It will be for the judicial authorities in the Colonies to determine what additional requirements, in the nature of practical experience and the like, the graduates of a Colonial law school must satisfy before they can be admitted to plead in the courts. We hope, however, that these requirements will be so framed as not to place Colonial graduates at a disadvantage as compared with those who have been called to the English Bar.

It will be for such authorities also to advise whether admission to the law school should be so regulated as to avoid producing a number of law graduates out of reasonable proportion to the needs of the community for legal aid. The existence of a legal profession of which the strength is greatly in excess of the public need for its services, so far from being of assistance to the administration of justice, may, as experience has shown, have the effect of fomenting litigation and of lowering the standards of professional conduct and incidentally 
remuneration. The danger is all the greater in those Colonies where the public itself is uneducated and has still to adjust itself to a novel system of law or a judicial procedure differing widely from the methods prescribed by tradition for deciding contested issues.

It will also be for the authorities responsible for legal education to advise how far the courses given at a law school should be of a general nature, designed to prepare the student for the services usually discharged in this country by a solicitor as well as those associated with the position of barrister, or whether separate provision should be made for training those who desire to qualify themselves for this special class of work. It will no doubt be found that the requirements of Colonies will vary in this respect.

\section{CHAPTER XVIII}

\section{ENGINEERING}

\section{The qualifications required of the civil engineer}

As was remarked by the Commission on Higher Education in East Africa*, the term engineering is used in such a variety of ways that there is apt to be some confusion when engineering is discussed as a subject of education. There can be no question of the need felt in the Colonies for the skilled craftsmen, technicians or tradesmen who are employed in various types of engineering work; but their training is mainly of a practical kind, and is normally given in technical and trade schools, or, in certain cases, in institutions which form part of the system of post secondary vocational instruction. Our own task, however, is to consider the questions arising in regard to the professional education of civil engineers, the men, that is, who are responsible for designing, constructing and maintaining the works needed by the state or by private enterprise in exploiting the natural resources of the country, or by the activities of the economic, social and public utility services. It is from these men also that guidance must be sought in organising the instruction given to the technicians and craftsmen to whom we have referred above. We need not emphasize the fact that there will be a greatly increased demand for them as the result of the programme of Colonial development for which finance is now being provided. And the demand will not arise merely from the need for expanding the state service of engineers; it will be felt also by many types of private enterprise.

While entry into the profession of civil engineer requires certain basic qualifications, men so qualified may in practice devote themselves to a variety of specialised lines of work. This is best illustrated by the figures of the officers of this class now in the employ of the Colonial Governments. The total number of officers is 890 . Of these the majority, 580 , are classified as civil engineers, and within this term are included not only the considerable number who deal with roads and buildings, but those dealing with irrigation projects, waterworks and sanitary systems, and those in the Railway Administrations (other than as mechanical engineers). I30 are classed as mechanical engineers, the majority of whom are employed on the railways, and I80 as electrical engineers. The latter deal not only with installations for the generation of electric power, but with the telegraph, telephone and wireless systems. While it is not possible to give figures of the numbers of civil engineers employed by private enterprises, they are considerable, especially in the employment of mining, sugar and rubber companies. 
The normal qualification prescribed for employment as a civil engineer in the government service is the corporate membership of the Institution of Civil Engineers in the United Kingdom or an engineering degree or diploma recognised as granting exemption from sections $\mathrm{A}$ and $\mathrm{B}$ of the A.M.I.C.E. examination, and at least two years' practical experience of good civil engineering work. Candidates for employment as civil engineers on the railways are required to have special experience of railway construction or maintenance; and special experience is similarly required of candidates for employment as mechanical or electrical engineers.

The science of engineering differs in one respect from some of the sciences which we have previously considered. We may with propriety speak of tropical medicine or tropical agriculture, not indeed as separate branches of science, but as aspects of the general science of medicine or agriculture which require special knowledge and experience. But we could not with equal propriety speak of tropical engineering. The civil engineer in the Colonies does not need qualifications different from the civil engineer in Europe; if there is any difference between them it lies mainly in the fact that in the Colonies the engineer must learn to make use of different materials, or to adjust himself to the different methods of working dictated by the comparative lack of competent local contractors or foremen and trained artisans. In his case, it will be of no special advantage to have acquired his qualifications by study in the Colonies, and there is one potential disadvantage. Not only does the efficacy of the theoretical instruction given to him depend on the availability of suitable laboratories and workshops, but, as we have shown, great stress is also laid on his having a period of practical experience " of good engineering work." In many specialised lines of civil engineering, the opportunities of such experience are at present, and must continue for some time to be, far fewer than in the United Kingdom and some of the Dominions.

\section{Facilities in the Colonies for education as civil engineer}

It will be an advantage at this stage to survey shortly the facilities for education in engineering already provided in the Colonies. The Royal University of Malta has a combined Faculty of Engineering and Architecture. In Palestine, there is at Haifa a School of Engineering which gives a diploma after a four years' course and the School has been recognised by the Hebrew University of Jerusalem as serving the purpose of a Faculty of Engineering. The University of Hong Kong had a Faculty of Engineering which provided a four years' course in civil engineering and special courses in mechanical and electrical engineering. Attendance at English classes was compulsory for all students save those exempted by the attainment of a high standard in English in the matriculation examination. In Ceylon, the Technical College, which is an independent institution, gives teaching up to a degree standard and is recognised by London University for the B.Sc. (Engineering) examination.

In Malaya, teaching in engineering was given at the Technical School at Kuala Lumpur. The standard for entrance was the School Certificate, and the course lasted three years; a considerable variety of subjects was taken, in order to meet the needs of different government departments. The Commission of I 939 recommended that the School should be raised to the status of a technical college rather than that Raffles College, Singapore, should establish a Faculty of Engineering. The School would be extended in order to provide for some 300 pupils, and the Commission assumed that it would have a few advanced students who would sit for the B.Sc. (Engineering) external degree of London University. These students would subsequently 
be given two or three years' pupilage in practical work under the direct supervision of a qualified civil engineer in the government service.

In the Gold Coast, the Prince of Wales College, Achimota, has been recognised by the University of London as a college teaching for the degree of B.Sc. (Engineering). Students who have passed the London matriculation or an equivalent test, receive a four years' degree course which has been successfully completed by eight students. Subsequent practical training may be acquired either by working for three years as probationer engineer under the Director of Public Works or for four years under the General Manager of the Railway. A larger number of students take the Intermediate course only; this course lasts two years and a proportion of the successful students have come to Great Britain to complete the degree course. At Yaba Higher College in Nigeria there is a four years' course for engineering students; it is designed to meet the needs of the various government departments and is given under the supervision of officers of those departments. As regards East Africa, the Commission on Higher Education in East Africa recommended that a school of civil engineering should be created in the College at Makerere, designed in the first instance to train students for the examination of the A.M.I.C.E.; but the Commission contemplated that at a later stage the College would work up to the full degree standard of the London external degree, until such time as it obtained power to grant its own degrees. The Commission considered that the course for professional training should occupy three years, with practical work in the vacations, and should be followed by three years pupilage in a government department, under a special officer appointed for the purpose. The development of this scheme has been interrupted by the war. In Khartoum the School of Engineering forms one of the series of institutions which, it is hoped, will be united in Gordon Memorial College. The Khartoum School of Science gives a preliminary course of one year to the students of the School of Engineering; the latter awards a diploma as the result of a four years' course.

\section{The part to be taken by Colonial universities in the education of civil engineers}

As will be seen, only in a few cases is provision made for more advanced education in civil engineering. For obvious reasons we desire to see the Colonial universities and university colleges take their part in equipping Colonial students for the important and expanding field of employment as engineers. Although, as we have pointed out, certain obstacles exist in regard to the supplementing of the theoretical courses by a period of practical training, we consider that instruction up to the stage of the B.Sc. (Engineering) degree can suitably be provided in the Colonies. Whether it will be possible to proceed to a further stage and provide the necessary facilities, in certain specialised lines such as mechanical and electrical engineering, must depend on circumstances.

The result must be that in the immediate future at all events Colonial students desiring to complete their education in those subjects must proceed overseas for the purpose.

It is unnecessary for us to add anything here as to a syllabus of instruction, since this will be of the standard form. We would suggest however that where students have not already attained a sufficient knowledge of English, special measures should be taken to complete their education in this respect.

\section{Research in subjects connected with engineering}

We are at some difficulty in foreseeing the extent to which the Colonial institutions can at any early date play a part in organising research in the subjects studied by the civil engineer. The equipment required for research in certain of the physical sciences, whether in the nature of libraries or of 
apparatus, becomes with the passing of time more and more elaborate and specialised. Further, the fuller facilities offered elsewhere may tempt the outstanding students to go overseas for training in post-graduate research. At the same time, it is clear that there exist useful opportunities for investigaation in the use of local materials, and in the effect of local conditions of climate, soil and the like in the special fields for which the civil engineer is responsible. Such investigations may be of the nature of "ad hoc" rather than of "fundamental " research, but to some extent they may supply the openings for original work which, as we have already remarked, are essential both to attract competent teachers and to maintain their value as instructors.

\section{CHAPTER XIX}

\section{THE TRAINING OF TEACHERS}

\section{The function of a university in the training of teachers}

We have in chapter III remarked on the reciprocal character of the relation which exists between a university and the school system. The relation could hardly be more close or more vital. For, as we there observed, while the university is dependent upon the schools for a continuous supply of wellprepared recruits, the schools are equally dependent upon the university for a continuous supply of well-qualified teachers. Further, in the course of years, the schools will themselves come to be profoundly influenced by the standards which the university sets, by the interpretation of the local culture to which it gives force and currency, and by the cultural relations with other lands which its activities must inevitably entail.

But while we may expect that the influence of the university will spread through the whole range of education in its area, its most direct effect will consist in the supply of suitably trained men and women to staff the secondary schools. The teachers whom we have in mind here are those who, because they are to teach in the secondary schools which prepare pupils both for university entrance and for various careers not requiring qualifications obtainable at a university, will particularly need that broadening of knowledge and of interest which a university training can give. The point we wish to emphasize is that the university has a peculiar responsibility for the education and training of secondary teachers quite apart from the fact that some proportion of secondary school pupils will in due course become undergraduates of the university. We are convinced that this is a duty to be laid upon any institution for higher education in Colonial areas and that it must be undertaken long before the institution has reached the stage of granting its own degrees.

\section{Present provision for the training of teachers for secondary schools}

The provision now made for the training of teachers for secondary schools cannot be regarded as adequate either in quantity or quality. We shall not attempt to survey the whole field, but will refer to the position in certain typical areas. The possibilities have been most fully developed in areas such as Ceylon which have universities of their own. In the West Indies, on the other hand, where there are well-established secondary schools in considerable numbers, qualifications appear to range all the way from an honours degree with a teacher's diploma to the matriculation certificate or even lower. There is as yet no recognized course of training for secondary school teachers in any part of the West Indies. 
In Malaya a department of education designed to undertake postgraduate training was instituted at Raffles College shortly before the outbreak of war. There has been no opportunity to develop it or test its quality. But from the information before us it would appear not to have been very adequately staffed, being too dependent for its teaching upon officers in the service of the government department of education. We desire to re-affirm the opinion expressed in the report of the Commission of 1939 that although for a time it may be necessary at some colleges to draw upon the assistance of government officers in this way, it is essential that every university training department should have from the first a sufficient nucleus of its own staff to ensure continuity and the relation with the university as a whole which is so vital to its work.

In Africa, plans are taking shape at Makerere which should result in the proluction of what may be termed a " semi-specialist" teacher, qualified to take charge of a group of cognate subjects in the secondary school. Plans on somewhat similar lines are in contemplation at Achimota. At present the College undertakes the training of teachers for the education department of the Gold Coast, but would doubtless agree that it is not yet adequately equipped to undertake the training of secondarv teachers at the level contemplated in this report. The Higher College at Yaba provides training for teachers which follows the general pattern in universities in Great Britain.

Provision in other parts of British Colonial Africa does not reach these standards, but a certain number of students sufficiently qualified go for education, if not for training, to Fort Hare in the Union of South Africa.

\section{The form which the training of teachers should take}

In some of the areas with which we are concerned it will be impracticable for many years to require that all teachers in the secondary schools shall be university graduates. Indeed it is probable that there will always be justification for the employment of a certain number of teachers who need not be graduates. We take the view, however, that apart from these special cases, the training of all teachers who are to work in secondary schools should be undertaken in the university. It will be for the authorities of the university or university college, in consultation with those whose duty it is to staff the schools, to determine how the training course shall be organised. We wish, however, to offer certain suggestions in this respect.

Those whom the university institution undertakes to train as secondary teachers may be said to fall into three main groups:-

(a) Those capable of taking charge of the teaching of their respective subjects at the higher levels. Normally they will have taken a good honours degree. There may be for some time relatively few in this group, particularly where the schools are small and therefore compelled to make wide use of teachers belonging to the next group.

(b) Teachers capable of handling two or three subjects in the middle forms of the school. They should have taken a good general degree in suitably related subjects. For some time teachers of this type may be in the majority among students in training.

(c) Teachers either of junior forms in secondary schools or of certain special subjects for which the usual degree courses are not the best preparation.

The general considerations which make it desirable that secondary teachers should be trained at a university institution will be reinforced in some areas and notably in Africa by certain more special considerations. In those areas education at the secondary level, though it need not and should not loosen the roots in the life and traditions of his own people, does carry him into 
a realm of ideas less richly illuminated and interpreted by the life around him than that in which he finds himself at the primary stage. $\mathrm{He}$ is passing, in fact, into the wider community of western culture and becoming the potential heir to a larger inheritance than the immediate resources of his native culture can afford. For him successful passage through this stage is of crucial importance, yet it is menaced by its own peculiar dangers. In a developed western country, the secondary school pupil is sustained by resources in the life around him which are akin to those of his school. There is a sense in which he is less dependent upon his school and his teachers than is, for example, his African brother.

It is because of this greater dependence of the pupil in many areas upon school and teachers that the teachers need to be specially equipped to take the extra strain. A fairly prolonged period of work in a well-developed university is the best means of providing this equipment and for many perhaps the only means. A certain degree of saturation in all that makes up the life of a university is perhaps of even greater importance than the course of training itself.

It is for such reasons that we suggest that the training of even the nongraduates referred to under $(c)$ above should be provided in the university, for they may be in even greater need of what we have called saturation. It may well be that the concluding stage of the general education of these non-graduates will be carried through at the university college where they also take the subsequent professional course, as happens now at Makerere. There will probably be a stage of development where in the same college some intending teachers complete a degree course while others cannot aim so high. We believe, however, that the latter class who, in English terminology would be of the training college and not of the university training department level, should not attempt to carry on a training course pari passu with academic studies. That would seem to be a sure way of frustrating both purposes.

We should deprecate any special adjustment of ordinary degree courses to meet the needs of intending teachers. A degree structure wisely planned to provide for the needs of the community and for diversity of interest among students generally would provide also for the scope that the intending teacher could reasonably ask. The point is of some importance, since we may expect a considerable proportion of graduates in arts will pass into the teaching service.

\section{The duration of the training course for teachers}

For both graduates and non-graduates the training course should come after completion of their general education. We realise that this involves four years of preparation beyond the matriculation stage and so presupposes the prospect of such status and remuneration for secondary teachers as will justify this expenditure of time. While it is beyond our province to make recommendations in such matters we feel bound to reiterate that the very possibility of a university is contingent upon the operation of well-staffed secondary schools. Where conditions are such as to afford no guarantee of this being achieved the attempt to set up a university may be either premature or entirely vain.

\section{The university department of education}

We assume that the form in which provision will be made for this work will consist usually of a department of education under a professor, and suitably staffed for the varieties of work it is called upon to do. We must emphasize, however, that a department of education which confines itself strictly to the function of training teachers will find that it cannot discharge even that function 
adequately. The work will fail in vitality unless two essential conditions are fulfilled.

(a) That the department should be a centre for active and systematic research in its own field.

(b) That it should establish intimate co-operative relations both with cognate departments within the university and with training-colleges and schools in its area.

The importance of research in education in many Colonial areas springs mainly from the fact that the actual work of education is permeated if not dominated by influences originating from outside the area. That this should be so is justifiable, at least in present circumstances, in the interests of the Colonial peoples themselves. But it does involve risks of misdinection of effort which are not so obviously incurred in countries more self-sufficing in cultural resources. The complex task of estimating the impact of current educational methods upon indigenous life, of determining from time to time what readjustments of method may be necessary, and of utilising all possible sources of educational inspiration in the common life itself, is a task that must be undertaken if disappointment is to be avoided. A university department of education should provide a central power-house for the discharge of this task. It should have resources of its own for the purpose and should also co-operate freely with other agencies working in the same field.

The above remarks apply more specifically to research in what may be called educational problems special to the Colonies. But it should not be overlooked that in the wider field of general research, the work in Colonial universities may provide valuable checks upon results arrived at elsewhere under very different conditions. Thus light may be shed upon problems in the teaching of English and of science, and we may learn something useful about the most effective means of drawing in the cultural resources of the community for the uses of the school. It is not fanciful to suggest, for example, that influences flowing from the Colonies might in time prove of benefit to schools in this country.

The co-operative relations into which the department of education would enter appear to fall into two main groups: (a) those within the university and (b) those beyond its borders.

(a) There is much experience to indicate that the work of the department is likely to lack inspiration if it is not in a position to draw freely upon the resources of cognate departments in its own university. Indeed to be effective, it must be in no sense a self-sufficing unit but must be an organ through which can be directed all those university influences serving to advance the general education of the people, and there is hardly any department in the university which has not some relevant contribution to offer.

(b) A department of education will also be more efficient if it maintains close relations not only with the schools and the government department of education, but also with the centres where the rank and file of the primary teachers are trained. Benefits here should be reciprocal, the training centres deriving guidance from the department and the department finding in the work of tratining centres valuable material and the necessary guarantees against excessive formalism and detachment.

Similarly in any extra-mural work which the university may undertake, particularly in respect of mass-education, the department should provide an effective instrument of action. The department can serve this purpose just because it is intimately concerned with agencies that touch the lives of the people at so many points. 


\section{CHAPTER XX}

\section{THE MEDIUM OF INSTRUCTION AND LINGUISTIC PROBLEMS}

\section{The relation of these subjects to work in the schools}

It will be convenient to discuss in the same chapter these two closely related topics. But it is impossible to appreciate their bearing on the work of the universities without raising important practical issues relating to the work of the schools.

There are at least two forms in which such issues arise. In the first place the fitness of a student to enter upon university courses is determined, inter alia, by his command of the language-medium in which the instruction is given. He must be able to receive intelligently what he hears in lectures or tutorials, and to employ the medium himself with ready facility and without injury to his own intellectual growth. We know from experience that these conditions are by no means always fulfilled even when the medium employed is the student's own mother-tongue. They will be even more difficult of fulfilment where the medium is to the student a foreign language, laboriously acquired and carrying thought-forms very different from those which are conveyed by his own vernacular. The effort not only to use the foreign language but also to learn to think in it is indeed formidable. But unless it achieves a satisfactory measure of success, the student is not only hampered in his studies but he may also be positively harmed by the mental confusion that will ensue. The capacity of the schools to bring pupils to the necessary standard of fitness in this respect becomes therefore a matter of the first importance.

In the second place, just as the university is dependent upon the schools in this matter, so conversely the schools are dependent upon the university. Work carried out by the university in linguistic studies and in the study of the problems which arise in the handling of language in the schools must inevitably react upon the schools in a way which cannot but be beneficial. We realise that it is for the appropriate authorities to take such action in the schools as may be found desirable. We wish only to insist that in the achievement of adequate university standards the part to be played by the schools is vital, and that the university can materially assist the schools by undertaking systematic studies in linguistic and in associated school problems.

So far as African education is concerned we understand that the Advisory Committee on Education in the Colonies has approved a report dealing with language policy. We do not anticipate that any measures advocated in our present report will be in conflict with the principles suggested in that document. With this explanation we can proceed to the discussion of the specific problems which arise. They can be classified in general under two main heads :-

(a) English as a medium of instruction.

(b) The study of the vernacular and kindred languages.

\section{The use of English as a medium of instruction}

Our remarks here relate mainly to the position (which will indeed be the most common) where English, as the medium of university instruction, is an acquired language. We feel strongly that far too little has yet been done in Great Britain itself to explore the nature and range of the problems which arise in the teaching of English as a foreign language. The success of the 
student who needs to acquire real command of English will depend largely upon the skill of those who teach him during his school years; but such skill in the teacher will be determined by the quality of those who train him and advise him on teaching-methods. It is here that a substantial contribution resulting from studies pursued in this country could be highly effective. In spite however of the work by a few isolated scholars, a contribution of the scope and authority that we now contemplate is still lacking. The study of these matters seems to be essentially one for the British universities to undertake; and we hope that the Inter-University Council will find it possible to encourage the investigation of a problem which baffling and complex as it may be, is of the first importance to the development of higher education in the Colonies.

In the Colonial areas themselves a main key to the situation will be found in the university teacher training departments and the training colleges. In staffing and equipment they will need to be exceptionally well supplied for the work both of teaching English itself and of training their students to teach others. One of our witnesses, speaking of the deficiencies of African teachers in this respeot, stated:-

"They learn their English from English people who are simply teachers and who themselves have never gone into the question as to how to teach English to someone whose native language is not English. Until something has been done about getting expert people for the training schools, people who know some of the principles of how to teach English to non-English speaking people, that situation will not be met."

He had found that Africans who had been taught by English teachers were more proficient than those who had had African teachers. But we accept his conclusion that to speak English as a mother-tongue, even if one has taken the usual course of training as a teacher, is not in itself a sufficient qualification. Specific study of the problems and the underlying principles is necessary.

We urge that courses of training provided in this country for men and women intending to undertake educational work in the Colonies should include instruction in the methods suitable for the teaching of English as a foreign language.

\section{Need for special courses in the method of teaching English}

There is need also for more specialised courses for those who intend to take posts in training institutions, and for teachers in service in the Colonies who wish to improve their qualifications in this respect. We understand that the practice of sending experienced teachers from the Colonies to Great Britain for studies of this kind has already begun, and we hope it may be extended. Some facilities for such studies are already provided at the University of London Institute of Education. We hope that they will be further developed and that if necessary further provision will be made at other centres. In all such arrangements it is desirable that those who have charge of specifically pedagogic studies and training should maintain close contact with studies of the linguistic problems of the various areas such as are now proceeding at the School of Oriental and African Studies.

It will be imposible, however, and undesirable, to train in this country a sufficient number of teachers to meet all the needs of the Colonies. Provision must be marle in training centres in the Colonies also. Here the university departments of education will have an important function to discharge and they will need to be staffed accordingly. 
In estimating the extent of the need it is well to remember that the desire to learn English is keen and widespread, practically everywhere among Colonial peoples. Indeed it is so strong that there is a danger that the earlier stages of education, important as they are, may be impaired by a premature introduction of English. It will be for the proper authority of any particular area to determine the point in the school course when the teaching of English as a subject of instruction should begin. There is little doubt that in many areas this point will come well before the end of the primary school course. For this, if for no other reason, the provision of training courses in the teaching of English cannot be confined to secondary teachers only, though it is upon them that the heaviest responsibility will fall. The fact that primary teachers also will need competent training affords some index of the extent of the need to be met.

We may note that the foregoing considerations are not without some application to the teaching of English as a mother-tongue in areas where the current English is debased and corrupted. In such circumstances standard English will itself have something of the character of a foreign language.

\section{The study of well established vernacular languages}

In some of the areas with which we are concerned, the mother-tongue of students will be a well established language with a long history, assured standards and a wealth of literature. In some cases it may be the medium of at least part of the instruction. There should be mo difficulty in such instances in planning suitable courses of university study leading, it may be, even to an honours degree. In such cases the institution of courses would not have to await the results of research and the production of literature. It will not for instance be so needed, as in the cases to which we subsequently refer, for settling questions of grammar and orthography. Nevertheless, research will have an important bearing on the course of instruction; it would in particular be valuable if it took the form of comparative study of the mother-tongue and English.

\section{The study of other vernacular languages}

There will, however, be other areas, such as most parts of Africa, in which the mother-tongue of students is not a well established language; often, indeed, the spoken language will not yet have taken, or will only just have begun to take a literary form. In such cases it is clear that the mothertongue of the student cannot at present serve as the medium of any part of the instruction given in the university, nor can it suitably form any part of a course of university instruction leading to a degree. But we do not for this reason regard such vernacular languages as lying outside the range of matters in which the university should interest itself. Even though a vernacular, at its present stage of development, may not form a suitable subject for a degree course, the study of his mother-tongue may, nevertheless, be an important factor in the earlier education of the student. We have been impressed by the evidence of certain of our witnesses who gave reasons for believing that the study of English as a foreign language is much facilitated if the pupil also makes some study of the phonetic and linguistic forms of his own mother-tongue. Conversely the study of English may have the effect of stimulating interest in a study of the vernacular. The Advisory Committee's report already referned to states:-

"The study of African languages has had the effect of increasing the African's appreciation of, and respect for, his own language. The introduction of African languages into the School Certificate syllabus has been a real incentive to the use and study of the vernacular the effect of which 
must not be underestimated. It may seem fanciful but it may also be true that the appreciation of their own language has developed as a result of the increasing study of English. Africans, it may be, only discover the possibilities of their own language as literature when they have come to appreciate the richness of English."

It would appear that the possibility of comparison thus opened up between the language forms and also between the thought forms underlying them is calclulated to illuminate the whole study. Comparative treatment thus assists the growth of a language consciousness, and it is desirable that such a consciousness should be developed so far as is possible from a study of the vernacular itself. For this reason we are glad to note that encouragement is given to such study by the provision made by certain of the Schools Examining Boards under which a vernacular language may be offered as a subject for School Certificate examinations. We understand that the list of languages which may thus be offered is now to be extended. Such a policy tends to increase respect for and interest in the native languages among those who speak them; but it will also facilitate the study of a second language in the way we have suggested.

\section{The function of the university in regard to the study of vernacular languages}

It has been necessary to make some reference to these considerations in order that we may indicate more clearly the functions of a Colonial university in this field of study. We are thinking particularly of cases where the mothertongue is not the medium of instruction in the university. We take the function of the university to be threefold:-

(a) to co-operate in linguistic researches; this duty is of particular importance in African areas.

(b) To assist the work of the schools in the study of the vernacular, by providing material, by offering guidance in the organisation of courses, and directly or indirectly by training teachers in the use of sound methods.

(c) In cases where it is decided that study in the vernacular and allied languages should become part of the university curriculum suitable arrangements should be made for systematic courses.

\section{Linguistic research in Colonial universities}

The extent and nature of the provision which can be made for linguistic research will vary from one area to another. Where a university is already in existence the problem will be mainly one of defining the field of study and securing command of the necessary resources. Where the stage of full university status has not yet been reached, the urgency of the need is such, particularly in Africa, that specific provision should be made in some suitable form without delay.

In Africa, the very possibility of providing suitable undergraduate courses of study in the vernacular at some future stage of its development, and even indeed of providing courses in the schools, must still wait upon the results of research. The profusion of languages in Africa (as many as 700 we are told) ; the fact that many of them have not yet been systematically studied ; the problems of orthography and phonetics which arise; all these conditions will have to be faced before satisfactory courses of teaching can be worked out. And even when that has been done there will still be for a long time a great deficiency of literature for use in the schools and colleges. We are encouraged by the knowledge that the School of Oriental and African Studies in London has long been working at these problems. It is endeavouring to work out standard courses of study for students and is at the same time 
dealing with the problem of selecting or adapting a language which for literary purposes can be understood and used by all who speak languages to which it is closely akin.

But while everything possible should be done in this country to support major studies of this kind, they will fail of their effect unless they are supported by corresponding studies in the areas concerned. We urge, therefore, that in the organisation of the department of social science referred to in chapter IV there should be included a number of research posts in linguistic study, the holders of which should be free to devote their main energies to their immediate task. Their work might with advantage be put in hand during the earliest stages of the development of a Colonial university institution.

The governing conslaeration in this matter is that in the circumstances we are now contemplating it is highly important that linguistic researches should be pursued in close association with anthropological and sociological studies. In support of this view an opinion expressed by the witness previously referred to is worth quoting.

"You are likely to have more trouble if you have people who are using as their medium of speech a language which does mot lend itself to their thinking, and you will have arising in Africa a form of English which the African would call English, but when the used it he would mean something different from what we do when we use the same words ... The African. because of his different thought-forms, even when he uses English, does not necessarily mean the same thing as we mean. The only way for him at present to overcome the difficulty is to be able to study his own language and become conscious of the fact that the thought-forms he is using are different. If I may give a purely technical illustration of what I mean: he has been taught now for some time that his language has adverbs and prepositions. Our recent studies of Bantu have shown that there are no adverbs or prepositions in Bantu languages. If the African realises that, then he will know that in the handling of English he has something completely different to manipulate and it will be easier for him to speak correctly in the English he does speak than it would be if he were introduced to it as the only language suitable for him to use and an attempt were made to correlate English with his own language without showing him that they are really quite different things."

We appreciate the force of this contention, recognising that the difficulty to which it refers is all the greater by reason of the remoteness of African students from the forms of social experience of which the English language is the reflection. We note also that it carries important implications. It means that the scope of a department of linguistic research must be wide and that it will need to maintain close contact with those who are teaching or studying modern languages.

One of our colleagues, Sir Richard Livingstone, asks us to add, "I dissent with regret from one item in this chapter-the proposal to encourage the survival of native languages of Africa. This seems to me to need thorough examination from the point of view not only of its immediate but its ultimate effect. There are grave objections to keeping these languages alive, especially as they have no literature to justify it. Their survival must be a dividing force between the different peoples of Africa and in the future an encouragement and support to various nationalisms. The world would not have gained if the pre-Roman languages of Spain and Gaul had survived instead of giving place to a great common tongue." 


\section{PART III}

\section{CHAPTER XXI \\ UNIVERSITY EDUCATION IN THE WEST INDIES \\ I. The report of the West Indies Committee}

In the foregoing chapters we have enunciated the principles which in our opinion are fundamental in the development of higher education in the Colonial Empire. But as we have already indicated, we have not assumed that these general principles will be capable of universal application. We recognise that modifications may be necessary in particular cases to accommodate the varying circumstances encountered in different sections of the Colonial field. It is possible for us now to test the application of these general principles to a definite Colonial area, and for this purpose we give in some detail a summary of the findings of the Committee which has reported on the provision of university education in the West Indies. We have already explained in chapter I of our report the circumstances in which this Committee was appointed, and have expressed our great appreciation of the manner in which it conducted its investigation.

At the date on which the Committee left this country our own deliberations as a Commission had not proceeded far enough to justify the formulation of comprehensive general principles and, in consequence, it was necessary for the Committee to exercise considerable latitude in the conduct of its enquiry. It was the primary duty of the Committee to examine the educational needs of a particular area, to recommend action appropriate to the geographical, social, racial and economic factors forming the background to the educational problems confronting it. Its approach to these problems was essentially practical and, in considerable measure, the educational survey of the West Indies was carried out as an independent investigation.

In these circumstances it is particularly gratifying to us to find that the detailed scheme recommended by the Committee for the establishment of a University of the West Indies is consistent with our own findings and contains no important element at variance with the fundamental principles we have formulated. We have no hesitation in giving support to the recommendations which the Committee has made. There is, however, one point, namely, the provision to be made for training in medicine, on which some members of the Commission who did not form part of the West Indies Committee find it necessary to reserve an opinion, in the circumstances to which we shall refer more fully in the concluding section of this chapter. As will appear there, our hesitation is not due to any difference on a question of principle, but to the fact that circumstances have subsequently arisen which seem to some of us to require further consideration before it is possible to arrive at a final recommendation.

\section{A summary of the report of the Committee}

\section{(a) Proposal for the early creation of a university}

The Committee considered that the evidence forthcoming justified a firm recommendation that a university should be provided in the West Indies at the earliest possible date. Indeed, throughout its report repeated emphasis is laid on the necessity for swift action: Good intellectual material is available in the West Indies, and the work of the secondary schools attains a high standard, but only a small proportion of the pupils from these schools can hope to obtain a university education. Under existing conditions, the opportunity for further study must be sought overseas and, in consequence, is limited to the selectod few. 
The Committee draws attention to the fact that in each of the Colonies of the West Indies there is a body of public opnion which holds enlightened views on the ultimate purpose of university education; despite years of discouragement, these small groups have not ceased to hope and even to plan for the realisation of schemes designed to promote access to advantages which are recognised as more than material. Attention is also directed to the expansion of the franchise and other legislative changes which have lately been carried out or are now in contemplation in the West Indies. The Committee emphasises the desirability of preparing for these advances by raising the general level of higher education and thereby adding to the intellectual equipment of those on whom the responsibility of leadership will increasingly rest. These factors, taken in conjunction with the need to educate a steady succession of West Indian students for professional life in the West Indies, combine to make the argument in favour of immediate university development exceptionally strong. There were not wanting some critics who, at first, opposed the idea that a university in the West Indies is necessary, but their objections were generally founded either on the fear that the special advantage of education overseas would thereby be lost to West Indians or that a university might fail to obtain recognition by other universities of the Empire through lack of staff and equipment of the necessary quality. For the most part, these objections were withdrawn when it was explained that the scheme envisaged by the Committee was based on the provision of teaching and administrative staff of the first rank, and that the opportunities for study overseas, in place of being curtailed, would in fact be increased.

\section{(b) A unitary university recommended}

It is of first importance to note that the Committee recommends the establishment of a unified university and rejects the alternative of federated colleges being set up in the different Colonies to function as constituents of a degree-granting university. This decision is emphatic. Bearing in mind the existence of a considerable measure of inter-island rivalry, the Committee took pains to discuss in each of the Colonies visited the advantages and disadvantages of the alternative schemes. This frank exchange of views had a considerable effect in modifying public opinion in favour of a unified university, it being recognised that only in this way could a university in the fullest sense and of the first rank be possible.

The Committee recommends that the University of the West Indles should not come into existence immedately as a fully-chartered autonomous institution. Time will be needed to establish the standards of teaching and the performance in research required to win recognition both locally and throughout the Empire; equally, time will be necessary for the governing bodies to gain experience in the complex problems of academic administration. For these reasons the Committee recommends that in the first instance the new institution should be given the status of a university college which will prepare its students for the degrees of London University. The hope is expressed that this formative period will not be prolonged beyond the minimum time necessary to establish the reputation of the University College as a centre of teaching and research.

\section{(c) The scheme of government proposed}

The scheme of government proposed for the University College has, in consequence, been framed on lines identical with those which apply to a chartered university. Two main governing bodies are recommended, namelv:

(i) a Council, charged with the management of finance and with the trusteeship of funds and properties, and 
(ii) a Senate, which would carry full responsibility in all academic matters, including teaching, research and discipline.

In addition, it is recommended that a Guild of Graduates be instituted on lines detailed in the report.

It is proposed that the Council, the supreme governing body, should consist of twenty-seven members, of whom seven would be nominated by the Governments of the contributing Colonies. The remaining members would hold office either ex officio (seven), or by election, the electing bodies being the Senate (seven) and the Guild of Graduates (four). The remaining two members would be provided by the Inter-University Council in Great Britain.

The proposed composition of the Council of the College provides for welldistributed territorial representation, and is designed to secure a suitable amalgamation of interests and experience, the proportion of academic and non-academic members having been adjusted with this end in view. In making these recommendations the Committee had in mind the necessity to avoid the creation of a university governed by the State or subject to political control.

The composition proposed for the Senate and for the Faculties follows normal lines, but deviates in some respects from the standard pattern. These variations, which take the form of broadening the representation on these bodies, are designed to have the effect of stimulating the interest of the entire staff in discharging the responsible duties devolved on the Senate. Particularly in a young university, it is important to create the feeling that each member of the staff plays some part in the development of the new institution of which he or she is a member.

With regard to the making of university appointments, the report prescribes special measures necessary to fill the first appointments, as these will have to be made before the Council comes into existence. Thereafter the responsibility will rest on the Council, with the proviso that the election to all teaching posts will be made only on the recommendation of the Senate. This procedure is regarded as specially desirable in founding a university in an area where academic standards have to be created.

\section{(d) Other characteristic features of the University}

The University should be open to women on precisely the same terms and conditions as are applicable to men. Similarly, no restriction should be imposed on grounds of race or creed; although the University would be undenominational, the Committee leaves the way open for local effort to take steps to supply the spiritual needs of the students.

It is recommended as essential that the University should be entirely residential and that the normal period of residence should be three years. In coming to this decision the Committee had in mind more than the comfort and physical well-being of the students. The halls of residence will not be merely dormitories in which students eat and sleep, but will carry features resembling those of residential colleges. The halls are designed to be centres of study where the work of the teaching departments will be consolidated and expanded. Under these conditions, the mingling of students, drawn from different Colonies and with widely different intellectual interests, should inevitably create a more fully educated type of young man and woman than the class-rooms alone can produce. It may also be expected that an indirect result of residential life will be the promotion of a spirit of co-operation between West Indians from different areas and that this will find its outlet in a desire to serve the West Indies when university days are done. 
With regard to the size of the University, the Committee recommends that, initially, provision should be made for a student population of 400 to 500 . In arriving at this figure it approached the problem from two opposite directions:-(i) the prospective annual number of pupils leaving school who hold the requisite entrance qualification and who would extend their studies on a university level if facilities were available in the West Indies at moderate cost; and (ii) an estimate of the annual absorption of graduates proceeding from the University who would seek employment within the Caribbean area. The totals provided by the two lines of enquiry were consistent and were confirmed from other sources. So far as can be predicted, therefore, a safe margin will exist between the opportunities for employment and the output of graduates, so that the possibility of " academic unemployment " can be ruled out. In all likelihood student numbers will increase considerably beyond the upper limit of 500 and the Committee's proposals have accordingly been framed to facilitate the future expansion of the University.

\section{(e) The site of the University}

At the conclusion of its tour the Committee was faced with the difficult problem of recommending the locus of the University. The Committee decided that it should be situated in Jamaica. It recognised that the Colony selected as the locus of a centralised university derives certain direct and indirect advantages and that, conversely, the remaining Colonies are confronted with disadvantages in varying degree. Certain compensations are, 'however, recommended in the report. For example, it is urged that for members of the Council, for the staff and for students, the transportation costs incurred in travelling from their homes to the University should be a charge on the University General Fund to which Jamaica, in common with other Colonies, would be a contributor. Of even greater importance is the comprehensive scheme of extra-mural studies which, directed from the central University, will operate in each of the Colonies. In short, an endeavour has been made to overcome the handicaps imposed by geographical separation. The Committee has sought to produce a scheme not for a University of Jamaica but for a University of the West Indies serving the entire Caribbean area.

\section{(f) The course of studies to be provided}

In any attempt to fill educational lacunae there is a natural tendency to attenuate both means and effort by spreading activities over too wide a field. The Committee has sought to avoid this mistake, and the teaching curriculum proposed initially for the new University is limited to the Faculties of arts, science and medicine. Future developments, and, if necessary, the creation of additional Faculties, are left to the Council and Senate who can best judge what lines of expansion are desirable. The subjects to be taught in the University have been chosen with special reference to West Indian conditions and should offer a sufficient variety to meet widely varying needs.

In its endeavour to provide a broad cultural education the Committee has drawn on the experience of the older universities of Great Britain and many of the subjects of study prescribed are identical with those taught in this country. Nevertheless, the Committee recommends that the training should not lose contact with West Indian conditions and requirements. Its intention in this respect is illustrated by the introduction of a Lectureship in West Indian history, by the scheme for a degree in modern languages (including Spanish and Portuguese) and by the emphasis laid on what may be described as local research. In many other subjects, as, for example, economics, geography, geology and the biological sciences, ample opportunity will be available for supplementing these studies by special reference to the West Indies. 
The Committee does not propose at this stage to establish schools of agriculture or of engineering; but provision is made for education leading to graduation in these important branches of applied science. The proposal is that students specialising in agriculture should take the previous degree of B.Sc. in the University of the West Indies and thereafter proceed to Great Britain or extend their studies at the Impcrial College of Tropical Agriculure in Trinidad. The Committee considers that the policy of utilising facilities already existing in the Colonies has much to commend it, particularly as it opens the way to a working association with the Imperial College without infringing the principle of a unified university.

In engineering the problem is similar, and the Committee did not feel justified in recommending the immediate creation of a fully-equipped school of engineering. In the absence of any engineering college in the West Indies comparable with the Imperial College of Tropical Agriculture, the Committee felt that it had no option but to advise that students of engineering should complete their science degree in the West Indies and then proceed to Great Britain for two years of specialised study.

The Committee's proposal to institute a department of education in the University is of much importance. As already stated, secondary schools in the West Indies are generally efficient and their record is praiseworthy, but in the educational system of these Colonies there is at present no provision for organised training so far as teaching in secondary schools is concerned. The Committee considers that this situation can be rectified by instituting a University diploma in education to be taken at the postgraduate stage. The department of education would also be responsible for continuous research on the special educational problems encountered within the university province, a field of enquiry too often neglected.

The Committee found the problem of training in medicine at a University of the West Indies to be at once simple in its long-term achievement, but beset with difficulties as regards the immediate future. In conformity with the policy of a unified university, the Committee recommends the establishment of a complete Faculty of medicine to be located at the seat of the University in Jamaica and working in association with the Kingston General Hospital. Obviously this recommendation could become operative only when the complete university scheme came into existence. But the situation in the West Indies in respect of the supply of medical officers and private practitioners does not admit of any delay in providing trained medical graduates. The need is urgent. The opportunities for West Indians to obtain a medical education in Great Britain or in the Dominions are shrinking and are unlikely to improve; to ignore the seriousness of the situation is unwarrantable. Confronted with this emergency, the Committee investigated the possibility of providing a medical course in the West Indies which could be brought into existence at an early date and would function as an emergency measure until the University comes into full operation. The Committee found that this aspect of its problem had already been studied and proposals made for its solution by Sir Rupert Briercliffe, Medical Adviser to the Comptroller for Development and Welfare. The scheme put forward by him involves the establishment of a temporary medical school in Trinidad working in association with McGill University, Montreal. Subject to certain minor modifications the Committee recommends the adoption of Sir Rupert Briercliffe's scheme as an emergency measure, without infringement of the condition that, on a permanent basis, the teaching of medicine must be conducted within the unified University. 
Reference has already been made to the scheme of extra-mural studies by which the Committee hopes to give practical effect to their desire " to carry the University to the people." It was not its intention to increase facilities for the taking of external degrees but rather to diffuse learning and to foster cultural studies throughout the whole of the Caribbean Colonies. The Committee is of opinion that in many respects the scheme of extra-mural studies is as important to the West Indies as the graduating courses to be provided within the University. It does not under-estimate the difficulties which will be encountered, but holds that this experiment in extra-mural education over a widely-dispersed area should certainly be tried.

In the course of its investigation the Committee was impressed with the need in the West Indies for improved facilities in technical training of all kinds. Plans are, however, under consideration by the Comptroller of Development and Welfare for supplying these needs and the Committee expresses the hope that the execution of these plans will not be delayed in consequence of the proposal now submitted for the establishment of a university. This support applics equally to other projects, also under consideration by the Comptroller and his advisers, for enlarging the experience and adding to the training of primary school teachers. In the opinion of the Committee, the creation of a university should not be regarded as in any sense competitive with or alternative to the plans being matured under the scheme of development and welfare

\section{(g) The staffing of the University}

It is emphasised repeatedly in the Committee's report that the University of the West Indies must be equipped and staffed in a way which would be recognised in Great Britain as conforming to a high standard. To attempt to economise in either of these respects would be fatal to the success of a great educational experiment. In the West Indies there is a small but responsible section of public opinion well aware of what is necessary to create a university capable of winning its way to a reputable place in the academies of the world, and to attempt anything less than the best is to court disaster. The Committee has drawn up approximate estimates of capital costs and recurring expenditure so that some idea may be given of the financial dimensions of the problem. In framing this tentative budget the Committee took into corrsideration the number of staff required and also the stipends which should be attached to the various offices if men and women of the first quality are to be attracted.

\section{(h) Research}

The Committee gives prominence to the position of research in the activities of the proposed University. The question of how far applied research should find a place is fully discussed; the Committee's hope is that fundamental, disinterested investigation should be the main feature of research activity. At the same time it is recommended that the University should not stand aloof from enquiries designed to benefit the West Indies, although applied research of this description should not be assigned to young graduates before they have undergone the discipline of training in pure research. In all branches of enquiry, humanistic and scientific, the Committee's intention is that, where possible, original work should focus on problems which can best be investigated in the West Indies or are of special importance to that region. The Committee also contemplates that not only will members of the University staff engage personally in original work but that in time they will be joined by some of their own students and graduates so that schools of research will come into existence. 
The Committee has not ignored the fact that research costs money-in the provision and equipment of laboratories and libraries, in the purchase of books and periodicals, and in the employment of a larger staff than teaching requirements or the number of students would appear to justify. The financial estimates make adequate allowance for these factors.

\section{(i) Financial assistance to students}

The Committee, although engaged on a wide survey, has not overlooked the needs of the individual student. His work will be supervised: friendly guidance and advice will be at his disposal should he find himself in difficulties related to his studies or of a personal nature. It is also recognised that many, and possibly the majorify of West Indian students will require financial assistance to attend the University. In attacking this problem, the Committee has evolved a scheme of scholarships and grants to be administered by the University from University funds, and advocates that the existing scholarships financed by the individual Governments for overseas study should be modified as'to the conditions of tenure. It is unged that greater benefit to the student will result if his period of overseas study is delayed until after graduation in the University of the West Indies. The financial estimates prepared by the Committee would seem to show that a student could spend the necessary three years at the University of the West Indies and thereafter have the advantage of two further years abroad at a total cost no greater than the scholarship stipend now paid for overseas study alone. It may not be easy to persuade the various Governments to modify scholarship schemes which have admittedly been successful in the past. But the situation would be entirely altered by the foundation of a University of the West Indies.

The Committee also advocates reform of the methods adopted in making scholarship awards. It holds that the use of School Certificate results as a test of outstanding ability or of fitness to profit from University study is now largely discredited, and it advocates a more effective method of selection. This includes scrutiny of the complete school records of the candidates supplemented by an examination, including an interview, conducted by the University authorities.

\section{(j) Estimates of expenditure involved}

As already stated, the Committee has provided an approximate estimate of the capital and recurring costs necessary to establish and maintain a University on the scale and on the lines envisaged in its report. The estimates refer to the time when the University College is in full working operation and it is unlikely that they will require material alteration when the College is transformed into a University. Obviously, in the formative years, both income and expenditure will differ greatly from the figures quoted.

\section{Capital Cost}

It is recommended:-

(a) that if the University is located in Jamaica, the Government of Jamaica should meet the cost of the site, approximately I50 to 200 acres;

(b) that the cost of buildings and equipment necessary to establish the University on the lines indicated should be met by the home Government, future changes under this heading to be met by the Colonial Governments concerned;

(c) that the University should be provided with an endowment fund, the income from which would be applied to the support of specified professorships and to the promotion of research. Should the provision of a capital endowment be considered inadvisable, the income equivalent could be paid in the form of a grant from the home Government. 
The estimated capital cost is $£ I, I 30,000$, or including a provision of $£ 500,000$ for endowment, $£ x, 630,000$.

\section{Recurring Expenditure}

The income of the University, apart from that referred to in $(c)$ above, would be derived from fees and from contributions from the Colonial Governments. It is estimated that $\{68,390$ per annum will require to be met by the Colonial Governments in proportions to be determined by mutual agreement. It should be noted that this contribution from the Colonies concerned is less than 5o per cent. of the total annual expenditure. It is recommended that these Governments should pay their contributions into the University General Fund without ear-marking in favour of special purposes. Further, such grants should be guaranteed for a period of five years and should be revised only at quinquennial periods, following the precedent. of the Treasury grants made through the University Grants Committee to the universities of the United Kingdom.

While the draft budget has been framed to provide a university of the first rank, the Committee has taken all steps in its power to avoid extravagance. All predictable items have been checked by reference to the cost of other institutions of similar size, with such modifications as seemed necessary in view of the level of costs in the West Indies. Moreover, the budget has been framed to minimise the cost to the student and to his parents. As already explained, travelling charges to and from the University will be met from University funds, while the remaining cost for tuition and maintenance will be of the order of Eroo per annum. This figure was selected by the Committee in exercise of the principle that the benefits of the University should be spread as widely as possible.

In their present form, the estimates forecast an annual expenditure of f. 539,690 , defrayed as under:-

(a) From tuition, examination and residence fees and from rentals $\quad \ldots \quad \ldots \quad \ldots$

(b) From endowment income or equivalent

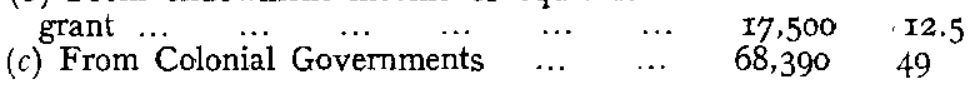

The Committee considers that the only major item in which alteration may subsequently be found necessary relates to the salaries to be attached to the various teaching posts. To take an example, the total for eight professorships corresponds with an average salary of $€ I, 500$ per annum. It may reasonably be predicted that, initially, the great majority of these senior posts will be filled by men and women from Great Britain or the Dominions, and the stipend suggested is no more than sufficient to induce experienced university officers of recognised standing to proceed overseas. But the figures should not be regarded as stabilised or as applicable to all future appointments. The necessity to recruit staff from overseas will, however, continue in some measure for a considerable period, and this fact carries in its train the necessity to pay certain stipends at least at overseas rates. One method-and it is perhaps the simplest-of dealing with this situation would be to fix a basic salary for each grade of post and fall back on the system of supplementary overseas allowances. But any differentiation in total stipend in respect of migration from overseas would be unwelcome to the West Indian members of the Committee, as is shown by their foot-note to paragraph 182 
of the report. An alternative has been suggested by Miss Perham in her own footnote to that paragraph; under this scheme the home Government would set aside part of its endowment in such a way that the revenue from it could be applied as expatriation allowances upon settled scales to staff drawn from overseas.

\section{(k) The procedure adopted by the Committee}

In the course of its enquiries, the Committee took evidence from a considerable number of witnesses, both official and non-official. For the most part, the witnesses provided memoranda of value, but there remained other sections of public opinion to which access could be obtained only by personal approach on the part of the Committee. All evidence and interviews were regarded as confidential and neither the press nor the public were admitted to the hearings; but this does not mean that, within the limitations attending any official enquiry of the kind, the public was not taken into the Committee's confidence. At intervals, brief statements were issued to the press which outlined, in general terms and without disclosing the findings, the progress made in the investigation and corrected uninformed speculative criticisms. Throughout the enquiry the press gave much constructive help especially in leading articles marked by appreciation and understanding.

At the close of the tour, an outline of the prospective recommendations was submitted confidentially and informally to three of the Legislatures, with the object of inviting criticism and of providing an idea of the cost to the contributing Colonies. These meetings proved most helpful; they revealed a width of vision which justifies the expectation that the findings of the Committee will be acceptable in the West Indies and if put into operation without delay will receive loyal and generous support.

\section{The view of the Commission reganding the proposals for medical training}

It has been indicated in the furst section of this chapter that while the Commission readily endorses all the other recommendations in the Committee's report, there is one point which, in the opinion of a number of us, will need some further examination. The Committee's proposals for the provision of medical education in the West Indies are outlined in part $(f)$ of the summary above. They were designed to meet the very urgent need for the provision of doctors qualified to practise in the West Indies. The scheme for the institution of a complete Faculty of medicine in the University of the West Indies could not, it was clear, become effective for some years; the Committee found that certain buildings at Port of Spain, Trinidad, which had been erected by the United States Army authorities, might become available for the purpose of a medical school; and the offer made by McGill University, Montreal, to staff the school and prepare its students for the medical degree of that University was accordingly welcomed by the Committee not only as opportune, but also as presenting in other ways a very satisfactory solution of the problem. We desire here to express our own appreciation of the spirit in which the University offered to the Committee its ready co-operation in this matter.

This proposal came to our notice during the final stage of our discussion with London University regarding the scheme outlined in chapter IX of our report, under which London University would provide assistance to the Colonial colleges in solving some of the problems incidental to the earlier stage of their development. We are convinced of the great value of that association. In the circumstances we thought it our duty to enquire whether London University could extend its co-operation by providing assistance to the proposed medical school at Trinidad and thus make it possible to bring the system for the award of medical degrees into line with that recommended 
for subjects in the faculties of arts and science. The reply received shows that the University is prepared to render this assistance and it has drawn attention to the connection already existing between the West Indies and the University particularly through the number of students who have come to London for training in the medical schools. There is however one difficulty which has not yet been fully investigated. It would appear that to associate the temporary medical school in Trinidad with London University would involve greater delay than would be the case if the attachment were to McGill University.

We are unwilling to delay the submission of our report until such information is forthcoming as would enable us to determine the period which might elapse before London University could, if it were decided to accept its offer, provide the necessary courses for the medical school at Trinidad. There are a number of considerations which must be taken into account in assessing the relative advantages of the association of MoGill University or alternatively of London University with the temporary medical school. But such considerations must be wcighed in the light of the fact that we are here dealing only with the needs of the interim period before the University of the West Indies can establish its own Faculty of medicine. The most important consideration is in our opinion time; the possibility in short, of a start being made in the course of this year, or at least not later than the summer of 1946 . We regret that we are compelled to leave the matter at this stage; but it would be undesirable that the further exploration of this particular point should postpone consideration of the many important proposals, affecting not only the West Indies but also other areas, which we have to commend to the attention of the Government.

Those of our members who formed part of the West Indies Committee wish to record that having considered the preliminary proposals put forward by the University of London, they are strongly of the opinion that in view of the grave and urgent need of the West Indies for medical practitioners, the plan drawn up with McGill University and with Sir Rupert Briercliffe should be put into operation forthwith.

\section{PART IV}

\section{SUMMARY OF THE RECOMMENDATIONS OF THE COMMISSION}

We preface this summary of our recommendations by referring to what has been said in section 5 of chapter I regarding the dual nature of the task undertaken by the Commission. There are in the Colonial Empire four institutions of full university status which as such are autonomous. The main body of the recommendations made by the Commission deals with the creation of universities or university colleges in areas not served by the existing universities. The Commission however expresses the hope that the detailed suggestions or recommendations put forward may in some cases be of interest also to the present Colonial universities.

In the same chapter the Commission, while not able to make specific recornmendations regarding the association of the universities of the Dominions and India with the Colonial institutions, nevertheless expresses the hope that these universities will join with those in this country in entering into effective relationships with the institutions of higher education in the Colonies. 


\section{Chapter III.-Place of universities and university colleges in the development \\ of bigher education} SECTION I

In the interests of higher education in the Colonies, it is essential that universities should be established at as early a date as possible in those areas which are not now served by an existing university. The immediate objective is to produce men and women who have the standards of public service and capacity for leadership which the progress of self-government demands, and to assist in satisfying the need for pcrsons with the professional qualifications required for the economic and social development of the Colonies.

SECTION 2

Among the vocational subjects for which facilities should be provided by a university, the training of teachers for secondary schools must take a high place.

\section{SECTION 3}

The first step towards the establishment of universities is the creation of university colleges; this should be undertaken immediately.

\section{SECTION 4}

The specific enquiries made regarding the West Indies and West Africa indicate the need for the early establishment of university colleges in these regions. The Commission supports the proposals made in I939 for the early establishment of a university in Malaya, and it also supports the proposal to develop Makerere College in East Africa to university status.

In determining the appropriate area which a university should serve, the test should not be the size of the population, but the capacity of the area to produce an adequate flow of students able to profit from higher education. The unitary type of university is to be preferred to that based on a system of federation.

\section{SECTION I}

\section{Chapter IV.-Academic life and range of studies}

A university will not fulfil its purpose unless it makes provision for a fairly wide range of subjects; it should be at the same time a centre for the study of subjects in the Faculties of arts and science, and for instruction in professional subjects. There should be a balance between the two: while the production of an educated or semi-educated class divorced from the community as a whole and unlikely to secure employment in it would be disastrous, concentration on professional training would be almost equally regrettable. It is suggested that as a minimum, facilities should be provided for some subjects in the Faculty of arts, for some in the Faculty of science, and for one or more professional subjects.

It is of equal importance that facilities should exist for research.

\section{SECTION 2}

The universities should be entirely residential, and open to men and women of all classes.

\section{SECTION 3}

In the Faculty of arts, English language and literature must have a special place, and there should be provision for the teaching of at least one European language other than English; in some areas the study of languages appropriate to the region is desirable. History, geography and the social sciences should be included at all university institutions; in arranging the syllabuses for these courses attention must wherever possible be paid to local conditions. There should be provision for the teaching of philosophy. 


\section{SECTION 4}

The Faculty of science should comprise departments of mathematics, physics, chemistry, botany and zoology; in some cases a department of geology may be needed.

\section{SECTIONS 5, 6}

The Faculties of arts and science should be fully staffed; where there is a professor there should be one or more lecturers. Fully equipped libraries and laboratories are essential.

Expert advice should be obtained in the siting and planning of buildings. SECTION 7

Universities should take a part in adult education by the organisation of extra-mural activities. These activities would at the same time assist to extend the infuence of the university, and make a contribution to the development of the community as a whole.

\section{SECTION I}

\section{Chapter V.-The staffing of universities}

The successful building up of the Colonial institutions will depend firstly, on the provision of a staff adequate in numbers and experience, and secondly, on creating conditions in which its members can maintain contact with intellectual and academic life in the outside world.

\section{SECTION 2}

The practice should be discontinued under which instruction in certain professional subjects is given by officers of government departments seconded for part time or full time duty.

\section{SECTION 3}

It is essential that the home universities should take an active interest in the enlistment of staff from overseas. The salaries attached to appointments in the Colonial institutions should not be related to those of different government departments in the Colony but to those of the academic staff in home universities. Conditions regarding pensionary or similar rights should not be such as to present an obstacle to the subsequent appointment of members of the staffs of Colonial institutions to academic posts at home or the appointment of members of home university staffs to serve in the Colonies. There should be liberal provision of leave and of opportunities for study leave.

\section{SECTION 4}

It is necessary to contemplate differential rates of remuneration for the staff recruited from overseas and that recruited locally. The difference between the two scales of remuneration might be met by the payment to the overseas staff of a supplement from a special fund provided by the Government of the United Kingdom.

\section{SECTION 5}

Part of the staff of the Colonial institutions should be provided by secondment to them of members of the academic staffs of home universities. These might be of varying seniority; but they should be guaranteed a reasonable prospect of return without loss of seniority to their home university.

\section{SECTION 6}

To facilitate the progressive recruitment of the academic staff from the Colonies themselves, local graduates of promise should be afforded experience as demonstrators or research assistants and should then be given the opporrunity of postgraduate study in Great Britain. 
SECTION I

Chapter VI.-The place of research

Research is an essential part of the life of a university. This must be recognised not only in planning the strength of the staff required by the university, but by providing time and facilities for research or original study.

SECTION 2

The research proper to a university is of a fundamental type, and utilitarian results should not be demanded from the research activities of members of the university staff. The Colonies present many special problems, both in the natural and social sciences, in which research of a fundamental type can be suitably and profitably undertaken by members of the academic staff.

\section{SECTION 3}

As regards research in the applied sciences, the chief contribution of the universities should be the training of graduates who are fitted to become research workers and to find a career in applying their scientific knowledge to practical problems.

SECTION 4

At the same time, workers in the field of applied sciences can benefit from close association with an academic staff, and institutes or organisations for investigation or research in these sciences should wherever possible be situated near a university.

\section{Chapter VII.-An Inter-University Council for Higher Education in the Colonies}

\section{SECTION I}

The development of the new Colonial institutions will depend largely on the active interest and co-operation of the home universities. This can best be secured through the creation of an Inter-University Council for Higher Education in the Colonies.

\section{SECTION 2}

The Council should be representative of all the home universities; it might co-opt representatives of certain university colleges and institutions of comparable status in Great Britain; each Colonial university or university college should be also invited to nominate a member.

\section{SECTION 3}

The Council would keep in touch with the development of the new Colonial institutions through regular visits of its members to them. Its services would be available in assisting them to engage staff from overseas; in helping to arrange for the secondment to them of members of home academic staffs; in approaching specialists in different branches of study or of knowledge, whom they might invite to visit them; and in rendering advice on any matter of academic policy on which its help was sought by a Colonial institution.

The services which the Inter-University Council can render to the new Colonial institutions should be equally available to such of the existing Colonial universities as may desire to avail themselves of them.

\section{SECTION 4}

It would be in a position to advise an intending student from the Colonies as to the institution in this country best fitted for his proposed studies and able to accommodate him. 


\section{SECTION 5}

It would finally be available for rendering advice to the Secretary of State on the academic aspect of any scheme for which financial aid is sought from this country.

\section{Chapter VIII.--The governing authority of Colonial universities and colleges}

\section{SECTION I}

Colonial universities should be autonomous in the same sense as universities in this country.

\section{SECTIONS 2 AND 3}

Following the precedent of most of the newer universities in this country, a Colonial university should have a Senate, which would have authority in purely academic matters, and a Council, which would be the supreme governing body and the trustee of the property of the institution. There should be a Chancellor appointed by the Crown, and a Vice-Chancellor appointed by the Council.

\section{SECTION 4}

The members of the Council of the University should not greatly exceed twenty in number. One-third should be members of the academic staff; up to one-third should be representatives of the Legislatures or Executive Governments of the area served by the university; the remaining places should be divided between representatives of the Inter-University Council, the Guild of Graduates, and nominees of the Chancellor.

\section{SECTION 5}

The Senate should be composed of the professorial staff and heads of departments, together with representatives elected by the non-professorial staff. These should not be more than one-sixth of the total number.

\section{SECTION 7}

The constitution proposed above for a university must be suitably adjusted to the needs of the interim period before a university college arrives at full university status.

\section{Chapter IX.-The period of tmansition from college to full university \\ status}

\section{SECTION I}

The test of a university as a centre of instruction and learning is the extent of the recognition accorded to its degrees in the academic world. But it will take time for the new Colonial institutions to reach a position in which their degrees can command general recognition, and in the initial stages of the growth of these institutions attention must be concentrated on securing for the Colonial graduate a qualification whose significance is clear.

\section{Section 3}

It is recommended therefore that for this interim period the Colonial colleges should enter into a special relationship with London University under which, subject to certain safeguards detailed in the report, their students may be awarded the degrees of that University. The University has agreed to consult with the colleges in order to secure that while the standard of the London degree is maintained, the syllabuses and examination requirements should be adjusted to meet local conditions. 


\section{SECTION 4}

Degree giving powers should be conferred on the Colonial institutions only when the following conditions have been fulfilled. The staff must have had adequate experience of work of a university standard; its conditions of work must have permitted of the active prosecution of research or original work; and a substantial number of students must have completed satisfactorily the courses for degrees in a sufficient variety of academic subjects.

\section{SECTION I}

\section{Chapter X.-Entrance qualifications}

The problem of the selection of students for admission to the Colonial colleges (and later to the universities) is of vital importance.

\section{SECTION 2}

Before being admitted to courses in the Faculties of arts and science (leading in the normal period of three years to the degree) students should have had the opportunity to spend two years in a sixth form at school. It follows that the normal age for transfer from school to college should not be less than $\mathrm{I} 8$.

In those colleges where students will take the degrees of the University of London, the minimum entrance qualifications for the degree course will be determined in the first place by the requirements for matriculating at London. It is hoped that the syllabuses and restrictions as to subjects taken will be adjusted to meet conditions in the Colonies at this stage as well as for the higher examinations.

The possession of the minimum qualifications prescribed should not however constitute any clain of entry to universities or colleges. The latter should settle their own standards of admission, apart from the satisfaction of the minimum requirements; the capacity of students to enter a degree course can best be tested in a college entrance examination.

\section{SECTION 3}

In certain areas, where these conditions may not be capable of fulfilment, it may be necessary to institute preliminary courses at the university college, conducted separately from the normal first year's course, or alternatively courses may be provided terminating in a diploma given by the college. The conditions imposed for entry to diploma courses should be as stringent as circumstances permit.

\section{SECTION 4}

Special provision may have to be made for over-age students, especially those who have spent a period in employment after leaving school.

\section{SECTION I}

\section{Chapter XI.-Scholarships and financial assistance}

The Colonial institutions will doubtless desire to follow the system of granting entrance scholarships as rewards for academic ability. But these will affect only a selected few, and in most areas an unusually large proportion of the students will be unable to undertake higher education without financial assistance.

\section{SECTION 2}

It is essential, therefore, that an adequate fund should be provided from which universities or colleges can assist students seeking entry to them. Such assistance should be related to the financial position of the student. Assistance may also be required in particular cases by students who have already entered upon their courses. 
Financial provision will also be needed to enable an increasing number of Colonial students to pursue their studies in Great Britain or the Dominions; but scholarships given for this purpose should be for postgraduate rather than for undergraduate studies.

\section{SECTION 3}

It is not desirable to encourage the practice under which recipients of scholarships or grants place themselves under a legal obligation to enter government or other service on completing their courses.

\section{Chapter XI1.-Colonial students in this country}

The undergraduate education of Colonial students should wherever practicable be carried on in Colonial institutions. Undergraduate study overseas should, as the colleges develop, be confined mainly to those students who wish to study exceptional subjects for which there is no local provision. The facilities for undertaking postgraduate studies overseas should be extended.

\section{SECTION 3}

\section{Chapter XIII._Finance}

On such estimates as can now be framed, the establishment of a university in the West Indies will involve capital expenditure of approximately $f_{1}, 130,000$ and recurrent expenditure of $£ \mathrm{r} 39,690$; some additional funds will also be required by the Imperial College of Tropical Agriculture at Trinidad.

It is understood that even greater expenditure may be required in respect of West Africa.

Considerable additional funds will be needed by Makerere College in East Africa. Financial assistance in varying degrees may be required in Palestine; by the Royal University of Malta; and in Malaya and Hong Kong.

\section{SECTION 4}

In addition provision must be made for assisting Colonial students to study overseas; these will mainly be postgraduates, but in some subjects also, undergraduates.

\section{SECtION 5}

Funds will be required for the Inter-University Council, and London University must be reimbursed the expenditure incurred in the operation of the special relationship which it will establish with Colonial colleges.

\section{SECTION 6}

The development of higher education in the Colonies must depend on the grant of substantial financial aid from Great Britain.

\section{SECTION 7}

In order to tender advice on the allocation of funds from the home Government, a Colonial University Grants Advisory Committee should be created, on which the Inter-University Council would be represented.

\section{SECTION 8}

It may be desirable that an appropriate part of the funds available under the Colonial Development and Welfare Act should be specially assigned as provision for the establishment of universities in the Colonies. 


\section{SECTION 9}

The orderly development of a university institution depends largely on the stability of its annual income. This can best be secured by a system similar to that followed in Great Britain by which Treasury grants are fixed for a period of five years.

It is also desirable that the Colonial institutions should build up endowment funds. Provision should be made for an annual grant to them which will serve as the basis for such funds.

\section{SECTrONS I AND 2}

\section{Chapter XIV._-Medicine}

To meet the urgent need for the expansion of the existing medical staff and of the ancillary health services in the Colonies, medical schools should be established to serve those Colonial regions which do not now possess them.

\section{SECTION 3}

Early steps should be taken to improve the quality of teaching in existing schools which have not yet received recognition from the General Medical Council in Great Britain.

\section{SECTION 4}

In the Colonial medical schools social and preventive medicine should receive increasing emphasis. While standards must be maintained which will secure recognition of diplomas by the General Medical Council, some elasticity should be allowed in arranging particular teaching and the forms of final examination, in view of the special conditions obtaining in different Colonial regions.

\section{SECTION 5}

Colonial medical schools should be staffed and equipped to a standard comparable ultimately with those in Great Britain; a number of detailed recommendations are made in this regard.

\section{SeCtion 6}

The provision of material facilities, such as laboratories and teaching hospitals, should not fall below standards considered appropriate elsewhere. A number of detailed recommendations are made in this respect also.

It is also important that facilities should be provided for research, though teaching and its sound organisation must be the first consideration.

\section{SECTION 7}

The training of hospital assistants should be carried out in schools distinct from those used for medical students; the course should not approach the medical curriculum either in content or length.

\section{SECTION 8}

The first step to be taken is to secure that the standards of teaching are such that the local medical diploma obtains recognition by the General Medical Council; the final stage will be reached when the centre of which the medical school is a part becomes a university awarding its own degrees. Between the first and second stages arrangements should be made by which the more able students can take the degree of a home or Dominion university. 


\section{SECTION 9}

Until facilities exist in the Colonies for postgraduate education in medicine, provision should be made for selected graduates to undertake postgraduate study at a home or Dominion university, in order to obtain experience in research or teaching methods.

\section{Section Io}

The medical school should become an integral part of a university, and students should participate fully in the university life. The school should be entirely residential.

\section{SECTION II}

Though there should be the closest collaboration between the staffs of the medical schools and the government medical departments, the schools, like other constituent parts of a university or university college, should be as far as practicable free from direct Government control,

\section{SECTION I2}

It is desirable that medical schools should be firmly established before dental schools are created. In the meanwhile a beginning should be made in providing opportunities for dental treatment in the hospitals of the larger towns; for this purpose scholarships available in this country should be awarded to a number of selected students each year who on return to the Colony might form the nucleus of a government dental service.

\section{SECTrON 3}

\section{Chapter XV.-Agriculture}

In regard to agriculture, the function which Colonial universities can discharge is to assist in producing men qualified to apply the principles of scientific agriculture to the circumstances prevailing in the Colonies or to conduct research into the special problems they present. But it is essential that their training should be practical as well as theoretical, and the organisation of a full Faculty of agriculture will not be practicable unless the university has its own farm lands.

\section{SECTION 4}

Where courses in agriculture are given by a university or university college, they should begin with a two years' course in the basic science subjects, followed by one year in agricultural studies of more specialised character, and by two years' practical work. The objective should be to attain a standard both in teaching and research which would, among other things, qualify the local student for admission to the Colonial Agricultural Service.

\section{SECTION I}

\section{Chapter XVI.-Veterinary training}

The provision of men trained in veterinary science and animal husbandry is of exceptional importance to the Colonies.

\section{SECTION 3}

It is desirable that veterinary teaching should be associated with a university rather than that it should be conducted in a separate institution. 


\section{SECTION 4}

The first three years of a veterinary course should be devoted to preliminary science subjects, some of which the veterinary student can share with medical students; but the veterinary student should in his second and third years make contact with field work.

\section{SECTION 5}

Wherever it is possible the university or university college should have its own field station; but where conditions make this impracticable arrangements must be made for clinical training under qualified instructors at a government or other station.

\section{SECTION 6}

Detailed recommendations are made regarding the staff; even if the clinical instruction is given in a government veterinary station, teaching should be given largely by full time members of the university or university college.

\section{SECTION 4}

\section{Chapter XVII.-Law}

In the majority of Colonies the qualification for practising in the Courts is a call to a $\mathrm{Bar}$ in the United Kingdom. Legal education may with advantage form one of the professional subjects for which Colonial universities should provide facilities. But since the present procedure for acquiring a practising qualification must continue for some time, certain recommendations are made regarding the conditions which Colonial students have normally to satisfy in order to be called to the Bar in England.

The requirement of " eating dinners" at an Inn of Court is over-exacting, and it would be a convenience if part I at least of the Bar examination could be passed in absentia, as has been possible during the war.

No recommendation is made regarding a modification of the procedure by which a qualification to practise as solicitor is obtained in Great Britain:

\section{SECTION 5}

When a Colonial university or university college establishes a law school, the collaboration of the judicial authorities should be sought in framing the curriculum and the form of final examination for the degree or diploma. This is necessary in order that the degree may be accepted as satisfying the educational requirements for admission to a local Bar, thus avoiding the imposition of any further educational test.

\section{SECTION 6}

It will be for the judicial authortties to decide what additional requirements, in the nature of practical experience, the Colonial student must satisfy before admission to practise. It is desirable that these should be so framed as not to place Colonial graduates at a disadvantage with persons who have been called to the English Bar.

It will also be for the judicial authorities to advise regarding the numbers to be admitted to the law school, with a view to avoiding the production of a number of graduates in law greatly in excess of the requirements of the community for legal advice.

\section{SECTION I}

\section{Chapter XVIII.-Engineering}

Subject to one qualification, civil engineering may form a suitable and valuable addition to the professional subjects studied at a Colonial university or university college. It is an accepted principle that the qualifications of the civil engineer must comprise two years' practical experience of good engineering work, and in most Colonies it may be difficult for some time to satisfy this condition. 


\section{SECTION 2}

Instruction up to the stage of B.Sc. (Engineering) can be given in Colonial universities or colleges. For the present it would be necessary for the student desirous of completing his full training as engineer to proceed overseas for the purpose.

\section{SECTION 4}

Colonial universities are unlikely for some time to offer facilities for fundamental research in subjects 'with which the civil engineer is concerned. But the teaching staff will find in the Colonies opportunities for original work in investigating the use of local materials.

\section{SECTION I}

\section{Chapter XIX.-The training of teachers}

While a university is dependent on the secondary schools for a supply of well prepared recruits, the schools are dependent on the university for a continuous supply of well-qualified teachers. The university has, therefore, a double interest in the education of teachers.

\section{SECTION 3}

It may for many years be impracticable to require that all teachers in the secondary schools shall be university graduates, but teachers in the higher and middle forms should if possible be graduates and the university should concern itself primarily with the training of intending teachers who have already graduated, and with other teachers required for secondary schools; some recommendations are made as to the type of instruction to be given.

\section{SECTION 5}

Both for graduates and non-graduates the training recommended will involve four years of work beyond the matriculation stage.

\section{SECTION 6}

The provision made for training will usually consist of a department of education under a professor. The department should be a centre of research in the many special problems of school education in Colonial conditions. It should be in close touch with cognate departments in the university and should take a large part in its extra-mural activities.

\section{Chapter XX.-Medium of instruction and linguistic training}

\section{SECTION I}

In the Colonies one of the most difficult problems of university education arises from the fact that the medium of instruction is usually English, and that this is often not the mother tongue of the student.

\section{SECTION 2}

Further investigation is needed into the general problems connected with the teaching of English as a foreign language; this, however, is a subject which can most profitably be pursued in this country. In the Colonies, it is essential that members of the university staff concerned with the training of teachers should be exceptionally well equipped for teaching English and for training their students to teach Englișh to others.

\section{SECTION 3}

Specialised courses in the teaching of English should be provided for those who are proceeding to the Colonies to take up posts in connection with the training of teachers. A similar provision should be made in training centres in the Colonies; the university departments of education can discharge an important function in this respect. 


\section{SECTION 4}

In some cases the mother tongue of students is. a well established language with its own literature, which can be adopted as a suitable subject for study as part of a degree course.

\section{SECTION 5}

There are many other cases, particularly in Africa, in which the mother tongue of students is not of this order and cannot form part of a university degree course. Its study may, however, have a definite value as part of school education.

\section{SECTION 6}

In regard to these languages the function of the university is mainly to co-operate in linguistic research, and to train teachers in the use of sound methods.

\section{SECTION 7}

In organising the department of social sciences in the Faculty of arts, the university should make provision for research posts in linguistic study. Research into linguistic problems should be pursued in close association with the departments of anthropological and sociological studies.

\section{Chapter XXI.-University education in the West Indies}

The Commission supports the recommendations of the West Indies Committee, summarised in Part III of this report, for the establishment of a University of the West Indies. Some of its members consider, however, that further examination is needed of the method by which it is proposed to provide for medical education during the period which must elapse before the University of the West Indies can develop its own Faculty of medicine.

\section{S. Robinson (Secretary).}

\begin{tabular}{|c|c|}
\hline igned) & 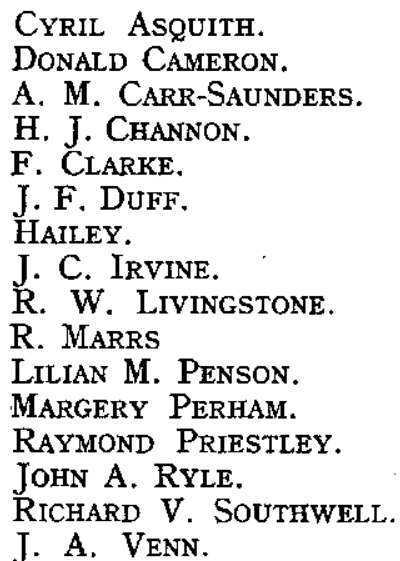 \\
\hline
\end{tabular}

3rd May, I945. 


\section{APPENDIX}

\section{UNIVERSITY AND NON-UNIVERSITY GOLONIAL STUDENTS AND COURSES AS AT 31st JANUARY, 1945}

London University

\begin{tabular}{|c|c|c|c|c|c|c|c|c|c|c|c|c|c|c|c|}
\hline & & & & 予 & 总 & 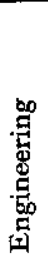 & 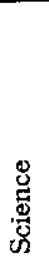 & $\frac{3}{4}$ & 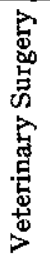 & 吕 & 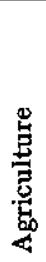 & 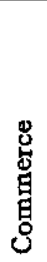 & 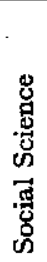 & 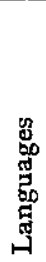 & 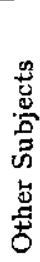 \\
\hline $\begin{array}{l}\text { Cyprus } \\
\text { Gibraltar } \\
\text { Malaya } \\
\text { Hong Kong } \\
\text { Malta } \\
\text { Kenya } \\
\text { Palestine } \\
\text { Ceylon } \\
\text { Fiji ...: } \\
\text { Uganda } \\
\text { Mauritius } \\
\text { Seychelles } \\
\text { Tanganyika } \\
\text { Zanzibar } \\
\text { Nyasaland } \\
\text { West Indies } \\
\text { Nigeria } \\
\text { Sierra Leone } \\
\text { Gold Coast } \\
\text { Gambia }\end{array}$ & $\begin{array}{l}\ldots \\
\ldots \\
\ldots \\
\ldots \\
\ldots \\
\ldots \\
\cdots \\
\ldots \\
\ldots \\
\ldots \\
\ldots \\
\ldots \\
\ldots \\
\ldots \\
\ldots \\
\ldots\end{array}$ & $\begin{array}{l}\cdots \\
\ldots \\
\ldots \\
\ldots \\
\ldots \\
\ldots \\
\ldots \\
\ldots \\
\ldots \\
\ldots \\
\ldots \\
\ldots \\
\ldots \\
\ldots \\
\ldots \\
\ldots \\
\ldots\end{array}$ & $\begin{array}{l}\cdots \\
\ldots \\
\cdots \\
\cdots \\
\ldots \\
\ldots \\
\ldots \\
\cdots \\
\ldots \\
\ldots \\
\cdots \\
\cdots \\
\ldots \\
\cdots \\
\ldots \\
\ldots \\
\ldots\end{array}$ & $\begin{array}{c}\cdots \\
\cdots \\
\ldots \\
\ldots \\
\ldots \\
\ldots \\
1 \\
\ldots \\
\ldots \\
\cdots \\
\cdots \\
\cdots \\
\cdots \\
\ldots \\
2 I \\
\cdots \\
4 \\
\cdots\end{array}$ & $\begin{array}{r}2 \\
\ldots \\
7 \\
1 \\
2 \\
\ldots \\
2 \\
3 \\
\ldots \\
\ldots \\
9 \\
I \\
1 \\
\ldots \\
\ldots \\
3 \\
2 \\
\ldots \\
3 \\
\ldots\end{array}$ & $\begin{array}{r}\cdots \\
\cdots \\
2 \\
\cdots \\
\cdots \\
\cdots \\
\cdots \\
2 \\
\ldots \\
\cdots \\
\text { I } \\
\cdots \\
\cdots \\
\cdots \\
\cdots \\
\cdots \\
5 \\
\ldots \\
\ldots \\
\cdots\end{array}$ & $\begin{array}{c}\cdots \\
\cdots \\
\cdots \\
\cdots \\
\cdots \\
\cdots \\
\cdots \\
\text { I } \\
\cdots \\
\cdots \\
\cdots \\
\cdots \\
\cdots \\
\cdots \\
\cdots \\
\cdots \\
\text { I } \\
\cdots \\
\text { I } \\
\ldots\end{array}$ & $\begin{array}{c}\mathbf{I} \\
\cdots \\
\cdots \\
\cdots \\
\cdots \\
\mathbf{I} \\
\cdots \\
\cdots \\
\cdots \\
\cdots \\
\cdots \\
\cdots \\
\cdots \\
\cdots \\
\cdots \\
3 \\
\cdots \\
I \\
\mathbf{I} \\
\ldots\end{array}$ & $\begin{array}{l}\cdots \\
\cdots \\
\cdots \\
\cdots \\
\cdots \\
\ldots \\
\cdots \\
\ldots \\
\cdots \\
\cdots \\
\cdots \\
\cdots \\
\cdots \\
\cdots \\
\ldots \\
\ldots \\
\ldots \\
\ldots \\
\ldots\end{array}$ & $\begin{array}{c}\cdots \\
\cdots \\
\cdots \\
\cdots \\
1 \\
\cdots \\
\cdots \\
\cdots \\
\cdots \\
\cdots \\
\cdots \\
\cdots \\
\cdots \\
\cdots \\
\cdots \\
4 \\
2 \\
\cdots \\
4 \\
\cdots\end{array}$ & $\begin{array}{c}\cdots \\
\ldots \\
\ldots \\
\ldots \\
\ldots \\
\ldots \\
\ldots \\
\ldots \\
\ldots \\
\cdots \\
\ldots \\
\cdots \\
\cdots \\
\cdots \\
\cdots \\
\ldots \\
\ldots \\
\ldots \\
\ldots \\
\ldots\end{array}$ & 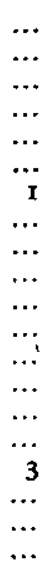 & $\begin{array}{r}\ldots \\
\ldots \\
2 \\
\ldots \\
\ldots \\
\ldots \\
\ldots \\
2 \\
\ldots \\
\ldots \\
3 \\
\ldots \\
2 \\
1 \\
\ldots \\
8 \\
18 \\
5 \\
7 \\
1\end{array}$ & $\begin{array}{r}\ldots \\
\ldots \\
\text { I } \\
\ldots \\
\ldots \\
\ldots \\
2 \\
\ldots \\
\ldots \\
1 \\
\ldots \\
\ldots \\
\ldots \\
1 \\
\ldots \\
\ldots \\
5 \\
\ldots \\
3 \\
\ldots\end{array}$ & $\begin{array}{r}\ldots \\
\ldots \\
\ldots \\
\cdots \\
\cdots \\
\cdots \\
1 \\
2 \\
\cdots \\
\ldots \\
\cdots \\
\cdots \\
\cdots \\
\ldots \\
\ldots \\
2 \\
1 \\
\cdots \\
2 \\
\ldots\end{array}$ \\
\hline
\end{tabular}

\section{Oxford University}

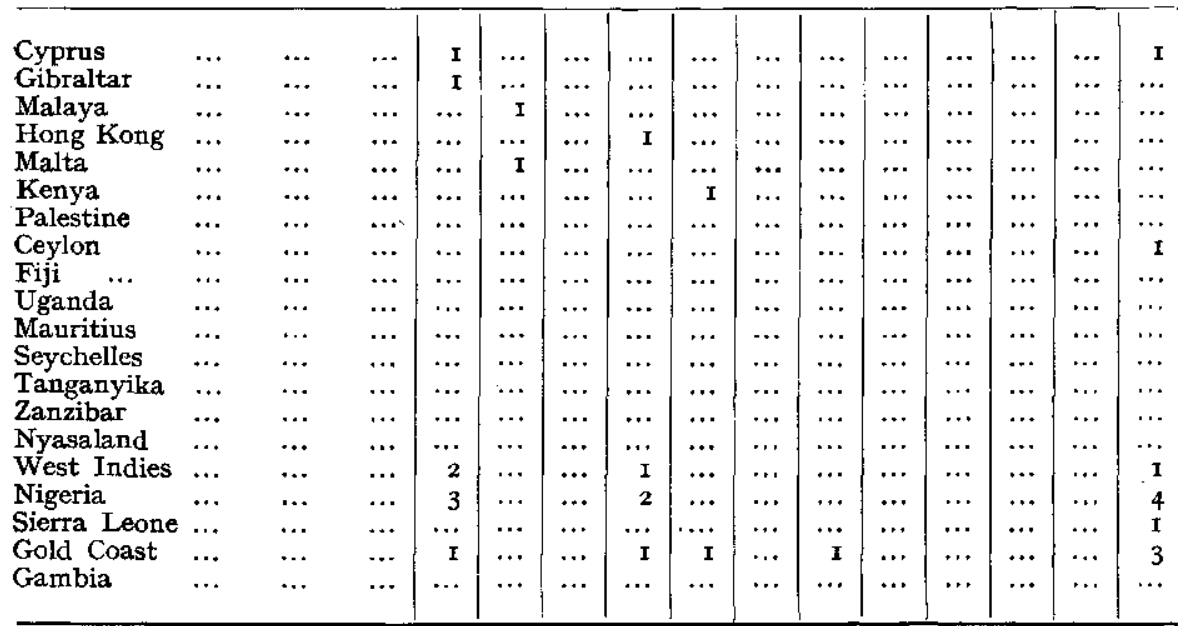


UNIVERSITY AND NON-UNIVERSITY COLONIAL STUDENTS AND

COURSES AS AT 31st JANUARY, 1945

Cambridge University

\begin{tabular}{|c|c|c|c|c|c|c|c|c|c|c|c|c|c|c|c|}
\hline & & & & 苞 & 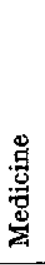 & 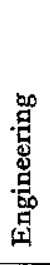 & 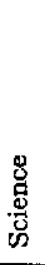 & $\stackrel{5}{4}$ & 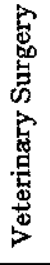 & 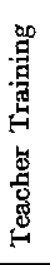 & 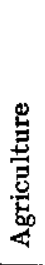 & 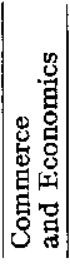 & 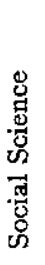 & $\begin{array}{l}\stackrel{8}{0} \\
\text { 品 } \\
\text { 品 } \\
\text { 哥 }\end{array}$ & 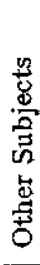 \\
\hline Cyprus & $\ldots$ & $\cdots$ & $\cdots$ & I & $\cdots$ & $\cdots$ & $\cdots$ & $\cdots$ & $\ldots$ & $\cdots$ & $\cdots$ & $\ldots$ & $\cdots$ & $\ldots$ & $\cdots$ \\
\hline Gibraltar & $\ldots$ & $\ldots$ & $\ldots$ & $\cdots$ & $\cdots$ & $\cdots$ & $\ldots$ & $\ldots$ & $\ldots$ & $\ldots$ & $\ldots$ & ... & $\ldots$ & $\ldots$ & $\ldots$ \\
\hline Malaya & $\ldots$ & ... & $\cdots$ & 4 & $\ldots$ & $\ldots$ & $\cdots$ & $\cdots$ & $\cdots$ & $\ldots$ & $\mathbf{I}$ & $\cdots$ & $\cdots$ & $\cdots$ & $\cdots$ \\
\hline Hong Kong & $\cdots$ & $\cdots$ & $\cdots$ & $\cdots$ & ... & $\ldots$ & $\cdots$ & $\cdots$ & $\ldots$ & $\ldots$ & $\ldots$ & $\cdots$ & $\cdots$ & $\cdots$ & ... \\
\hline Malta & $\ldots$ & $\cdots$ & $\cdots$ & $\ldots$ & I & $\ldots$ & $\cdots$ & $\ldots$ & $\cdots$ & $\ldots$ & $\ldots$ & $\ldots$ & $\cdots$ & $\cdots$ & $\cdots$ \\
\hline Kenya & $\cdots$ & $\ldots$ & $\ldots$ & $\ldots$ & $\cdots$ & $\ldots$ & $\mathbf{I}$ & $\ldots$ & $\mathbf{I}$ & $\ldots$ & $\ldots$ & $\ldots$ & $\ldots$ & $\ldots$ & $\ldots$ \\
\hline Palestine & $\cdots$ & $\cdots$ & $\cdots$ & $\ldots$ & $\cdots$ & $\cdots$ & 2 & $\cdots$ & $\cdots$ & $\cdots$ & $\cdots$ & $\ldots$ & $\ldots$ & $\cdots$ & $\cdots$ \\
\hline Ceylon & $\cdots$ & $\cdots$ & $\cdots$ & 3 & $\cdots$ & $\cdots$ & 2 & $\cdots$ & $\cdots$ & $\ldots$ & $\ldots$ & $\ldots$ & $\ldots$ & $\ldots$ & $z$ \\
\hline Fiji & $\ldots$ & $\ldots$ & $\ldots$ & $\ldots$ & I & $\ldots$ & $\cdots$ & $\ldots$ & $\cdots$ & $\ldots$ & $\ldots$ & $\ldots$ & $\ldots$ & $\ldots$ & $\ldots$ \\
\hline Uganda & $\ldots$ & $\ldots$ & $\ldots$ & $\cdots$ & $\mathbf{I}$ & $\cdots$ & $\cdots$ & $\cdots$ & $\cdots$ & $\cdots$ & $\cdots$ & $\cdots$ & $\cdots$ & $\ldots$ & $\cdots$ \\
\hline Mauritius & $\cdots$ & $\cdots$ & $\cdots$ & $\cdots$ & $\cdots$ & $\cdots$ & $\cdots$ & $\cdots$ & $\cdots$ & $\cdots$ & $\cdots$ & $\cdots$ & $\cdots$ & $\cdots$ & $\cdots$ \\
\hline Seychelles & $\cdots$ & $\cdots$ & $\cdots$ & $\cdots$ & $\cdots$ & $\cdots$ & $\cdots$ & $\cdots$ & $\cdots$ & $\ldots$ & $\cdots$ & $\cdots$ & $\cdots$ & $\cdots$ & $\cdots$ \\
\hline Tanganyika & $\cdots$ & $\cdots$ & $\cdots$ & $\cdots$ & $\cdots$ & $\ldots$ & $\cdots$ & $\cdots$ & $\cdots$ & $\cdots$ & $\cdots$ & $\cdots$ & $\cdots$ & $\cdots$ & $\cdots$ \\
\hline Zanzibar & $\cdots$ & $\cdots$ & $\ldots$ & $\cdots$ & $\ldots$ & $\ldots$ & $\cdots$ & $\ldots$ & $\cdots$ & $\cdots$ & $\ldots$ & $\ldots$ & $\ldots$ & $\ldots$ & $\ldots$ \\
\hline Nyasaland & $\ldots$ & $\ldots$ & $\ldots$ & $\ldots$ & $\ldots$ & $\cdots$ & $\ldots$ & $\ldots$ & $\ldots$ & $\ldots$ & $\ldots$ & $\cdots$ & $\therefore$ & $\cdots$ & $\cdots$ \\
\hline West Indies & $\ldots$ & $\ldots$ & $\ldots$ & 2 & $\cdots$ & $\cdots$ & $\cdots$ & $\ldots$ & $\ldots$ & $\ldots$ & I & $\cdots$ & $\cdots$ & $\ldots$ & $\cdots$ \\
\hline Nigeria & $\ldots$ & $\cdots$ & $\cdots$ & 8 & 3 & $\cdots$ & $\cdots$ & $\cdots$ & $\cdots$ & $\cdots$ & $\cdots$ & $\cdots$ & I & $\cdots$ & I \\
\hline Sierra Leone & $\ldots$ & $\ldots$ & $\cdots$ & $\ldots$ & I & $\cdots$ & $\cdots$ & $\cdots$ & $\cdots$ & $\ldots$ & $\ldots$ & $\ldots$ & $\cdots$ & $\cdots$ & $\ldots$ \\
\hline Gold Coast & $\ldots$ & $\ldots$ & $\ldots$ & $\cdots$ & 2 & $\cdots$ & 3 & $\mathbf{I}$ & $\cdots$ & $\ldots$ & 2 & $\mathbf{I}$ & $\ldots$ & $\cdots$ & 2 \\
\hline Gambia & ... & $\ldots$ & $\cdots$ & $\cdots$ & $\cdots$ & $\cdots$ & $\cdots$ & $\ldots$ & $\cdots$ & $\ldots$ & $\cdots$ & $\cdots$ & $\cdots$ & $\cdots$ & $\cdots$ \\
\hline
\end{tabular}

Other English Universities and University Colleges

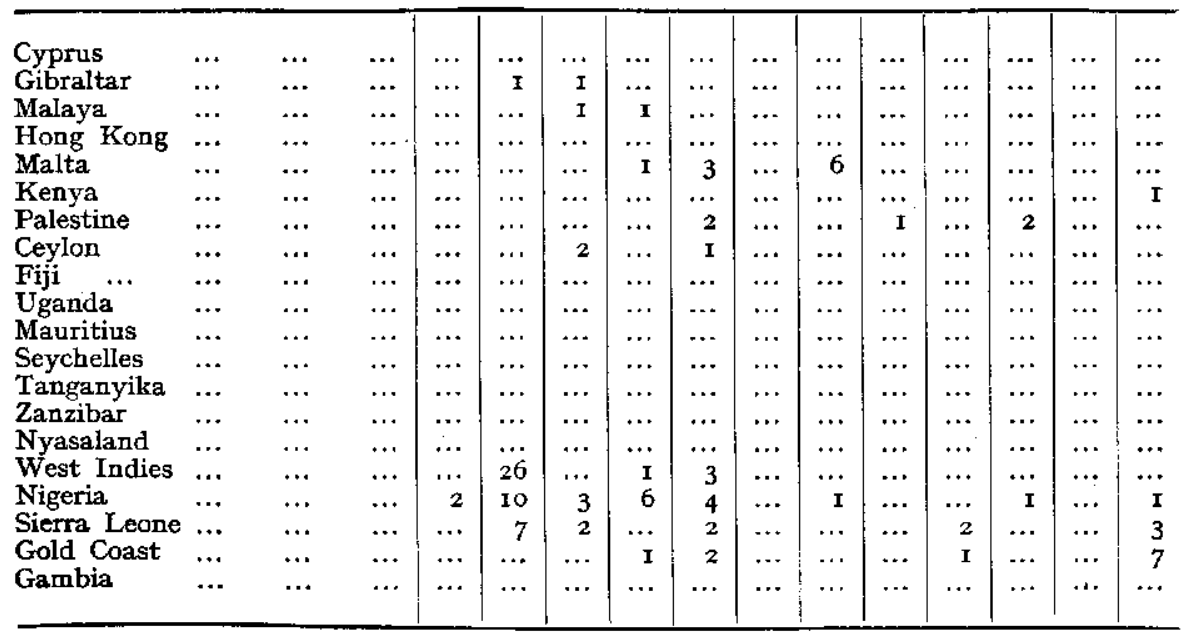




\section{UNIVERSITY AND NON-UNIVERSITY COLONIAL STUDENTS AND COURSES AS AT 31st JANUARY, 1945}

Edinburgh University

\begin{tabular}{|c|c|c|c|c|c|c|c|c|c|c|c|c|c|c|c|}
\hline & & & & 第 & 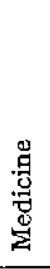 & 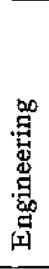 & 总 & $\frac{H^{2}}{4}$ & $\begin{array}{l}5 \\
0 \\
0 \\
50 \\
0 \\
0 \\
0 \\
0 \\
0 \\
0 \\
0\end{array}$ & 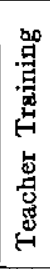 & 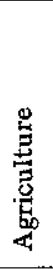 & $\begin{array}{l}\text { 巳 } \\
\text { 巳 } \\
\text { : } \\
\text { 马 }\end{array}$ & 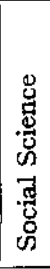 & 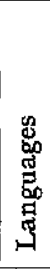 & 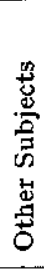 \\
\hline Cyprus & $\ldots$ & $\ldots$ & $\ldots$ & $\ldots$ & $\ldots$ & $\ldots$ & $\ldots$ & $\mathbf{I}$ & $\ldots$ & $\ldots$ & $\ldots$ & $\ldots$ & $\ldots$ & $\ldots$ & $\ldots$ \\
\hline Gibraltar & $\ldots$ & $\ldots$ & $\ldots$ & $\ldots$ & $\ldots$ & $\ldots$ & $\ldots$ & $\ldots$ & $\ldots$ & $\ldots$ & $\ldots$ & $\ldots$ & $\ldots$ & $\ldots$ & $\ldots$ \\
\hline Malaya & $\ldots$ & $\ldots$ & $\ldots$ & $\ldots$ & 5 & $\ldots$ & $\ldots$ & $\ldots$ & $\ldots$ & $\ldots$ & $\ldots$ & $\ldots$ & $\ldots$ & $\ldots$ & I \\
\hline Hong Kong & $\ldots$ & $\ldots$ & $\ldots$ & $\ldots$ & I & $\cdots$ & $\mathbf{r}$ & $\ldots$ & $\ldots$ & $\ldots$ & $\ldots$ & $\ldots$ & $\cdots$ & $\cdots$ & $\ldots$ \\
\hline Malta & $\cdots$ & $\cdots$ & $\cdots$ & $\cdots$ & $\ldots$ & $\cdots$ & $\cdots$ & $\cdots$ & $\cdots$ & $\cdots$ & $\cdots$ & $\cdots$ & $\cdots$ & $\ldots$ & $\cdots$ \\
\hline Kenya & $\ldots$ & $\ldots$ & $\ldots$ & $\ldots$ & I & $\cdots$ & $\ldots$ & $\ldots$ & $\ldots$ & $\cdots$ & $\ldots$ & $\ldots$ & $\ldots$ & $\ldots$ & I \\
\hline Palestine & ... & $\ldots$ & $\cdots$ & $\ldots$ & $\cdots$ & $\ldots$ & $\cdots$ & $\cdots$ & $\cdots$ & $\ldots$ & $\cdots$ & $\cdots$ & $\cdots$ & $\ldots$ & $\ldots$ \\
\hline Ceylon & $\ldots$ & $\ldots$ & $\ldots$ & $\cdots$ & I & $\ldots$ & $\cdots$ & $\mathbf{I}$ & $\cdots$ & $\cdots$ & $\ldots$ & $\cdots$ & $\cdots$ & $\ldots$ & $\ldots$ \\
\hline Fiji & $\cdots$ & $\ldots$ & $\ldots$ & $\ldots$ & $\ldots$ & $\ldots$ & $\ldots$ & $\ldots$ & $\cdots$ & $\cdots$ & $\ldots$ & $\cdots$ & $\ldots$ & $\cdots$ & $\cdots$ \\
\hline Ugand & $\ldots$ & $\ldots$ & $\ldots$ & $\ldots$ & $\ldots$ & $\ldots$ & $\ldots$ & $\cdots$ & $\ldots$ & $\ldots$ & $\ldots$ & $\cdots$ & $\ldots$ & $\ldots$ & $\ldots$ \\
\hline Mauritius & $\ldots$ & $\ldots$ & $\cdots$ & $\ldots$ & $\cdots$ & $\cdots$ & $\ldots$ & $\cdots$ & $\cdots$ & $\ldots$ & $\cdots$ & $\ldots$ & $\ldots$ & $\cdots$ & 2 \\
\hline Seychelles & $\cdots$ & $\cdots$ & $\ldots$ & $\cdots$ & 2 & $\ldots$ & $\cdots$ & $\cdots$ & $\cdots$ & $\cdots$ & $\cdots$ & $\cdots$ & $\cdots$ & $\cdots$ & $\cdots$ \\
\hline Tanganyika & $\ldots$ & $\ldots$ & $\cdots$ & $\cdots$ & $\cdots$ & $\cdots$ & $\ldots$ & $\ldots$ & $\ldots$ & $\ldots$ & $\ldots$ & $\ldots$ & $\ldots$ & $\ldots$ & $\ldots$ \\
\hline Zanzil & $\ldots$ & $\ldots$ & $\ldots$ & $\ldots$ & $\ldots$ & $\ldots$ & $\ldots$ & $\ldots$ & $\ldots$ & $\ldots$ & $\ldots$ & $\ldots$ & $\ldots$ & $\ldots$ & $\ldots$ \\
\hline Nyasaland & $\ldots$ & $\ldots$ & $\ldots$ & .. & $\cdots$ & $\ldots$ & $\cdots$ & $\ldots$ & $\ldots$ & $\cdots$ & $\ldots$ & $\cdots$ & $\cdots$ & $\cdots$ & I \\
\hline West Indies & $\cdots$ & $\ldots$ & $\ldots$ & $\cdots$ & 9 & $\cdots$ & $\mathbf{I}$ & 2 & $\ldots$ & $\ldots$ & $\ldots$ & $\cdots$ & $\ldots$ & $\cdots$ & I \\
\hline Nigeria & $\ldots$ & $\ldots$ & $\ldots$ & $\ldots$ & 5 & $\cdots$ & $\ldots$ & & $\ldots$ & $\ldots$ & $\ldots$ & $\ldots$ & $\ldots$ & $\ldots$ & $\cdots$ \\
\hline Sierra Leone & $\ldots$ & $\ldots$ & $\ldots$ & $\ldots$ & 2 & $\ldots$ & $\cdots$ & $\cdots$ & $\ldots$ & $\ldots$ & $\ldots$ & $\ldots$ & I & $\ldots$ & 2 \\
\hline Gold Coast & $\cdots$ & $\ldots$ & $\cdots$ & $\cdots$ & 15 & $\cdots$ & $\cdots$ & I & I & $\cdots$ & $\cdots$ & I & $\cdots$ & $\cdots$ & 5 \\
\hline Gambia & & 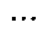 & $\ldots$ & $\cdots$ & 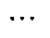 & $\ldots$ & $\cdots$ & $\ldots$ & $\cdots$ & $\because$ & $\cdots$ & $\cdots$ & $\cdots$ & $\ldots$ & I \\
\hline
\end{tabular}

Other Scottish University (St. Andrews, Glasgow, Aberdeen)

\begin{tabular}{llll|l|l|l|l|l|l|l|l|l|l|l|l}
\hline Cyprus & $\ldots$ & $\ldots$ & $\ldots$ & $\ldots$ & $\ldots$ & $\ldots$ & $\ldots$ & $\ldots$ & $\ldots$ & & & & & & \\
Gibraltar & $\ldots$ & $\ldots$ & $\ldots$ & $\ldots$ & $\ldots$ & $\ldots$ & $\ldots$ & $\ldots$ & $\ldots$ & $\ldots$ & $\ldots$ & $\ldots$ & $\ldots$ & $\ldots$ & $\ldots$ \\
Malaya & $\ldots$ & $\ldots$ & $\ldots$ & $\ldots$ & $\ldots$ & I & $\ldots$ & $\ldots$ & I & I & $\ldots$ & $\ldots$ & $\ldots$ & $\ldots$ & $\ldots$ \\
Hong Kong & $\ldots$ & $\ldots$ & $\ldots$ & $\ldots$ & $\ldots$ & $\ldots$ & $\ldots$ & $\ldots$ & $\ldots$ & $\ldots$ & $\ldots$ & $\ldots$ & $\ldots$ & $\ldots$ & I \\
Malta & $\ldots$ & $\ldots$ & $\ldots$ & $\ldots$ & $\ldots$ & $\ldots$ & $\ldots$ & $\ldots$ & $\ldots$ & $\ldots$ & $\ldots$ & $\ldots$ & $\ldots$ & $\ldots$ & $\ldots$ \\
Kenya & $\ldots$ & $\ldots$ & $\ldots$ & $\ldots$ & $\ldots$ & $\ldots$ & $\ldots$ & $\ldots$ & $\ldots$ & $\ldots$ & I & $\ldots$ & $\ldots$ & $\ldots$ & I \\
Palestine & $\ldots$ & $\ldots$ & $\ldots$ & $\ldots$ & $\ldots$ & $\ldots$ & $\ldots$ & $\ldots$ & $\ldots$ & $\ldots$ & I & $\ldots$ & $\ldots$ & $\ldots$ & $\ldots$ \\
Ceylon & $\ldots$ & $\ldots$ & $\ldots$ & $\ldots$ & $\ldots$ & $\ldots$ & $\ldots$ & $\ldots$ & $\ldots$ & $\ldots$ & $\ldots$ & $\ldots$ & $\ldots$ & $\ldots$ & $\ldots$ \\
Fiji $\ldots$ & $\ldots$ & $\ldots$ & $\ldots$ & $\ldots$ & $\ldots$ & $\ldots$ & $\ldots$ & $\ldots$ & $\ldots$ & $\ldots$ & $\ldots$ & $\ldots$ & $\ldots$ & $\ldots$ & $\ldots$ \\
Uganda & $\ldots$ & $\ldots$ & $\ldots$ & $\ldots$ & $\ldots$ & $\ldots$ & $\ldots$ & $\ldots$ & $\ldots$ & $\ldots$ & $\ldots$ & $\ldots$ & $\ldots$ & $\ldots$ & $\ldots$ \\
Mauritius & $\ldots$ & $\ldots$ & $\ldots$ & $\ldots$ & $\ldots$ & $\ldots$ & $\ldots$ & $\ldots$ & $\ldots$ & $\ldots$ & $\ldots$ & $\ldots$ & $\ldots$ & $\ldots$ & $\ldots$ \\
Seychelles & $\ldots$ & $\ldots$ & $\ldots$ & $\ldots$ & $\ldots$ & $\ldots$ & $\ldots$ & $\ldots$ & $\ldots$ & $\ldots$ & $\ldots$ & $\ldots$ & $\ldots$ & $\ldots$ & $\ldots$ \\
Tanganyika & $\ldots$ & $\ldots$ & $\ldots$ & $\ldots$ & $\ldots$ & $\ldots$ & $\ldots$ & $\ldots$ & $\ldots$ & $\ldots$ & $\ldots$ & $\ldots$ & $\ldots$ & $\ldots$ & $\ldots$ \\
Zanzibar & $\ldots$ & $\ldots$ & $\ldots$ & $\ldots$ & $\ldots$ & $\ldots$ & $\ldots$ & $\ldots$ & $\ldots$ & $\ldots$ & $\ldots$ & $\ldots$ & $\ldots$ & $\ldots$ & $\ldots$ \\
Nyasaland & $\ldots$ & $\ldots$ & $\ldots$ & $\ldots$ & $\ldots$ & $\ldots$ & $\ldots$ & $\ldots$ & $\ldots$ & $\ldots$ & $\ldots$ & $\ldots$ & $\ldots$ & $\ldots$ & $\ldots$ \\
West Indies & $\ldots$ & $\ldots$ & $\ldots$ & $\ldots$ & 8 & $\ldots$ & $\ldots$ & $\ldots$ & $\ldots$ & $\ldots$ & $\ldots$ & $\ldots$ & $\ldots$ & $\ldots$ & $\ldots$ \\
Nigeria & $\ldots$ & $\ldots$ & $\ldots$ & $\ldots$ & I & $\ldots$ & $\ldots$ & $\mathbf{I}$ & $\ldots$ & $\ldots$ & $\ldots$ & $\ldots$ & $\ldots$ & $\ldots$ & $\ldots$ \\
Sierra Leone & $\ldots$ & $\ldots$ & $\ldots$ & $\ldots$ & $\ldots$ & $\ldots$ & $\ldots$ & $\ldots$ & $\ldots$ & $\ldots$ & $\ldots$ & $\ldots$ & $\ldots$ & $\ldots$ & $\ldots$ \\
Gold Coast & $\ldots$ & $\ldots$ & $\ldots$ & $\ldots$ & $\ldots$ & $\ldots$ & $\ldots$ & $\ldots$ & $\ldots$ & $\ldots$ & $\ldots$ & $\ldots$ & $\ldots$ & $\ldots$ & $\ldots$ \\
Gambia & $\ldots$ & $\ldots$ & $\ldots$ & $\ldots$ & $\ldots$ & $\ldots$ & $\ldots$ & $\ldots$ & $\ldots$ & $\ldots$ & $\ldots$ & $\ldots$ & $\ldots$ & $\ldots$ & $\ldots$ \\
\hline
\end{tabular}


UNIVERSITY AND NON-UNIVERSITY COLONIAL STUDENTS AND

COURSES AS AT 31st JANUARY, 1945

Dublin and Belfast Universities

\begin{tabular}{|c|c|c|c|c|c|c|c|c|c|c|c|c|c|c|c|}
\hline & & & & 急 & 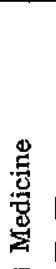 & 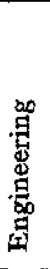 & 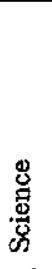 & $\frac{5}{4}$ & 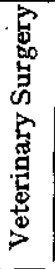 & 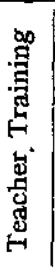 & 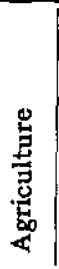 & $\begin{array}{l}8 \\
8 \\
\text { 䙷 } \\
8\end{array}$ & 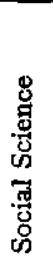 & 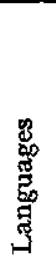 & 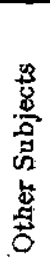 \\
\hline Cyprus & $\ldots$ & $\ldots$ & $\ldots$ & $\ldots$ & $\cdots$ & $\ldots$ & $\ldots$ & $\ldots$ & $\cdots$ & $\ldots$ & $\ldots$ & & & & $\ldots$ \\
\hline Gibre & $\ldots$ & $\ldots$ & $\ldots$ & $\ldots$ & $\ldots$ & $\ldots$ & $\ldots$ & $\ldots$ & $\ldots$ & $\ldots$ & $\ldots$ & $\cdots$ & $\cdots$ & $\begin{array}{l}\cdots \\
\cdots\end{array}$ & $\ldots$ \\
\hline Malaya & $\ldots$ & $\ldots$ & $\ldots$ & $\cdots$ & $\ldots$ & $\cdots$ & $\cdots$ & $\cdots$ & $\ldots$ & $\ldots$ & $\ldots$ & $\ldots$ & $\ldots$ & $\ldots$ & $\cdots$ \\
\hline Hong Kong & $\ldots$ & $\cdots$ & $\cdots$ & $\cdots$ & $\cdots$ & $\cdots$ & $\cdots$ & $\cdots$ & $\cdots$ & $\cdots$ & $\cdots$ & $\ldots$ & $\cdots$ & $\ldots$ & $\ldots$ \\
\hline Malta ... & $\cdots$ & $\cdots$ & $\ldots$ & $\ldots$ & $\cdots$ & $\cdots$ & $\cdots$ & $\ldots$ & $\ldots$ & $\ldots$ & $\ldots$ & $\cdots$ & $\ldots$ & $\ldots$ & $\cdots$ \\
\hline Kenya ... & $\ldots$ & $\ldots$ & $\cdots$ & $\cdots$ & $\cdots$ & $\cdots$ & $\cdots$ & $\cdots$ & $\cdots$ & $\cdots$ & $\cdots$ & $\cdots$ & $\cdots$ & ... & $\cdots$ \\
\hline Palestine & $\cdots$ & $\cdots$ & $\cdots$ & $\cdots$ & $\cdots$ & $\cdots$ & $\cdots$ & $\cdots$ & $\cdots$ & $\cdots$ & $\cdots$ & $\cdots$ & $\cdots$ & $\cdots$ & $\cdots$ \\
\hline Ceylon & $\ldots$ & $\cdots$ & $\ldots$ & .. & $\cdots$ & $\cdots$ & $\cdots$ & $\cdots$ & $\cdots$ & $\cdots$ & $\cdots$ & $\cdots$ & $\cdots$ & $\cdots$ & $\cdots$ \\
\hline Fiji & $\cdots$ & $\cdots$ & 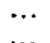 & $\cdots$ & $\cdots$ & $\cdots$ & $\cdots$ & $\cdots$ & $\cdots$ & $\cdots$ & $\cdots$ & $\cdots$ & $\cdots$ & $\cdots$ & $\cdots$ \\
\hline $\begin{array}{l}\text { Uganda } \\
\text { Mauritius }\end{array}$ & $\ldots$ & $\ldots$ & $\cdots$ & & $\ldots$ & $\cdots$ & $\ldots$ & $\cdots$ & $\ldots$ & $\cdots$ & $\cdots$ & $\cdots$ & $\cdots$ & $\cdots$ & $\cdots$ \\
\hline Seych & ... & $\ldots$ & $\ldots$ & $\ldots$ & $\ldots$ & $\ldots$ & $\ldots$ & $\ldots$ & $\ldots$ & $\begin{array}{l}\cdots \\
\ldots\end{array}$ & $\ldots$ & $\cdots$ & $\cdots$ & $\cdots$ & $\cdots$ \\
\hline Tanganyika & $\ldots$ & $\ldots$ & $\ldots$ & $\ldots$ & $\cdots$ & $\ldots$ & $\ldots$ & $\ldots$ & $\ldots$ & $\ldots$ & $\ldots$ & $\ldots$ & ... & $\ldots$ & $\cdots$ \\
\hline $\mathrm{Za}$ & $\ldots$ & $\ldots$ & $\ldots$ & $\ldots$ & $\cdots$ & $\ldots$ & $\ldots$ & $\ldots$ & $\ldots$ & $\ldots$ & $\ldots$ & $\ldots$ & $\ldots$ & $\ldots$ & $\ldots$ \\
\hline aland & $\cdots$ & & $\cdots$ & & 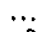 & $\cdots$ & $\ldots$ & $\ldots$ & $\cdots$ & ... & $\ldots$ & $\ldots$ & $\ldots$ & $\ldots$ & $\ldots$ \\
\hline West Indies & $\cdots$ & $\cdots$ & $\cdots$ & $\ldots$ & 8 & $\cdots$ & $\cdots$ & $\cdots$ & $\ldots$ & $\ldots$ & $\ldots$ & $\ldots$ & $\ldots$ & $\ldots$ & $\cdots$ \\
\hline Nigeria & $\ldots$ & $\ldots$ & $\cdots$ & $\mathbf{I}$ & I2 & $\ldots$ & $\ldots$ & I & $\ldots$ & $\ldots$ & $\cdots$ & I & $\ldots$ & $\ldots$ & $\ldots$ \\
\hline Sierra Leone & $\cdots$ & $\cdots$ & $\cdots$ & $\cdots$ & I & $\cdots$ & $\cdots$ & $\therefore$ & $\cdots$ & $\cdots$ & $\cdots$ & $\cdots$ & $\cdots$ & $\cdots$ & $\cdots$ \\
\hline Gold Coast & $\cdots$ & $\cdots$ & $\ldots$ & $\cdots$ & 2 & $\cdots$ & $\cdots$ & $\cdots$ & $\ldots$ & $\cdots$ & $\cdots$ & $\cdots$ & $\cdots$ & $\cdots$ & $\ldots$ \\
\hline $\mathrm{Ga}$ & $\cdots$ & $\cdots$ & $\cdots$ & $\cdots$ & $\cdots$ & $\cdots$ & $\cdots$ & $\cdots$ & $\cdots$ & $\cdots$ & $\cdots$ & $\cdots$ & $\cdots$ & $\cdots$ & $\cdots$ \\
\hline
\end{tabular}

Non-University Students in London

\begin{tabular}{|c|c|c|c|c|c|c|c|c|c|c|c|c|c|c|c|}
\hline Cyprus & $\cdots$ & $\cdots$ & $\cdots$ & $\cdots$ & $\cdots$ & $\ldots$ & $\cdots$ & $\cdots$ & $\cdots$ & I & $\cdots$ & $\cdots$ & $\cdots$ & $\cdots$ & 2 \\
\hline Gibraltar & $\cdots$ & $\cdots$ & $\cdots$ & $\cdots$ & $\cdots$ & $\cdots$ & $\cdots$ & $\cdots$ & $\cdots$ & $\mathbf{I}$ & $\cdots$ & $\cdots$ & $\cdots$ & $\cdots$ & 2 \\
\hline Malaya & $\cdots$ & $\cdots$ & $\cdots$ & I & I & $\ldots$ & I & $\ldots$ & $\cdots$ & $\cdots$ & $\cdots$ & $\cdots$ & $\ldots$ & $\cdots$ & 2 \\
\hline Hong Kong & $\cdots$ & $\cdots$ & $\cdots$ & $\cdots$ & $\cdots$ & $\cdots$ & $\ldots$ & $\cdots$ & $\cdots$ & $\cdots$ & $\cdots$ & $\cdots$ & $\cdots$ & $\cdots$ & $\cdots$ \\
\hline Malta ... & $\ldots$ & $\cdots$ & $\cdots$ & $\cdots$ & 3 & I & $\mathbf{I}$ & $I$ & $\cdots$ & $\cdots$ & $\cdots$ & $\cdots$ & $\cdots$ & $\cdots$ & 3 \\
\hline Kenya ... & $\ldots$ & $\cdots$ & $\cdots$ & $\ldots$ & $\cdots$ & $\cdots$ & $\ldots$ & $\cdots$ & $\cdots$ & $\cdots$ & $\cdots$ & $\cdots$ & $\cdots$ & $\cdots$ & $\cdots$ \\
\hline Palestine & $\cdots$ & $\cdots$ & $\cdots$ & $\cdots$ & I & I & $\cdots$ & $\mathbf{I}$ & $\cdots$ & $\cdots$ & $\cdots$ & $\cdots$ & $\cdots$ & $\cdots$ & $\cdots$ \\
\hline Ceylon & $\cdots$ & $\cdots$ & $\cdots$ & 2 & $\cdots$ & 2 & $\cdots$ & $\cdots$ & $\cdots$ & $\cdots$ & $\cdots$ & $\cdots$ & $\cdots$ & $\cdots$ & $z$ \\
\hline$F_{i j i} \quad \cdots$ & $\cdots$ & $\cdots$ & $\cdots$ & $\cdots$ & $\cdots$ & $\cdots$ & $\cdots$ & $\cdots$ & $\cdots$ & $\cdots$ & $\cdots$ & $\cdots$ & $\cdots$ & $\cdots$ & $\cdots$ \\
\hline Uganda & $\cdots$ & $\cdots$ & $\cdots$ & $\cdots$ & $\ldots$ & $\cdots$ & $\ldots$ & $\cdots$ & $\cdots$ & $\cdots$ & $\cdots$ & $\cdots$ & $\cdots$ & $\cdots$ & $\cdots$ \\
\hline Mauritius & $\cdots$ & $\cdots$ & $\cdots$ & $\cdots$ & $\cdots$ & $\cdots$ & $\cdots$ & $\cdots$ & $\cdots$ & $\cdots$ & $\cdots$ & $\cdots$ & $\cdots$ & $\cdots$ & $\cdots$ \\
\hline Seychelles & $\cdots$ & $\cdots$ & $\cdots$ & $\mathbf{I}$ & $\cdots$ & $\cdots$ & $\cdots$ & $\cdots$ & $\cdots$ & $\cdots$ & $\cdots$ & $\because$ & $\cdots$ & $\cdots$ & $\cdots$ \\
\hline Tanganyika & $\cdots$ & $\cdots$ & $\cdots$ & $\cdots$ & $\cdots$ & $\cdots$ & $\cdots$ & $\cdots$ & $\cdots$ & $\cdots$ & $\cdots$ & $\therefore$ & $\cdots$ & $\cdots$ & $\cdots$ \\
\hline Zanzibar & $\cdots$ & $\cdots$ & $\cdots$ & $\cdots$ & $\cdots$ & $\cdots$ & $\cdots$ & $\cdots$ & $\cdots$ & $\cdots$ & $\cdots$ & $\cdots$ & $\cdots$ & $\cdots$ & $\cdots$ \\
\hline Nyasaland & $\ldots$ & $\cdots$ & $\cdots$ & $\cdots$ & $\cdots$ & $\cdots$ & $\cdots$ & $\cdots$ & $\cdots$ & $\cdots$ & $\cdots$ & $\cdots$ & $\cdots$ & $\cdots$ & $\cdots$ \\
\hline West Indies & $\cdots$ & $\ldots$ & $\cdots$ & 9 & $\mathbf{I}$ & 4 & I & $\cdots$ & $\cdots$ & $\cdots$ & I & $\cdots$ & $\cdots$ & $\cdots$ & 22 \\
\hline Nigeria & $\cdots$ & $\cdots$ & $\cdots$ & 25 & $\cdots$ & 4 & 2 & $\cdots$ & $\ldots$ & $\cdots$ & $\ldots$ & 2 & $\cdots$ & $\cdots$ & IO \\
\hline Sierra Leone & $\cdots$ & $\cdots$ & $\ldots$ & 4 & 2 & $\cdots$ & I & $\cdots$ & I & 5 & $\cdots$ & $\cdots$ & $\ldots$ & $\ldots$ & 4 \\
\hline Gold Coast & $\cdots$ & $\cdots$ & $\cdots$ & 2 & $\cdots$ & $\cdots$ & $\cdots$ & $\cdots$ & $\cdots$ & $\ldots$ & $\cdots$ & $\cdots$ & $\cdots$ & $\ldots$ & 2 \\
\hline Gambia & $\cdots$ & $\cdots$ & $\cdots$ & 2 & $\mathbf{I}$ & $\cdots$ & $\cdots$ & $\cdots$ & $\cdots$ & $\cdots$ & $\cdots$ & $\cdots$ & $\cdots$ & $\cdots$ & $\cdots$ \\
\hline
\end{tabular}


UNIVERSITY AND NON-UNIVERSITY COLONIAL STUDENTS AND COURSES AS AT 31st JANUARY, 1945

Non-University Students in other centres

\begin{tabular}{|c|c|c|c|c|c|c|c|c|c|c|c|c|c|c|c|}
\hline & & & & 寻 & 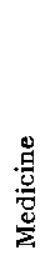 & 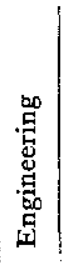 & 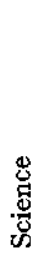 & $\frac{5}{4}$ & 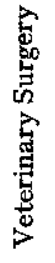 & 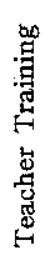 & 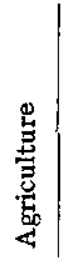 & $\begin{array}{l}8 \\
8 \\
\text { 巳 } \\
\text { E. } \\
8 \\
8\end{array}$ & 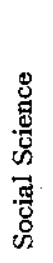 & 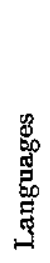 & 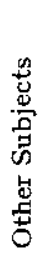 \\
\hline Cyprus & $\ldots$ & $\ldots$ & $\ldots$ & $\cdots$ & $\cdots$ & $\ldots$ & $\ldots$ & $\ldots$ & $\ldots$ & $\ldots$ & $\ldots$ & $\ldots$ & $\ldots$ & $\cdots$ & $\ldots$ \\
\hline ar & $\ldots$ & $\ldots$ & $\ldots$ & $\ldots$ & $\ldots$ & $\ldots$ & $\ldots$ & $\ldots$ & $\ldots$ & $\ldots$ & $\ldots$ & $\ldots$ & $\ldots$ & $\ldots$ & I \\
\hline Malaya & $\ldots$ & $\ldots$ & $\ldots$ & I & $\cdots$ & $\ldots$ & $\ldots$ & $\ldots$ & $\ldots$ & $\ldots$ & $\ldots$ & $\ldots$ & $\ldots$ & $\ldots$ & 2 \\
\hline Hong Kong & $\ldots$ & $\cdots$ & $\ldots$ & $\ldots$ & $\ldots$ & $\cdots$ & $\cdots$ & $\cdots$ & $\ldots$ & $\ldots$ & $\ldots$ & $\ldots$ & $\ldots$ & $\ldots$ & I \\
\hline Malta ... & $\ldots$ & $\cdots$ & $\ldots$ & $\cdots$ & $\ldots$ & $\ldots$ & $\ldots$ & $\cdots$ & $\cdots$ & 3 & $\ldots$ & $\ldots$ & $\ldots$ & $\ldots$ & Io \\
\hline Kenya ... & $\ldots$ & $\ldots$ & $\ldots$ & $\ldots$ & $\ldots$ & $\cdots$ & $\ldots$ & $\ldots$ & $\ldots$ & $\ldots$ & I & $\ldots$ & $\ldots$ & $\ldots$ & $\ldots$ \\
\hline Palestine & $\ldots$ & $\ldots$ & $\cdots$ & $\ldots$ & $\cdots$ & $\cdots$ & $\cdots$ & $\cdots$ & $\ldots$ & $\cdots$ & $\ldots$ & $\ldots$ & $\ldots$ & $\ldots$ & $\cdots$ \\
\hline Ceylon & $\cdots$ & $\ldots$ & $\ldots$ & $\ldots$ & $\ldots$ & $\cdots$ & $\cdots$ & $\cdots$ & $\ldots$ & $\cdots$ & $\cdots$ & $\cdots$ & $\ldots$ & $\ldots$ & 4 \\
\hline Fiji & $\ldots$ & $\ldots$ & $\ldots$ & $\ldots$ & $\ldots$ & $\cdots$ & $\ldots$ & $\ldots$ & $\ldots$ & $\cdots$ & $\ldots$ & $\ldots$ & $\ldots$ & $\ldots$ & $\ldots$ \\
\hline Uganda & $\ldots$ & $\cdots$ & $\cdots$ & $\ldots$ & $\ldots$ & $\ldots$ & $\ldots$ & $\cdots$ & $\ldots$ & $\ldots$ & $\ldots$ & $\ldots$ & $\cdots$ & $\ldots$ & $\ldots$ \\
\hline Mauritius & $\ldots$ & $\cdots$ & $\ldots$ & $\ldots$ & $\ldots$ & $\cdots$ & $\ldots$ & $\cdots$ & $\ldots$ & $\ldots$ & $\ldots$ & $\cdots$ & $\ldots$ & $\ldots$ & $\ldots$ \\
\hline Seychelles & $\cdots$ & $\ldots$ & $\ldots$ & $\ldots$ & $\ldots$ & $\cdots$ & $\cdots$ & $\cdots$ & $\cdots$ & $\cdots$ & $\cdots$ & $\cdots$ & $\ldots$ & $\ldots$ & $\ldots$ \\
\hline Tanganyika & $\ldots$ & $\cdots$ & $\ldots$ & $\ldots$ & $\ldots$ & I & $\ldots$ & $\cdots$ & $\ldots$ & $\cdots$ & $\ldots$ & $\ldots$ & $\ldots$ & $\ldots$ & $\ldots$ \\
\hline Zanziba & $\ldots$ & $\cdots$ & $\ldots$ & $\cdots$ & $\cdots$ & $\cdots$ & $\cdots$ & $\cdots$ & $\cdots$ & $\cdots$ & $\ldots$ & $\ldots$ & $\cdots$ & $\ldots$ & $\cdots$ \\
\hline Nyasaland & $\cdots$ & $\ldots$ & $\ldots$ & $\ldots$ & $\ldots$ & $\ldots$ & $\ldots$ & $\cdots$ & $\ldots$ & $\cdots$ & $\ldots$ & $\cdots$ & $\cdots$ & $\ldots$ & $\ldots$ \\
\hline West Indies & $\ldots$ & $\ldots$ & $\ldots$ & $\ldots$ & 2 & $\ldots$ & $\ldots$ & $\ldots$ & $\ldots$ & $\ldots$ & $\ldots$ & $\ldots$ & $\ldots$ & $\ldots$ & 2 \\
\hline Nigeria & $\ldots$ & $\ldots$ & $\ldots$ & $\ldots$ & $\ldots$ & $\mathrm{I}$ & $\ldots$ & $\ldots$ & $\ldots$ & $\ldots$ & $\ldots$ & $\ldots$ & $\ldots$ & $\ldots$ & 12 \\
\hline Sierra Leone & $\ldots$ & $\ldots$ & $\cdots$ & $\ldots$ & $\cdots$ & 3 & $\cdots$ & $\ldots$ & $\cdots$ & 7 & $\ldots$ & $\cdots$ & $\cdots$ & $\ldots$ & 3 \\
\hline Gold Coast & $\ldots$ & $\ldots$ & $\ldots$ & $\ldots$ & $\cdots$ & I & $\cdots$ & $\cdots$ & $\cdots$ & $\cdots$ & $\cdots$ & ... & $\cdots$ & $\ldots$ & 5 \\
\hline Gambia & $\ldots$ & $\ldots$ & $\ldots$ & $\cdots$ & $\cdots$ & $\ldots$ & $\cdots$ & $\ldots$ & $\cdots$ & $\ldots$ & $\ldots$ & $\ldots$ & $\ldots$ & $\ldots$ & $\mathrm{x}$ \\
\hline
\end{tabular}




\section{LONDON}

PRINTED AND PUBLISHED BY HIS MAJESTY'S STATIONERY OFFICE

To be parchased directly frum H.M. STATIONERY OFFICE at the following addresses: York House, Kingsway, London, W.C.2; 13a Castle Strect, Edinburgh 2 ; 39-4I King Street, Manchester 2; I St. Andrew's Crescent, Cardiff;

80 Chichester Street, Belfast;

or through any booksellet

\section{I945}

Price 2s. od. net 